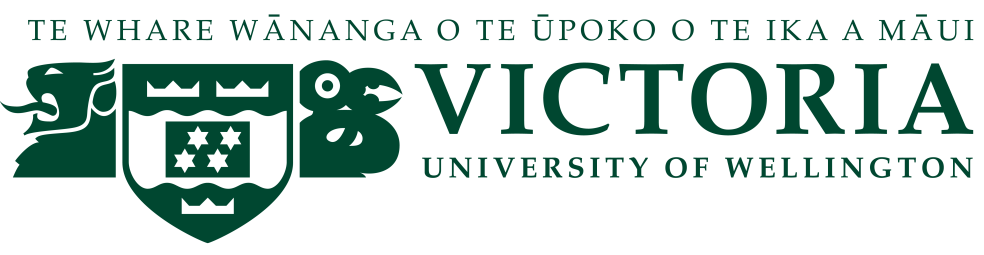

\title{
UNCERTAINTY AND INVESTMENT \\ CHOICE IN A REAL-OPTIONS MODEL OF THE FIRM
}

By

CAMERON M. HOBBS

\author{
A thesis \\ submitted to Victoria University of Wellington \\ in fulfilment of the requirements for the degree of \\ Master of Commerce \\ in Finance
}

Victoria University of Wellington 



\title{
Uncertainty and Investment Choice in a Real-Options Model of the Firm
}

\author{
CAMERON M. HOBBS
}

\begin{abstract}
A firm must consider many factors when adopting an investment policy including, but not limited to the size, scope, and cost of each investment, as well as the firm's financial condition. The multitude of considerations makes optimal decision-making much more complex than is indicated by standard real-option models of investment. This thesis investigates the behaviour of a cash-constrained firm that has access to two distinct investment opportunities. Such a firm must not only choose the timing of each investment, but often it must also choose between investments.

When compared with similar one-project models of the past, the introduction of an additional investment opportunity alters the general results in a variety of ways. If one of the projects has a high yield, and therefore a quick payback period, this project can provide benefits over and above its NPV as the cash it generates relaxes future capital constraints for follow-up investment. When the firm is sufficiently constrained, this can lead to an investment policy where high-yield low-NPV projects are implemented instead of lower-yield higher-NPV projects, a direct deviation from the NPV rule. If one of the projects can raise a relatively large proportion of its value as collateral for investment, then the constrained firm will at times accelerate investment in this project in order to free up cash reserves for the other opportunity.

In single-project models, when the firm is able to invest in a low NPV project, the value of additional cash is low. This is because the project will be delayed regardless of the level of cash. However, when the firm has a second investment opportunity, if one project has a low NPV and the other a high NPV then additional cash is beneficial to the firm. The two-project model also provides insights into how resources should be allocated if the constrained firm decides to split and operate the projects as separate firms. When cash is low, more resources should go to the spin-off with the high NPV project in order to give it the best chance of being initiated. However, when cash is high, disproportionately more resources should go to the spin-off with the lower NPV project as investment in the higher NPV project is likely to occur without the help of additional resources.
\end{abstract}





\section{Contents}

1 Introduction 1

2 Model Setup and Solution $\quad 7$

2.1 Overview . . . . . . . . . . . . . . . . . . 7

2.2 One Investment . . . . . . . . . . . . . . . . . . . . . . . . . . . 8

2.2.1 The Unconstrained Firm . . . . . . . . . . . . . . . . . . 10

2.2.2 The Constrained Firm . . . . . . . . . . . . . . . . . 11

2.2.3 A Numerical Solution . . . . . . . . . . . . . . . 13

2.3 Two Investments: One Launched, One Opportunity . . . . . . . . . . 18

2.3.1 The Unconstrained Firm . . . . . . . . . . . . . . . . 23

2.3.2 The Constrained Firm . . . . . . . . . . . . . . . . . 23

2.3.3 An Intuitive Solution . . . . . . . . . . . . . . . 26

2.3.4 A Numerical Solution . . . . . . . . . . . . . . . 29

2.4 Two Investments: None Launched, Two Opportunities . . . . . . . . 34

2.4.1 The Unconstrained Firm . . . . . . . . . . . . . . . . . 35

2.4.2 The Constrained Firm . . . . . . . . . . . . . . . . 36

2.4.3 A Numerical Solution . . . . . . . . . . . . . . . . . . 42

3 Model Applications $\quad 47$

3.1 Overview. . . . . . . . . . . . . . . . . 47

3.2 Asymmetric Investment Policies . . . . . . . . . . . . . . . . . . 48 
3.2 .1 Literature . . . . . . . . . . . . . . . . . . . . . . . . . . 48

3.2 .2 The Deterministic Case . . . . . . . . . . . . . . . 50

3.2 .3 Fast Payback Projects . . . . . . . . . . . . . . . . 54

3.2.4 High Pledgeability Projects _. . . . . . . . . . 58

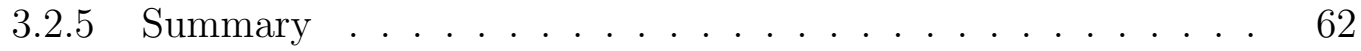

3.3 The Value of Cash . . . . . . . . . . . . . . . . . . . . . 63

3.3 .1 Literature . . . . . . . . . . . . . . . . . . . . . 63

3.3.2 Cash Now vs Cash Later . . . . . . . . . . . . . . . . 66

3.3.3 The Marginal Value of Cash . . . . . . . . . . . . . . 71

3.3 .4 Summary . . . . . . . . . . . . . . . 76

3.4 Mergers and Spin-offs . . . . . . . . . . . . . . . . . 76

3.4 .1 Literature . . . . . . . . . . . . . . . . . . . . . . 77

$3.4 .2 \quad$ Spin-Offs . . . . . . . . . . . . . . . . . . . 80

$3.4 .3 \quad$ Summary . . . . . . . . . . . . . . . . . . . 88

$\begin{array}{lll}4 & \text { Numerical Methods } & 91\end{array}$

4.1 Overview . . . . . . . . . . . . . . . . . . . . . . . 91

4.2 The Solution Algorithm _ . . . . . . . . . . . . . . . . . . 92

4.3 Transformation of Coordinates . . . . . . . . . . . . . . . . 93

4.3.1 New Partial Differential Equations _... . . . . . . . . . 94

4.3 .2 Functional Form . . . . . . . . . . . . . . . . 97

5 Concluding Remarks $\quad 99$

$\begin{array}{ll}\text { A Derivations and Solution Procedures } & 103\end{array}$

A.1 Equation Derivations . . . . . . . . . . . . . . . . . 103

A.1.1 Derivation of Equation $(2.28) \ldots \ldots \ldots \ldots$

A.2 Solution Procedures . . . . . . . . . . . . . . . 106 
A.2.1 Numerical Solution Procedure for Equation (2.11) . . . . . . . 106

A.2.2 Numerical Solution Procedure for Equation (2.28) . . . . . . . 107

A.2.3 Numerical Solution Procedure for Equation (2.39) . . . . . . . 111 



\section{List of Figures}

2.1 Baseline Regions: One Investment . . . . . . . . . . . . . . . . . 14

2.2 Baseline Policy: One Investment . . . . . . . . . . . . . . . . 15

2.3 Option Value: One Investment . . . . . . . . . . . . . . . . . 17

2.4 The Optimal Divestment Policy . . . . . . . . . . . . . . . . . 22

2.5 Baseline Regions: Two Investments - One Launched, One Opportunity 26

2.6 Intuitive Policy Solution: Two Investments - One Launched, One Op-

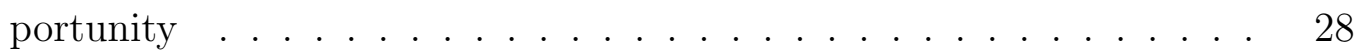

2.7 Investment Policy: Two Investments - One Launched, One Opportunity 30

2.8 Intuitive Policy Solution $\ldots \ldots \ldots \ldots$

2.9 Divestment: Now-or-Never Payoff . . . . . . . . . . . . . . 33

2.10 Divestment: Waiting Payoff $\ldots \ldots \ldots \ldots \ldots$

2.11 Baseline Regions: Two Investments - None Launched, Two Opportunities . . . . . . . . . . . . . . . . . . . . 41

2.12 Baseline Policy: Two Investments - None Launched, Two Opportunities 43

3.1 Acceleration in the Deterministic Case . . . . . . . . . . 53

3.2 Fast Payback Projects: Investment Policy _. . . . . . . . . . . 56

3.3 High Pledgeability: Investment Policy . . . . . . . . . . . . . . 60

3.4 Fast Payback Projects: No Future Cash _ . . . . . . . . . . . 68

3.5 High Pledgeability: No Future Cash . . . . . . . . . . . . . . 70

3.6 Marginal Value of Cash: Fast Payback Project . . . . . . . . . . 72 
3.7 Marginal Value of Cash: High-Pledgeability Project . . . . . . . . 75

3.8 Merged and Split Firm Liquidation Thresholds . . . . . . . . . . . 83

3.9 Resource Allocation in a Spin-off . . . . . . . . . . . . . . . 85

4.1 Solution Algorithm . . . . . . . . . . . . . . . . . . . . . 92

4.2 Transformation Functional Form . . . . . . . . . . . . . . . . 97

4.3 Clustered Grid Points . . . . . . . . . . . . . . . . . . . . . . . 98 


\section{List of Tables}

2.1 Baseline Parameters: One Investment . . . . . . . . . . . . . . 13

2.2 Baseline Parameters: Two Investments - One Launched, One Oppor-

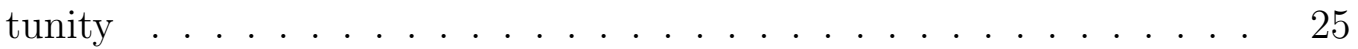

2.3 Baseline Parameters: Two Investments - None Launched, Two Opportunities. . . . . . . . . . . . . . . . . . . 40

3.1 High Implicit Yield Parameters . . . . . . . . . . . . . . . . . . 55

3.2 High Pledgeability Parameters . . . . . . . . . . . . . . . 59

A.1 Logic for Solving: Two Investments - One Launched, One Opportunity 110

A.2 Logic for Solving: Two Investments - None Launched, Two Opportu-

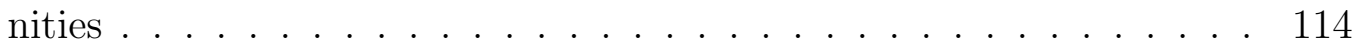





\section{Chapter 1}

\section{Introduction}

There are many factors relevant to a firm's investment decision, including but not limited to the size, scope, and cost of each investment opportunity. It should come as no surprise then that the optimal investment decision is not a particularly easy one to make. McDonald and Siegel (1986) provide one of the first insights into the problem. They use a real-options model to develop an optimal investment rule for an unconstrained firm with access to a single investment opportunity. Their work not only considers the payoff to investing, but also the timing of investment and therefore the value associated with delaying investment. Their model is later refined by Dixit and Pindyck (1994) in their book Investment Under Uncertainty; however, it is not until the work of Boyle and Guthrie (2003) that the problem of the cash constrained firm is explored. In their article, Boyle and Guthrie (2003) extend the model of McDonald and Siegel (1986) to include an endogenous financing constraint. The introduction of this constraint shows that due to the risk of future funding shortages, the constrained firm with a moderate level of cash will over invest and accelerate their investment when compared to the unconstrained firm. In contrast, constrained firms with sufficiently low liquidity will be forced to implement a delayed investment policy when compared to the unconstrained firm as insufficient resources are available for investment.

There has been a recent surge in corporate finance literature that explores the 
interaction between constraints and investment. Cleary et al. (2007) use empirical data to develop the idea of an investment curve that is u-shaped in cash. They show that, for low levels of internal funds, investment is decreasing monotonically, while for high levels of internal funds, investment is increasing monotonically. The same investment behaviour is described in Flor and Hirth (2013); however, they look at how the redeployability of assets affects investment decisions. ${ }^{1}$ They show that firms with highly liquid assets in place will experience a lower sensitivity of investment to internal funds. Shibata and Nishihara (2012) develop a model where the firm faces an exogenous debt capacity constraint. In their setup, the firm can only raise a restricted amount of funds via debt issuance. Within their base case, a stronger debt financing constraint leads to a reduction in the credit spread and therefore a reduction in the probability of default. As such they find that the investment threshold is u-shaped in the debt capacity constraint. Hirth and Uhrig-Homburg (2010a) show that, due to stockholder-bondholder conflicts, the constrained firm's investment threshold is monotonically decreasing in internal funds.

In addition to the aforementioned, costly external finance and its effect on investment has recently received a great deal of exposure. Lyandres (2007) shows that investment/cash flow sensitivity is non-monotonic in the cost of external funds. For low financing costs, investment-cash flow sensitivity is decreasing in the level of cost and vice versa. Hirth and Uhrig-Homburg (2010b) extend the model of Boyle and Guthrie (2003) to include issuance costs associated with raising external finance. Their results are qualitatively similar to those in Boyle and Guthrie (2003) for high and low liquidity firms; however, for moderate levels of liquidity, the investment threshold depends largely on the convexity of the cost function. Under a linear cost function, the results are qualitatively similar to Bolton et al. (2014). However, Bolton et al. (2014) describe a large increase in the investment threshold when the firm is close to being able to cover the cost of investment entirely from internal funds. This occurs because the firm is willing to delay investment to avoid drawing on costly financing.

\footnotetext{
${ }^{1}$ In their study redeployability measures the ease with which existing assets can be sold to other firms.
} 
Although dynamic and informative in nature, a large proportion of the relevant literature revolves around a firm that is constrained not only in resources, but also in investment opportunities. That is to say, the literature predominantly explores models where the firm has access to a single investment project. In doing so it overlooks the interaction between investments, the dynamic effect of one investment on another and the associated investment choice problem. Nishihara and Shibata (2013) provides a step in the right direction by investigating the investment policy surrounding expansions of differing scale. Additionally, Almeida et al. (2011) and Johnson et al. (2015) provide useful insights into the investment choice problem. The former describes a model where firms with access to a range of projects will prefer projects with shorter payback periods and high pledgeability. The latter looks at how optimal capital charge rates are affected when only a limited number of investments can be launched.

In order to explore the investment choice problem further, this thesis extends the model of Boyle and Guthrie (2003) to include an additional investment opportunity. The resulting model and conclusions help to supplement the existing literature and further develop understanding of the constrained firm. The analysis completed helps to answer the following questions:

1. How does the cash-constrained firm's investment policy for a given project change when the firm gains access to an additional investment opportunity?

2. How does the ability to sell assets in place (to fund investment) alter the constrained firm's investment policy?

3. When choosing to invest in a project, which effect is more important: the constraint-tightening effect of reducing the cash balance due to capital expenditure, or the constraint-relaxing effect of cash being generated by projects post investment?

4. How does the marginal value of cash change when a firm has access to more than one investment opportunity?

5. How should resources be allocated between firms when a firm with two invest- 
ment opportunities splits and operates the projects as separate firms?

The addition of an extra investment to the model in Boyle and Guthrie (2003) provides numerous new insights. When projects are symmetric, the introduction of an extra project leads to an upwards shift of the original project's investment threshold. Thus, investment delay occurs as the firm does not want to invest in one project to find out ex-post it would have been better to do the other project. If projects are not symmetric, then the firm in some states will invest in a lower NPV, fastpayback project instead of a higher NPV, slow-payback project, as the project with a faster payback better facilitates follow-up investment after being launched via the cash it generates. If the firm instead has one project that can raise a relatively larger proportion of its value as debt for funding, then the introduction of an otherwise identical project with lower debt capacity will in some states shift the investment threshold downwards. A downwards shift means that the project value required for investment is lower, for a given level of internal funds. In these states, investment in the high capacity project occurs earlier in order to free up cash that can be used for investment in the remaining project. In both above asymmetric scenarios, the investment-delay effect of spending scarce resources to fund investment outweighs the investment-acceleration effect of the cash generated post-investment. Additionally, as long as one of the projects has at least a moderate value and the firm is sufficiently cash constrained, the marginal value of cash will be high.

The model in this thesis is set up in a progressive manner and solved backwards in project-time. First, a cash constrained firm that has access to only one investment opportunity is explored in a manner analogous to Boyle and Guthrie (2003). From here, the model is built up to consider the same firm with one investment opportunity that now has access to existing assets in place which are resultant from previous investment decisions. The addition of these existing assets helps provide an insight into the optimal divestment policy of the firm, whereby selling assets raises sufficient resources to fund investment. In its third stage, the model is developed to show the investment decision of a firm with access to two distinct and separate investment 
projects. In this setting the firm not only decides on the optimal timing for each investment, but in states where investment in either (but not both projects) is possible, the firm must also choose between projects.

The remainder of this thesis is organised as follows. Chapter 2 describes the investment environment and presents the investment choice model. Once set up, the model can be applied to variety of areas. Chapter 3 discusses some applications of the investment choice model and looks at asymmetric projects, the value of cash and resource allocation in a spin-off. Each state within the model depends on the cash balance and the value of each of the two projects. As such, the solution procedure is computationally intensive and requires the use of innovative numerical solutions to converge in a reasonable period of time. Chapter 4 outlines these numerical techniques and illustrates how the quality of results are enhanced through their use. Lastly, Chapter 5 contains some concluding remarks. 


\section{Chapter 2}

\section{Model Setup and Solution}

\subsection{Overview}

A natural extension to the model of Boyle and Guthrie (2003) is to investigate a firm that has access to more than one investment project. An unconstrained firm with perpetual rights to two projects will behave in a similar way to the one-project unconstrained firm and invest at the optimal level for each project. However, the problem of the financially constrained firm becomes much more complex as it becomes not only a question of investment timing, but also of investment choice.

Before exploring the case where the firm must choose between two investment opportunities, first, the situation where the firm must only choose the investment timing on one investment opportunity is explored. This is analogous to the work of Boyle and Guthrie (2003) although the frictions employed here provide a richer and more realistic investment environment. Next, the situation where the firm has launched its initial investment and now has a second investment opportunity is explored. The increased complexity of this problem stems from the previously undertaken investment opportunity. Because investment has already been undertaken in this first project, it is now generating cash which can help to relax the cash constraint of the firm. The setup is such that this new asset can be sold to raise capital to fund investment in the latest project. Selling existing assets comes at a cost to the firm, which leads the 
firm to increase the threshold required for investment when assets in place must be sold to fund said investment. After this, the final situation where the firm has rights to two investment projects and must choose the timing on both is explored in detail.

\subsection{One Investment}

Consider a firm that has perpetual rights to an investment project (project A) that, once initiated, generates a perpetual cash flow $\left(A_{t}\right)$ at date $t$ that evolves according to the following Geometric Brownian Motion

$$
d A_{t}=\mu_{A} A_{t} d t+\sigma_{A} A_{t} d \xi_{A, t}
$$

where $\mu_{A}$ and $\sigma_{A}$ are constants that specify the drift and volatility of $A$ respectively, while $d \xi_{A, t}$ is the increment to a Weiner process. It follows that once launched, the present value of project $\mathrm{A}$ at date $t, V_{A, t}$, will be equal to the current cash flow discounted at the risk adjusted discount rate less the cash flow growth rate. That is to say

$$
V_{A, t}=\frac{A_{t}}{\left(r+\lambda_{A}\right)-\mu_{A}}
$$

where $r$ is the risk free interest rate and $\lambda_{A}$ is the risk premium of project A. Further simplification of Equation (2.2) can most readily be obtained by defining $r+\lambda_{A} \equiv$ $\mu_{A}+\delta_{A}$, where $\delta_{A}$ represents the opportunity cost of cash flows forfeited due to waiting. More commonly, this is known as the implicit dividend yield. It follows that $V_{A, t}=A_{t} / \delta_{A} \cdot 1$

In addition to the option rights, the firm has a cash stock $X_{t}$ at time $t$ and assets in place worth the constant $G$. Investment can occur at date $t$ if and only if

$$
I_{A} \leq X_{t}+G+\gamma_{A} \theta_{A} V_{A}
$$

\footnotetext{
${ }^{1}$ For further details see Chapter 6 of Dixit and Pindyck (1994).
} 
for some constants $I_{A}, \gamma_{A} \in[0,1)$ and $\theta_{A} \in[0,1) .{ }^{2}$ The left hand side of the investment constraint represents the lump sum cost that must be paid in order to initiate investment. The right-hand side is composed of all the resources available to the firm to fund investment, cash plus the accessible value of the firm's assets. In this case, the accessible value of the firm's assets is the amount of short term risk free debt $\left(G+\gamma_{A} \theta_{A} V_{A}\right)$ that can be raised from creditors by pledging the assets in place, $G$, and the soon to be launched project $\mathrm{A}$ as collateral. The friction $\gamma_{A}$ captures the information asymmetry between the firm and outside creditors, and $\theta_{A}$ is a discount applied because the creditors do not have control of the project. It is in the use of these two frictions where the setup diverges from that of Boyle and Guthrie (2003) and will later be the driving factor in how the firm divests assets in place. Nevertheless, the policy results under the two frictions are qualitatively the same as in Boyle and Guthrie (2003). Under these frictions, the firm is able to borrow money at a fair rate; however, it is unable to borrow up to the full value of the asset. Without loss of generality no frictions are placed on $G$ because there is no uncertainty around their value to creditors and therefore the firm may borrow up to their full value. ${ }^{3}$ The frictions on $V_{A}$ mean that there will be states where the payoff to investment, $V_{A}-I_{A}$, is positive yet the firm is unable to invest. These states occur when $X+G+\gamma_{A} \theta_{A} V_{A}<I_{A}<V_{A}$ and mean that the firm is forced to postpone investment.

As time goes on, both $X$ and $G$ can help to relax the cash constraint. Firstly, the cash balance is invested in risk free securities earning a rate of return $r$. Secondly, the existing assets $G$ generate uncertain operational cash flow with dynamics $\nu d t+\phi d \zeta$, where $\nu$ and $\phi$ are constants and $\zeta$ is a Weiner process that satisfies $d \zeta d \xi_{A, t}=\rho_{X A} d t$ for some constant $\rho_{X A} \in[-1,1]$. The cash stock prior to investment therefore evolves according to the following process

$$
d X=r X d t+\nu d t+\phi d \zeta
$$

\footnotetext{
${ }^{2}$ For the remainder of this section $t$ subscripts will be dropped for simplicity as the explicit date at which investment occurs is not material.

${ }^{3}$ Frictions could be placed on $G$ without changing the results; however, for simplicity no frictions are placed on $G$.
} 
Under Equation (2.4) the level of cash may become negative, which represents the firm issuing short term debt to cover cash flow problems. Should the cash deficit exceed the accessible value of the firm's non-cash assets, the firm will face liquidation and be forced to sell the project rights for $F^{U A}\left(\gamma_{A} A\right) .{ }^{4}$ In a competitive environment, the buyer of the rights will be an unconstrained firm, accordingly $F^{U A}\left(\gamma_{A} A\right)$ represents the value to the unconstrained firm evaluated at $\gamma_{A} A$. It is worth noting that when selling the rights, the control friction $\theta_{A}$ is not applied because once sold, the unconstrained buyer will be able to manage and control the project as they see fit. There still exists an information asymmetry so $\gamma_{A}$ is applied as usual. Shareholders are free to trade their shares on the open market, so the objective of the firm will be to maximise its value. That is, to maximise the sum of its cash, assets in place and the value of the investment option. Therefore, maximising the value of the option will also maximise the value of the firm. However, let us first revisit in detail the investment problem of the unconstrained firm, as it serves as a useful benchmark as well as a limiting case for the constrained firm.

\subsubsection{The Unconstrained Firm}

The unconstrained firm has a sufficient cash balance such that in any state it can afford to invest. McDonald and Siegel (1986) were the first to investigate and provide a solution to this investment decision. Their efforts were later refined by Dixit and Pindyck (1994). An unconstrained firm will invest if the current project cash flow exceeds some fixed investment threshold $\hat{A}^{u}$. Before investment, the unconstrained option value, $F^{U A}$, satisfies the following ordinary differential equation

$$
\frac{1}{2} \sigma_{A}^{2} A^{2} F_{A A}^{U A}+\left(r-\delta_{A}\right) A F_{A}^{U A}-r F^{U A}=0
$$

where subscripts on $F^{U A}$ denote partial derivatives. ${ }^{5}$ In order to solve for the value of the option, a few conditions are required. First, the option will be worth nothing

\footnotetext{
${ }^{4}$ Liquidation occurs when $X+G+F^{U} A\left(\gamma_{A} A\right) \leq 0$ where $F^{U A}\left(\gamma_{A} A\right)$ is the value of the investment option to the unconstrained firm evaluated at $\gamma_{A} A$.

${ }^{5}$ Details of the derivation of Equation (2.5) can be found on page 140 of Dixit and Pindyck (1994).
} 
when the project value is zero, $F^{U A}(0)=0 .{ }^{6}$ Second, at the investment threshold the option will be worth the payoff to exercising, $F^{U A}\left(\hat{A}^{u}\right)=V_{\hat{A}^{u}}-I_{A}$. The second condition is the well-known value matching condition that ensures the option value will be continuous at the investment boundary. The simplicity of the problem allows for an analytical solution of the option value before investment of the form

$$
F^{U A}(A)=\left(V_{\hat{A}^{u}}-I_{A}\right)\left(\frac{V_{A}}{V_{\hat{A}^{u}}}\right)^{\beta_{A}}
$$

where

$$
\beta_{A}=\frac{1}{2}-\frac{r-\delta_{A}}{\sigma_{A}^{2}}+\sqrt{\frac{2 r}{\sigma_{A}^{2}}+\left(\frac{1}{2}-\frac{r-\delta_{A}}{\sigma_{A}^{2}}\right)^{2}}>1 .
$$

Given the above equations, the option value to the firm can take on two forms - one when it is optimal to delay investment, $A<\hat{A}^{u}$, and another when investment is optimal, $A \geq \hat{A}^{u}$.

$$
F^{u}(A)=\left\{\begin{array}{cc}
V_{A}-I_{A} & \text { if } A \geq \hat{A}^{u} \\
\left(V_{\hat{A}^{u}}-I_{A}\right)\left(\frac{V_{A}}{V_{\hat{A}^{u}}}\right)^{\beta_{A}} & \text { if } A<\hat{A}^{u}
\end{array}\right.
$$

Maximisation of Equation (2.8) provides the optimal investment threshold of

$$
\hat{A}^{u}=\frac{\beta_{A} I_{A} \delta_{A}}{\beta_{A}-1} .
$$

It is worth noting that as $\beta_{A}>1$, the investment threshold will be such that there will exist states where the payoff to investing, $V_{A}-I_{A}$, is positive although the firm chooses to delay investment.

\subsubsection{The Constrained Firm}

The problem faced by the constrained firm is that it has limited resources so there are states where it is unable to invest even if it would like to. In this case, the value of

\footnotetext{
${ }^{6}$ This is an absorbing barrier in that upon reaching zero, a Geometric Brownian Motion will stay there indefinitely, so that the option will never be exercised and is therefore worthless.
} 
the project rights become a function of both cash and project cash flow, denoted by $F(X, A)$. Like the unconstrained problem there will be an investment threshold, $\hat{A}$, whereby if $A \geq \hat{A}$ the firm will invest and receive a payoff worth $V_{A}-I_{A}$. However, $\hat{A}$ is now a function of $X$ rather than a constant as in the unconstrained case. The option will be worthless when the project cash flows are zero, $F(X, 0)=0$, and the option will be worth the exercise payoff at the investment boundary, $F(X, \hat{A})=V_{\hat{A}}-I_{A}$. As the cash balance increases, the constraint is relaxed and the value of the option will approach that of the unconstrained case,

$$
\lim _{X \rightarrow \infty} F(X, A)=F^{U A}(A)
$$

When $A$ is below the investment threshold then the firm will delay investment and the option value will satisfy the following partial differential equation

$$
\frac{1}{2} \sigma_{A}^{2} A^{2} F_{A A}+\rho_{X A} \sigma_{A} \phi A F_{X A}+\frac{1}{2} \phi^{2} F_{X X}+\left(r-\delta_{A}\right) A F_{A}+r(X+G) F_{X}-r F=0
$$

where subscripts on $F$ denote partial derivatives. ${ }^{7}$ The complexity of this equation means than an analytical solution is not available and therefore numerical methods are required to solve it.

Before discussing the solution, it is worthwhile to identify the situations the firm may find itself in for any state. There exists a total of three scenarios that dictate the actions available to the firm. Firstly, if $X+G+F^{U A}\left(\gamma_{A} A\right) \leq 0$, the firm is within the liquidation region and it is forced to sell the project rights for $F^{U A}\left(\gamma_{A} A\right)$ as above. This corresponds to region 1 of Figure 2.1, which has been constructed using the values from Table 2.1. The figure demonstrates that as the potential project cash flows and therefore the present value of a launched project increase, the firm is able to avoid liquidation for more and more negative levels of cash. Secondly, the firm can be in a state where it has enough resources to continue operation even though it does not have enough resources to undertake investment. This will occur when both

\footnotetext{
${ }^{7}$ Details of the derivation can be found in the Appendix.
} 
Table 2.1: This table outlines the parameter values used to numerically solve Equation (2.11) for the optimal investment timing policy. Most values are similar to those used in Boyle and Guthrie (2003). The frictions on investment however are instead represented by two separate parameters: information asymmetry as represented by $\gamma_{A}$ and the control discount represented by $\theta_{A}$.

\begin{tabular}{lc}
\hline \hline Project investment cost $(\$)$ & $I_{A}=100$ \\
Project cash flow volatility & $\sigma_{A}=0.20$ \\
Project dividend yield & $\delta_{A}=0.03$ \\
Information asymmetry & $\gamma_{A}=0.80$ \\
Control discount & $\theta_{A}=0.40$ \\
Risk free interest rate & $r=0.03$ \\
Firm cash flow - Project A cash flow correlation & $\rho_{X A}=0.50$ \\
Firm cash flow volatility & $\phi=60$ \\
Market value of existing assets & $G=100$ \\
\hline \hline
\end{tabular}

$X+G+F^{U A}\left(\gamma_{A} A\right)>0$ (the firm is liquid) and $I_{A}>X+G+\gamma_{A} \theta_{A} V_{A}$ (the firm is unable to invest). These states where forced delay occur correspond to region 2 of Figure 2.1. Even if the firm would like to invest here it is unable to, although it may be able to invest in the future if the constraints are relaxed. Finally, the firm will be able to choose between investing or waiting when $I_{A} \leq X+G+\gamma_{A} \theta_{A} V_{A}$, as shown by region 3 of Figure 2.1. Similar to the liquidation region the firm has the choice to invest for more and more negative values of cash as the project cash flow increases. It is worth noting that no matter how large $V_{A}$ is, there will always exist a level of cash that forces the firm to delay investment. This result is in contrast to Boyle and Guthrie (2003) who only employ a single investment friction. The use of a single investment friction means that there will be a critical level of project cash flows beyond which the firm will find itself either liquidated or able to invest for any level of cash. The grey dashed line of Figure 2.1 shows the investment threshold of the unconstrained firm.

\subsubsection{A Numerical Solution}

In order to provide a solution to Equation (2.11), numerical methods based on finite differences and successive over-relaxation are implemented, the details of which can 


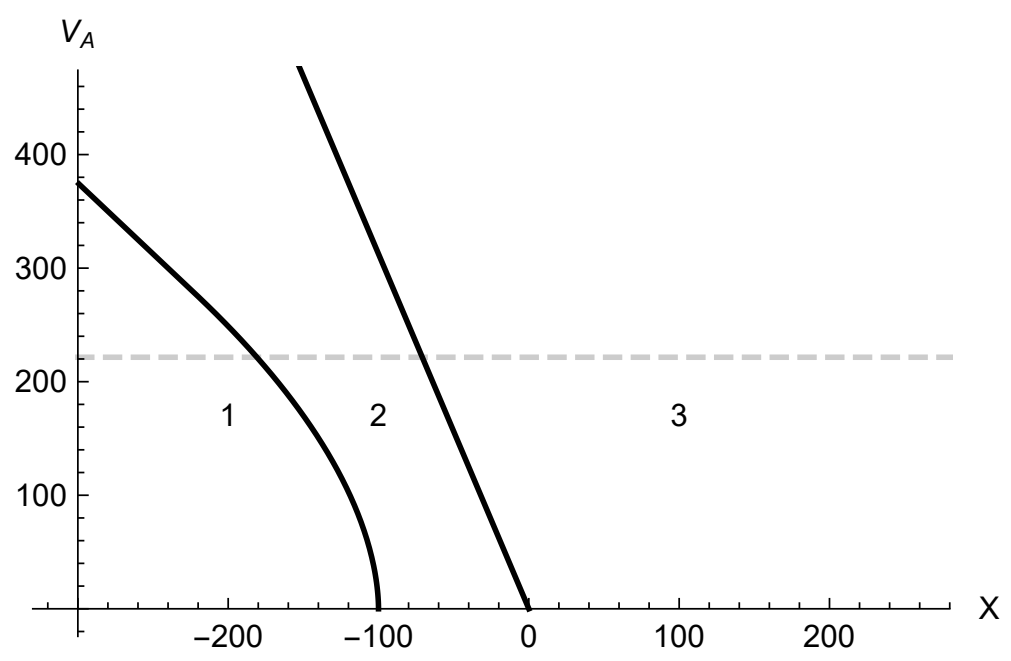

Figure 2.1: This figure shows the three regions the constrained firm can be in using the parameters of Table 2.1. The horizontal dashed line is the unconstrained investment threshold. Region 1 corresponds to the liquidation region where $X+G+F^{U A}\left(\gamma_{A} A\right) \leq 0$. It is here where the firm is forced to sell the rights to the project for $F^{U A}\left(\gamma_{A} A\right)$. Region 2 is the forced waiting region. Here the firm has sufficient resources to continue operation, $X+G+\gamma_{A} \theta_{A} V_{A}>0$, but does not have enough resources to fund investment, $I_{A}>X+G+\gamma_{A} \theta_{A} V_{A}$. Within region 3 the firm is able to invest as it has sufficient resources to do so, $I_{A} \leq X+G+\gamma_{A} \theta_{A} V_{A}$.

be found in Chapter 4 and in the Appendix. The impact of being constrained is best shown by analysing the investment policy undertaken by the firm. Refer to Figure 2.2 , which plots the regions and unconstrained threshold of Figure 2.1 as well as the optimal constrained investment threshold $\hat{A}$ (the black curve). The unconstrained firm will invest when the value of the project equals or exceeds 221.53. In comparison to this, when the constrained firm has considerably lower levels of cash, the financing constraint binds and $\hat{A}>\hat{A}^{u}$. As the constraint binds the firm invests as soon as possible due to the risk of future funding shortfalls being such that the firm can not afford to miss out. The more negative the cash balance the further the constrained firm delays investment when compared to the unconstrained firm. For moderately low levels of cash the investment constraint still binds however the firm accelerates investment compared to that of the unconstrained firm, that is it over invests. In this region, the threat of future funding shortfalls is still great enough that the constrained firm chooses to invest as soon as possible in order to avoid losing the investment opportunity in the future. As the cash balance increases, the constraint no longer binds, although the firm still invests earlier than the unconstrained level. The level 


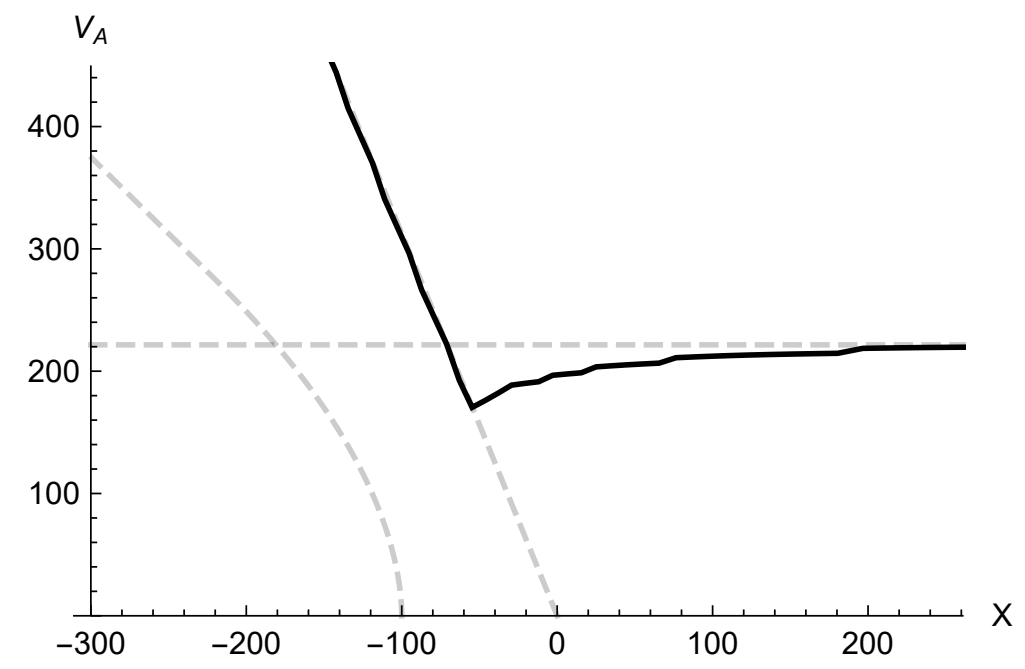

Figure 2.2: This figure shows the investment threshold of the constrained firm under the parameters in Table 2.1. The grey dashed lines correspond to the unconstrained threshold, liquidation constraint and investment constraint of Figure 2.1. The black curve is the constrained firm's investment threshold.

of acceleration decreases with cash as the risk of funding shortfalls gets smaller and smaller. Eventually the firm has so much cash that, due to the extremely low shortfall risk, it invests at the unconstrained level.

Not only do the financial constraints of a constrained firm alter the investment policy undertaken, they also reduce the value of the investment option. Figure 2.3 demonstrates how the option value changes with cash under the parameters in Table 2.1. Consider the graphs in the top row where the firm has a cash balance of -237 . The leftmost graph shows the value of the investment option for a range of $V_{A}$. The dashed grey line shows the "now-or-never" value of the project to the unconstrained firm. The "now-or-never" payoff is essentially a European call at maturity on the investment opportunity with strike price $I_{A} \cdot{ }^{8}$ For low levels of $V_{A}$, the option is more valuable than the investment payoff due to the value of waiting. In fact, for $V_{A} \leq 300$ the firm is forced to liquidate and sell the investment rights. When $V_{A}>300$, the firm is forced to delay investment due to insufficient resources; however, it is still solvent. As the firm is forced to wait, the option value is less than the payoff to investing. The rightmost graph shows that for the range of $V_{A}$ illustrated, the firm is unable to invest due to insufficient cash.

\footnotetext{
${ }^{8}$ For $V_{A}>I_{A}$ it is positive and increasing one-for-one with increases in $V_{A}$ and zero elsewhere.
} 
Now consider the graphs within the middle row of Figure 2.3, where the cash balance of -127 is still negative although much less so. From the rightmost graph it can be seen that for low levels of $V_{A}$ the firm is liquidated and therefore sells the rights for $F^{U A}\left(\gamma_{A} A\right)$. However, for moderate levels of $V_{A}$ the firm has sufficient resources to continue operation although not enough to allow investment and is therefore forced to wait. Within the waiting region the value of the rights increases steeply with $V_{A}$ as the likelihood the firm will have enough resources to invest in the future increases. Finally, for high levels of $V_{A}$ the firm has enough resources to invest and does so immediately. As $V_{A}$ increases in the investment region, the option value increases at a lower rate than compared to the waiting region. In the investment region, the risk of future shortfalls does not matter as the firm chooses to invest straight away so a $\$ 1$ increase in $V_{A}$ is reflected by a $\$ 1$ increase in the investment option. On the contrary the marginal value of a $\$ 1$ increase in $V_{A}$ in the waiting region is considerably higher than $\$ 1$ because it brings the firm closer to being able to invest and reduces the risk of losing the opportunity to undertake a significantly good project.

Lastly consider the graphs of Figure 2.3 contained within the bottom row, where the cash balance is 137. Here the firm's financial health is good enough to allow investment for the full range of $V_{A}$. Now that the firm is able to freely choose its investment policy it chooses to postpone investment only when it is such that the value of waiting is more than the payoff to investing. If this was not the case, then it would alter its policy and invest earlier. The potential for cash shortfalls in the future still exists, so the option value is therefore lower than that of the unconstrained firm.

It is worth noting that when the investment constraint binds, the option value is not smoothly pasted. ${ }^{9}$ In fact, when the constraint binds, as $V_{A}$ increases and the firm moves from the waiting to the investment region, the option value gradient sharply changes from relatively steep to a much flatter level. A binding constraint forces the hand of the constrained firm on the investment timing decision. When the

\footnotetext{
${ }^{9}$ The use of smooth pasting ensures that the waiting and exercise values meet tangentially, a requirement for optimality. Smooth pasting only occurs when the firm has the freedom to choose its investment policy, when the financing constraint does not bind. Refer to page 108 of Dixit (1993b) for further details.
} 

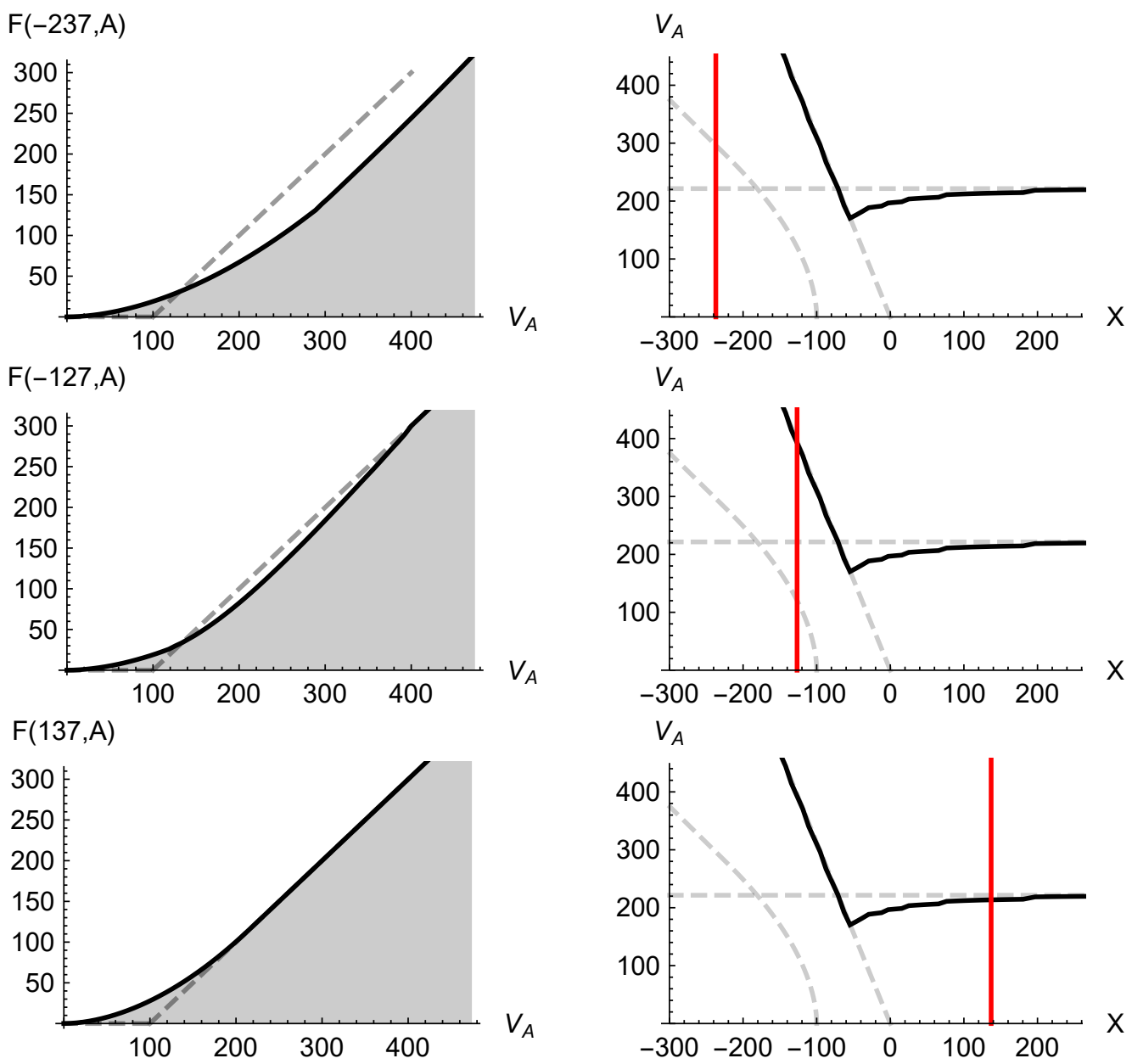

Figure 2.3: This figure demonstrates the option value plotted against $V_{A}$ for a given level of cash. The left-hand graph of each row shows the option value while the right hand graph shows the region map and plots the level of $X$ that corresponds to the option value. Within the first row of graphs, cash is sufficiently low that the firm is unable to invest at any point for the given range of $V_{A}$. Accordingly the option value is less than the "now-or-never" payoff (which is indicated by the dashed lines) for all but very low levels of $X$. The middle row of graphs shows the option value and region plot for a cash balance of -127 . Here cash is large enough that for high values of $V_{A}$ the firm can invest and does so as soon as possible to avoid future funding shortfalls. In the final row the firm has a large enough cash balance that it can invest for any $V_{A}$ within the illustrated range. When the investment constraint does not bind investment is accelerated relative to the unconstrained firm as there is the possibility of funding shortfalls in the future.

firm can freely choose its investment policy without a limiting constraint, the result is a maximised option value that is smoothly pasted. The concept of smooth pasting will become much more important when the firm is able to sell assets in place in the 
following section. For a more in depth analysis of the single investment opportunity case, refer to Boyle and Guthrie (2003).

\subsection{Two Investments: One Launched, One Oppor- tunity}

Now imagine that the investment opportunity in Section 2.2 has been undertaken. The firm's assets in place now consist of $G$ plus project A, which generates cash according to Equation (2.1). Consider that a new investment is now available to which the firm has perpetual rights. Let this opportunity be called project B. Suppose that once initiated it generates cash flow that evolves according to the following Geometric Brownian Motion

$$
d B=\mu_{B} B d t+\sigma_{B} B d \xi_{B, t}
$$

where $\mu_{B}$ and $\sigma_{B}$ are constant parameters that specify the drift and volatility of the cash flow respectively and $\xi_{B, t}$ is a Weiner process that satisfies $d \xi_{A, t} d \xi_{B, t}=\rho_{A B} d t .^{10}$ It follows from earlier reasoning that once launched the project will have a present value $\left(V_{B}\right)$ equal to

$$
V_{B}=\frac{B}{\left(r+\lambda_{B}\right)-\mu_{B}}=\frac{B}{\delta_{B}}
$$

where $\lambda_{B}$ is the risk premium of $\mathrm{B}$ and $\delta_{B}$ the implicit dividend yield.

As time goes on $X, G$ and $A$ can help to relax the cash constraint. As before, the cash balance is invested in risk free securities earning a rate of return $r$ and $G$ generates uncertain operational cash flow with dynamics $\nu d t+\phi d \zeta$ where $\zeta$ is a Weiner process that satisfies $d \zeta d \xi_{A, t}=\rho_{X A} d t$ and $d \zeta d \xi_{B, t}=\rho_{X B} d t$. In addition to this, project A will generate cash according to Equation (2.1), resulting in an overall evolution of the cash stock prior to investment of

$$
d X=r X d t+\nu d t+\phi d \zeta+A d t
$$

\footnotetext{
${ }^{10}$ If the firm did not have project A launched and in place, then the option value of project B can be calculated in the same manner as the previous section and is represented by $F^{B}(X, B)$.
} 
Analogous to the single-project case, the cash stock here is able to become negative and, depending on its magnitude, the firm may be forced into liquidation for sufficiently negative values. In this case, forced liquidation will occur if $X+G+\gamma_{A} V_{A}+$ $F^{U B}\left(\gamma_{B} B\right) \leq 0 .{ }^{11}$ Once cash is low enough to trigger forced liquidation, the investment rights are sold for $F^{U B}\left(\gamma_{B} B\right)$ which is the value of the rights to an unconstrained firm evaluated at $\gamma_{B} B$.

Unlike the single-project set up of Section 2.2, the firm now has existing assets of $G$ as well as project A. The original existing assets $G$ carry no frictions so either selling or borrowing against them will provide the same level of resources. In contrast to the original assets, the borrowing capacity of project A differs from its selling capacity. Investment in this second project without divesting existing assets can occur if and only if

$$
I_{B} \leq X+G+\gamma_{A} \theta_{A} V_{A}+\gamma_{B} \theta_{B} V_{B}
$$

The left hand side of Equation (2.15) represents the lump sum investment cost of investing while the right hand side represents all the resources available to fund investment. That is, cash plus the debt capacity of assets in place plus the borrowing capacity of project B. Both of the $\gamma_{A}$ and $\theta_{A}$ frictions still apply as there exists information asymmetry as well as a control discount for project A. Once again, without loss of generality, there are no frictions placed on $G$ as it is a constant and any frictions would only lead to a shift in constraints without changing the underlying behaviour. The borrowing capacity of the new project is represented by $\gamma_{B} \theta_{B} V_{B}$ where the constants $\gamma_{B} \in[0,1)$ and $\theta_{B} \in[0,1)$ are borrowing frictions applied due to information asymmetry and creditors not having control over the project respectively.

The firm is also able to divest a proportion of project A in order to fund investment. Consider the case where the firm does not utilise the borrowing capacity of project A, investment requires that $I_{B} \leq X+G+\gamma_{B} \theta_{B} V_{B}$. If this does not hold then the

\footnotetext{
${ }^{11}$ In liquidation existing assets will be sold to an unconstrained firm, Therefore, only the information asymmetry friction appears on $V_{A}$ and not the control friction $\theta_{A}$ as the new owner has controlling rights of the project.
} 
firm needs to raise

$$
J_{A}=I_{B}-X-G-\gamma_{B} \theta_{B} V_{B}
$$

from Project A to fund investment. As detailed in Equation (2.15) riskfree debt of up to $\gamma_{A} \theta_{A} V_{A}$ can be undertaken. This represents the maximum capacity of how much the firm can raise from the external capital market via creditors provided that project A is pledged as collateral. The amount borrowed is fairly priced so there is no cost in raising capital this way. The firm may also sell a proportion of the asset to an outside investor where selling the full asset provides capital of $\gamma_{A} V_{A}$. Selling does not incur the $\theta_{A}$ friction because once launched the project is assumed to be entirely divisible. As such, the borrowing capacity of project A is less than what can be raised from selling. Therefore, in order to invest by divesting some proportion of project A it must be such that

$$
I_{B} \leq X+G+\gamma_{A} V_{A}+\gamma_{B} \theta_{B} V_{B}
$$

The two financing options are not mutually exclusive so a combination of borrowing and selling can be implemented. If a proportion $\psi_{B A} \in(0,1]$ is borrowed against and $\psi_{S A} \in(0,1]$ sold, then it will be the case that

$$
J_{A} \leq \psi_{B A} \gamma_{A} \theta_{A} V_{A}+\psi_{S A} \gamma_{A} V_{A}
$$

in order to invest. ${ }^{12}$ The optimal mix of borrowing and selling is motivated by the idea that where possible the firm will prefer to borrow instead of selling. This notion is in line with the "pecking order theory" as discussed in Myers and Majluf (1984). It also mirrors the results presented in Lang et al. (1995) where a firm will sell assets only when alternative funding is insufficient. In contrast to borrowing, selling is costly to the firm. When divesting a proportion $\psi_{S A}$ of project $\mathrm{A}$ the firm will give up $\psi_{S A} V_{A}$

\footnotetext{
${ }^{12}$ The constraint will be binding as the setup is such that there is no incentive for the firm to raise and horde extra cash.
} 
of asset value but only receives $\gamma_{A} \psi_{S A} V_{A}$ for it. As such, the overall payoff is

$$
\psi_{S A} V_{A}\left(\gamma_{A}-1\right)<0
$$

The loss made on divesting illustrates why the firm prefers to borrow where possible. It is important to note that any policy undertaken must be within the firm's feasible set. That is to say it is not possible to utilise the full debt capacity of the project whilst also selling the rights to the entire project, $\psi_{B A}+\psi_{S A} \leq 1$. Partial divestment is possible in a sense that the firm can sell an ownership stake within the existing asset. The overall payoff when divesting to raise capital and subsequently investing will be the investment payoff, $V_{B}-I_{B}$, less the loss on divestment. In order to maximise firm value, the firm will choose $\psi_{B A}$ in order to minimise their loss. As such their objective function is

$$
\begin{array}{ll}
\min & \psi_{S A} \\
\text { s.t. } & J_{A}=\psi_{B A} \gamma_{A} \theta_{A} V_{A}+\psi_{S A} \gamma_{A} V_{A} \\
& \psi_{B A}+\psi_{S A} \leq 1 \\
& \psi_{S A} \geq 0
\end{array}
$$

The problem can best be illustrated via a graph of the constraints as seen in Figure 2.4. On the left is a graph that demonstrates the case where $J_{A}$ can be raised entirely by borrowing a proportion equal to $\psi_{B A}^{*}$. The black line represents all combinations of $\psi_{B A}$ and $\psi_{S A}$ that allow the firm to raise $J_{A}$, while the grey line illustrates the limit of resources that can be raised from project $\mathrm{A}, \psi_{B A}+\psi_{S A}=1$. In the left hand case the payoff to investment will be the same as in the standard case, $V_{B}-I_{B}$. As $J_{A}$ increases, the black line will shift outwards until the borrowing capacity is not sufficient for investment. The graph on the right shows a situation where this has occurred and partial divestment is required to fund investment. In this instance the $J_{A}$ line intersects the funding constraint and therefore both borrowing and divestment are required at levels $\psi_{B A}^{*}$ and $\psi_{S A}^{*}$ respectively. Solving Equation (2.20) provides an 

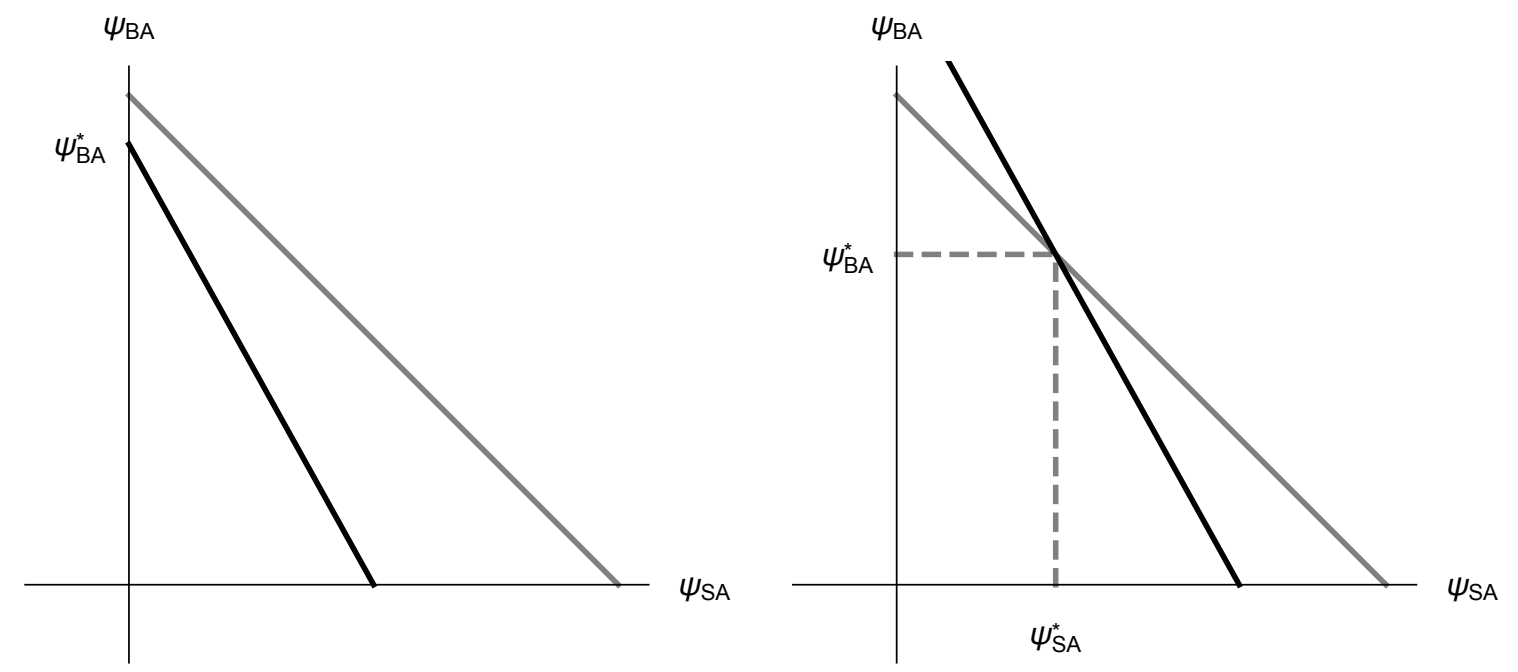

Figure 2.4: These graphs demonstrate the general behaviour of the optimal divestment policy. The black line on each graph represents the amount of extra funding required to be raised from project $\mathrm{A}$ in order to invest in project B. The grey line illustrates the funding constraint where $\psi_{B A}+\psi_{S A}=1$. The graph on the left hand side shows a situation where the firm can raise the extra funds required to invest in project B by solely using a percentage $\psi_{B A}^{*}$ of the borrowing capacity of project B. The right hand graph shows a situation where the firm must use borrowing capacity $\psi_{B A}^{*}$ of project $\mathrm{A}$ as well as as divest a proportion $\psi_{S A}^{*}$ of project $\mathrm{A}$ in order to fund investment in project $\mathrm{B}$.

analytical solution for $\psi_{S A}^{*}$ of the form

$$
\psi_{S A}^{*}=\frac{J_{A}}{\gamma_{A}\left(1-\theta_{A}\right) V_{A}}-\frac{\theta_{A}}{1-\theta_{A}} .
$$

Upon substitution and rearrangement, the payoff to investing in project B via divestment in project $\mathrm{A}$ will therefore be equal to

$$
\left(V_{B}-I_{B}\right)-\left(\frac{J_{A}}{\gamma_{A}}-\theta_{A} V_{A}\right)\left(\frac{1-\gamma_{A}}{1-\theta_{A}}\right) .
$$

It is worth remembering that this payoff will only be applicable when the maximum borrowing capacity of project A does not raise sufficient capital for investment. Before further discussing the constrained firm, the unconstrained case is illustrated below. 


\subsubsection{The Unconstrained Firm}

The situation of the unconstrained firm will not change as they can still invest when they want without ever needing to sell existing assets. The option value to such a firm will be

$$
F^{U B}(B)=\left\{\begin{array}{cl}
V_{B}-I_{B} & \text { if } B \geq \hat{B}^{u} \\
\left(V_{\hat{B}^{u}}-I_{B}\right)\left(\frac{V_{B}}{V_{\hat{B}^{u}}}\right)^{\beta_{B}} & \text { if } B<\hat{B}^{u}
\end{array}\right.
$$

where

$$
\beta_{B}=\frac{1}{2}-\frac{r-\delta_{B}}{\sigma_{B}^{2}}+\sqrt{\frac{2 r}{\sigma_{B}^{2}}+\left(\frac{1}{2}-\frac{r-\delta_{B}}{\sigma_{B}^{2}}\right)^{2}}>1 .
$$

The optimal investment threshold will be

$$
\hat{B}^{u}=\frac{\beta_{B} I_{B} \delta_{B}}{\beta_{B}-1} .
$$

\subsubsection{The Constrained Firm}

The objective of the constrained firm is to choose an investment threshold that maximises its option value. This value now becomes a function not only of cash and potential cash flow, but also of the cash flow being generated by Project A, denoted $F^{B A}(X, A, B)$ where $F^{B A}$ refers to the option to invest in project B given that project A has already been initiated. As in the single-project case, the option is worthless when the project cash flows are zero, $F^{B A}(X, A, 0)=0$. When the cash flows of Project A are zero then the solution simplifies down to the single-project case of section $2.2, F^{B A}(X, 0, B)=F^{B}(X, B) .{ }^{13}$ As the cash balance increases, the financing constraint is relaxed, and the value of the option will approach that of the unconstrained firm,

$$
\lim _{X \rightarrow \infty} F^{B A}(X, A, B)=F^{U B}(B)
$$

\footnotetext{
${ }^{13}$ When $A=0$, project $\mathrm{A}$ is so bad that it is generating no cash.
} 
As the cash flow generated by project $\mathrm{A}$ increases, and the financing constraint is relaxed, the value of the option will also approach that of the unconstrained firm,

$$
\lim _{A \rightarrow \infty} F^{B A}(X, A, B)=F^{U B}(B)
$$

Prior to investment the option value will satisfy the following partial differential equation

$$
\begin{aligned}
& \frac{1}{2} \sigma_{A}^{2} A^{2} F_{A A}^{B A}+\frac{1}{2} \sigma_{B}^{2} B^{2} F_{B B}^{B A}+\left(r-\delta_{A}\right) A F_{A}^{B A}+\left(r-\delta_{B}\right) B F_{B}^{B A}+(r(X+G)+A) F_{X}^{B A} \\
& +\frac{1}{2} \phi^{2} F_{X X}^{B A}+A B \rho_{A B} \sigma_{A} \sigma_{B} F_{A B}^{B A}+\rho_{X B} \sigma_{B} B \phi F_{X B}^{B A}+\rho_{X A} \sigma_{A} A \phi F_{X A}^{B A}-r F^{B A}=0
\end{aligned}
$$

where subscripts on $F^{B A}$ denote partial derivatives. ${ }^{14}$ Again the complexity of this equation precludes an analytical solution so numerical techniques are used to find an approximate solution. Before discussing the solution, it is worthwhile to assess the states the firm may find itself in and how the firm is affected. With the added complexity of assets in place, the firm may find itself in one of four situations depending on the levels of $X, A$ and $B$. Refer to Figure 2.5, which has been constructed using the parameter values of Table 2.2. The graphs are analogous to those in Figure 2.1, but drawn for different levels of "other-project" cash flow. The top left graph shows the situation where the cash flow of Project $A$ is equal to 0. Due to the characteristics of the cash flow process, 0 is an absorbing barrier and therefore the project will generate no further cash flow. In such a scenario the investment problem becomes equivalent to that of Section 2.2. In region $1, X+G+\gamma_{A} V_{A}+F^{U B}\left(\gamma_{B} B\right) \leq 0$, so the firm is liquidated and the project rights are sold for $F^{U B}\left(\gamma_{B} B\right)$. In region 2 the firm is liquid, $X+G+\gamma_{A} V_{A}+F^{U B}\left(\gamma_{B} B\right)>0$, however is unable to invest, $I_{B}>X+G+\gamma_{B} \theta_{B} V_{B}$, so it is forced to postpone investment. Region 3 is not present as project $A$ is worthless and therefore can not be used to raise resources for investment. In region 4 the firm has sufficient resources to invest if it wishes to, $I_{B} \leq X+G+\gamma_{B} \theta_{B} V_{B}$.

\footnotetext{
${ }^{14}$ A full derivation of Equation (2.28) can be found in the Appendix.
} 
Table 2.2: This table outlines the parameter values used to numerically solve Equation (2.28) for the optimal investment timing policy. The parameters of each project are identical and where possible similar to those of Boyle and Guthrie (2003).

\begin{tabular}{lcc}
\hline \hline & Project A & Project B \\
\cline { 2 - 3 } Project investment cost $(\$)$ & $I_{A}=100$ & $I_{B}=100$ \\
Project cash flow volatility & $\sigma_{A}=0.20$ & $\sigma_{B}=0.20$ \\
Project dividend yield & $\delta_{A}=0.03$ & $\delta_{B}=0.03$ \\
Information asymmetry & $\gamma_{A}=0.80$ & $\gamma_{B}=0.80$ \\
Control friction & $\theta_{A}=0.60$ & $\theta_{A}=0.60$ \\
\cline { 2 - 2 } Risk free interest rate & $r=0.03$ \\
Firm cash flow-Project A cash flow correlation & $\rho_{X A}=0.5$ \\
Firm cash flow-Project B cash flow correlation & $\rho_{X B}=0.5$ \\
Project A cash flow-Project B cash flow correlation & $\rho_{A B}=0.5$ \\
Firm cash flow volatility & $\phi=60$ \\
Market value of existing assets & $G=100$ \\
\hline \hline
\end{tabular}

The top right graph illustrates the applicable regions where the present value of Project $\mathrm{A}$ is equal to 67 . Regions 1 and 2 still represent liquidation and forced waiting respectively. Region 3 is applicable when the firm is able to invest although doing so requires divestment in project $\mathrm{A}$, that is $\gamma_{A} \theta_{A} V_{A}<J_{B} \leq \gamma_{A} V_{A}$. Along the line separating regions 2 and 3 is where the firm must sell project $A$ in its entirety to fund investment. Region 4 corresponds to the situation where the firm is able to invest without divesting, $I_{B} \leq X+G+\gamma_{A} \theta_{A} V_{A}+\gamma_{B} \theta_{B} V_{B}$. Moving from the top right graph to the bottom left graph and then the bottom right graph, the present value of project A increases from 67 to 141 and then to 200. Multiple flow-on effects occur within the choices available to the firm. Firstly, as project A generates more cash the firm is able to absorb more and more negative cash balances whilst continuing to operate. Secondly, the firm is able to invest via divestment for more and more negative levels of cash. Not only this but the applicable divestment region increases in width as the funds that can be raised increase with $V_{B}$. Lastly, the firm is also able to invest without divesting for more and more negative cash balances. The next section will discuss an intuitive solution to the investment threshold within these regions. 

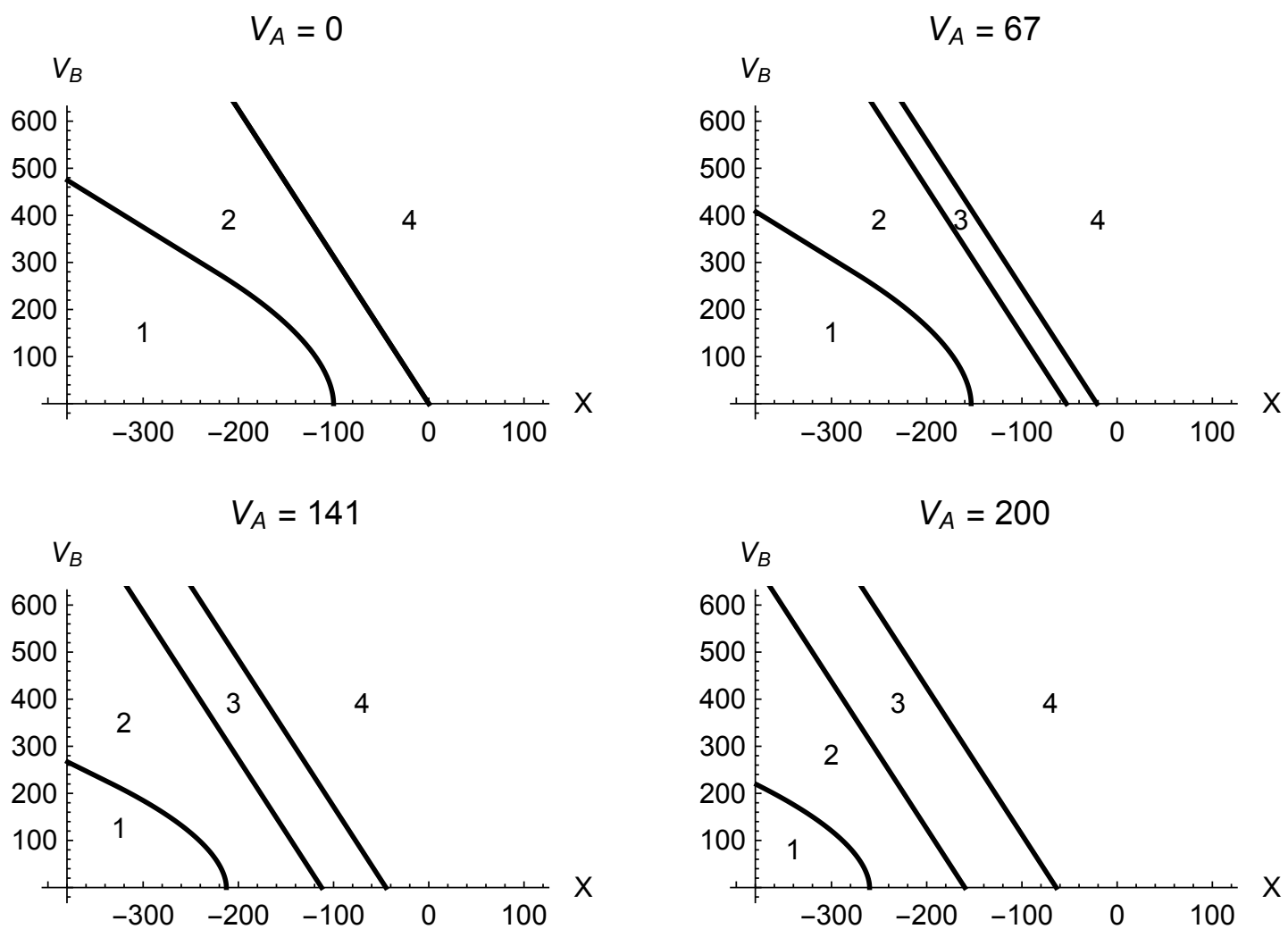

Figure 2.5: This figure shows the regions of the constrained firm with one project launched and one yet to be launched under the parameters of Table 2.2. Because one project has already been initiated the regions will depend on how much cash this launched project is generating. The displayed graphs have values of $V_{A}$ equal to $0,67,141$ and 200. In Region 1 the firm is forced to liquidate. In Region 2 the firm is forced to delay investment. In Region 3 the firm can invest but must divest a proportion of Project A in order to do so. In Region 4 the firm is able to invest without divesting any assets in place.

\subsubsection{An Intuitive Solution}

The frictions associated with investment will in some states force the constrained firm to delay although it would like to invest if it was unconstrained. In addition, the constrained firm will in some states choose to divest a proportion of existing assets in order to raise capital for investment, a costly exercise. This behaviour implies that

$$
F^{B A}(X, A, B) \leq F^{U B}(B) .
$$

It is the constraints placed on the firm that force it to implement a suboptimal investment policy relative to the unconstrained firm. Depending on the levels of the cash stock $(X)$ and project value $\left(V_{A}\right)$ the constrained firm may either postpone (under 
invest) or accelerate (over invest) investment when compared to the unconstrained firm. Delayed investment can be either voluntary or involuntary. Involuntary delay occurs when the financial constraints are severe enough to prevent investment regardless of whether the firm would like to invest or not. Voluntary delay happens when although the firm is able to invest, to do so would require the costly divestment of assets in place. If the project value is not sufficiently large to justify the divestment cost, the constrained firm chooses to delay. Acceleration of investment happens when the firm has the resources required for investment but the threat of future shortages leads them to invest early.

Figure 2.6 displays the intuitive constrained investment threshold for an arbitrary $A>0$. The result is qualitatively similar to the one described in Hirth and UhrigHomburg (2010b) under linear issuance costs. For a low $X, X<X_{A}$, the investment threshold is high and steeply increasing as $X$ decreases. This behaviour occurs because the investment constraint where the entire capacity of divestment occurs is binding. In order to avoid the risk of future shortfalls, investment occurs as soon as possible regardless of the cost associated with divesting as the firm does not want to miss out on the project. For moderately low levels of cash, $X_{A}<X<X_{B}$, the firm chooses to invest, although doing so requires the divestment of assets in place. Within this range the threshold decreases in cash because increasing cash relaxes the cash constraint and means the firm can divest a smaller proportion and still afford investment. As cash increases, the friction-driven cost of investment decreases and the firm is willing to invest for a lower project value. For a moderately high level of cash, $X_{B}<X<X_{C}$, the investment without divestment constraint is binding. For lower levels of $X$ within this range there is underinvestment, while higher levels lead to over investment. The firm is averse to selling because doing so is costly, which means they are willing to either delay until a time where $V_{B}$ is relatively large and justifies the divestment cost or accelerate investment in order to avoid having to sell to invest in the future. For high levels of cash, $X>X_{C}$, the firm accelerates investment in order to avoid the risk of future financing constraints. As the cash balance gets larger and larger the level of acceleration reduces and the threshold approaches 


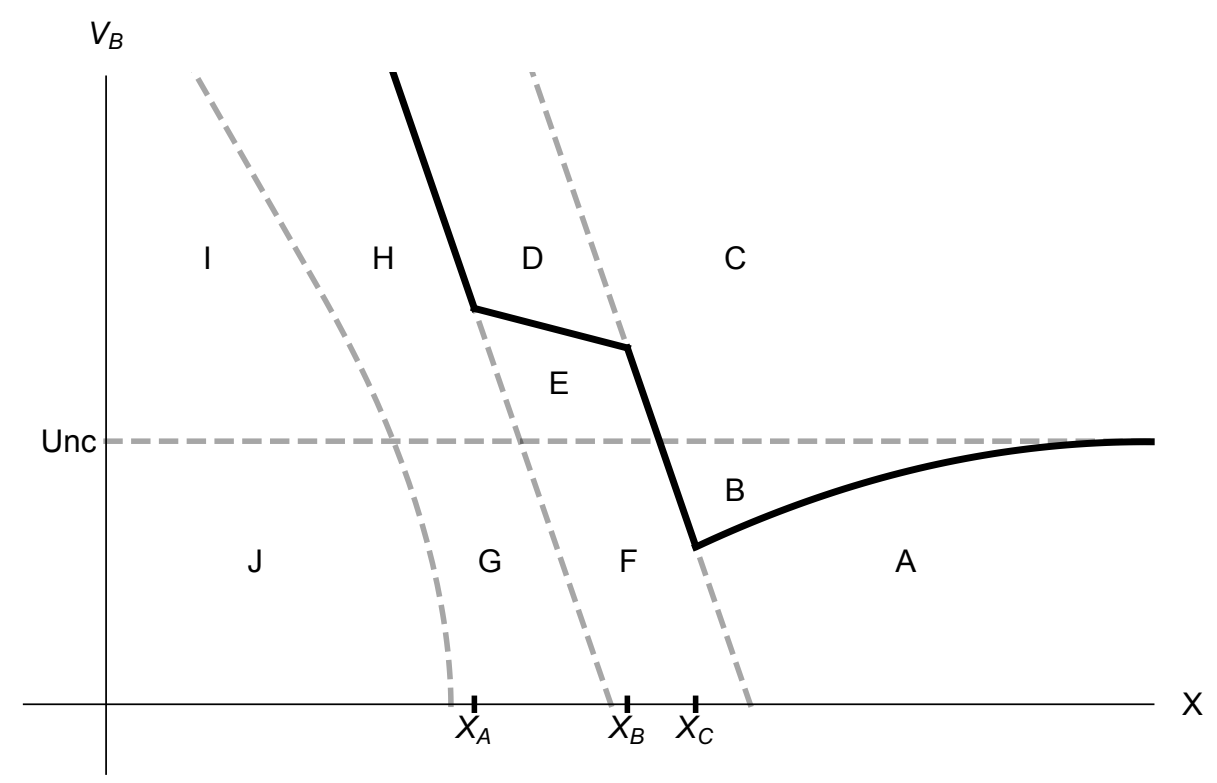

Figure 2.6: This figure shows the general shape of the constrained optimal investment threshold for some $A>0$. The constrained firm will choose to invest for values of $V_{B}$ and $X$ that are above the black curve. The grey dashed lines illustrate the investment, investment via divestment and liquidation constraints as well as the unconstrained threshold in a similar fashion to Figure 2.5. In region $\mathrm{A}$ neither the constrained nor the unconstrained firm chooses to invest. In region $\mathrm{B}$ the constrained firm chooses to invest due to the risk of not having the resources to do so in the future while the constrained firm is able to wait. In region $\mathrm{C}, V_{B}$ is sufficiently large that both the constrained and unconstrained firms will invest. In region $\mathrm{D}, V_{B}$ is large enough that the constrained firm is willing to invest by selling a proportion of assets in place in order to raise capital, the unconstrained firm also invests. In region $\mathrm{E}$ in order to invest the constrained firm would need to divest assets which is costly, $V_{B}$ is not large enough to justify this cost so investment is postponed while the unconstrained firm invests. In region $\mathrm{F}$ neither the constrained nor the unconstrained firm choose to invest. In regions $\mathrm{G}$ and $\mathrm{H}$ the constrained firm is forced to postpone investment while the unconstrained firm postpones and invests respectively. In regions I and $\mathrm{J}$ the constrained firm is liquidated while the unconstrained firm invests and postpones respectively.

that of the unconstrained firm.

Figure 2.6 also demonstrates the action taken by the constrained firm for a given state. In region $\mathrm{A}$ both the constrained and unconstrained firms choose to delay investment. In region $\mathrm{B}$ the constrained firm invests in order to avoid the risk of future resource shortfalls while the unconstrained firm delays. Within region $\mathrm{C}$ both the constrained and unconstrained firms invest. In region $\mathrm{D}, V_{B}$ is large enough that the constrained firm is willing to divest some assets at a cost in order to fund investment; the unconstrained firm also invests. In region $\mathrm{E}, V_{B}$ is not large enough to justify the cost associated with divesting assets in order to raise capital so the constrained firm delays investment while the unconstrained firm invests. Both the 
constrained and unconstrained firms will choose to delay investment when in region F. In regions $\mathrm{G}$ and $\mathrm{H}$, the constrained firm is forced to delay investment because it lacks the resources to invest. With its increased flexibility, the unconstrained firm chooses to delay in region $\mathrm{G}$ but invest in region $\mathrm{H}$. When finding itself in region $\mathrm{I}$ and $\mathrm{J}$ the constrained firm is still unable to invest although now its lack of resources force it into liquidation where it must sell the option rights. In contrast, the unconstrained firm is able to continue operating and invests when in region I and delays when in region $\mathrm{J}$.

\subsubsection{A Numerical Solution}

The above intuition is confirmed with the use of numerical methods based on finite difference equations and successive over-relaxation to solve Equation (2.28), followed by further intuitive analysis. The parameters shown in Table 2.2 are used for the baseline case. The results of the numerical solution procedure for a variety of $V_{B}$ are displayed in Figure 2.7 which superimposes the optimal investment threshold on Figure 2.5. The top left graph corresponds to the case where $A=0$ and therefore project A is worthless, thus the investment policy is comparable to the one in Section 2.2 , but with project $B$ the subject rather than project $A$. The remaining graphs show the policy for levels of $V_{A}$ equal to 67, 141 and 200. Recall from Figure 2.5 that as the cash flows of Project $\mathrm{A}$ increase, the firm is able to continue operation for greater negative values of cash. Accordingly, the investment threshold shifts leftwards with the investment and liquidity constraints.

The numerical solution backs up the intuition behind the intuitive solution discussed prior, although it is not entirely convincing that the no divestment investment constraint is binding. The numerical solution is found by solving Equation (2.28) on

a finite grid with discrete grid points. Smaller gaps between grid points would lead to a more accurate solution, but are computationally more intensive, so a compromise is required. In an effort to avoid imposing an incorrect structure on the solution, no smoothing is applied and the graphs of Figure 2.7 plot the grid points at which 

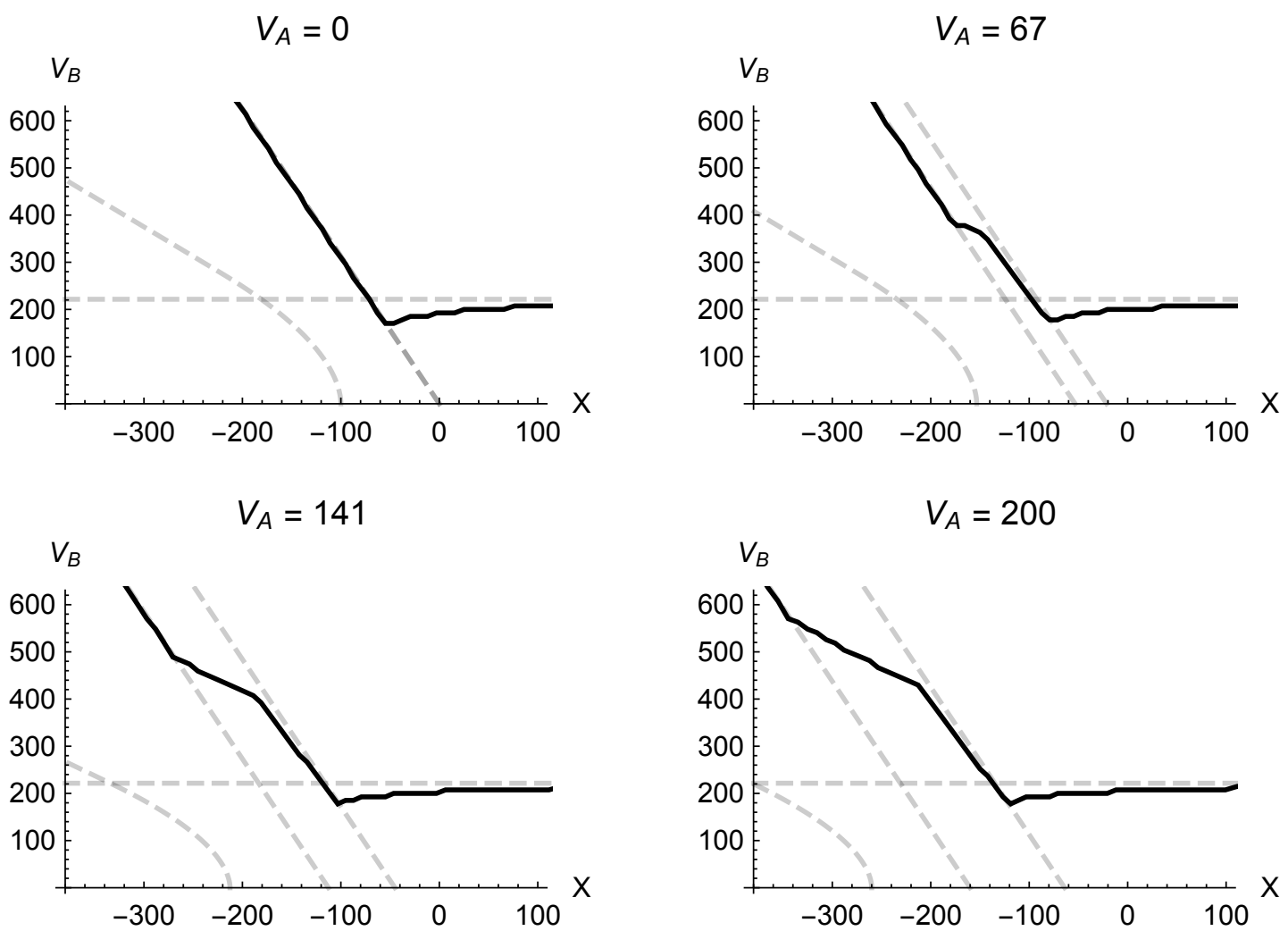

Figure 2.7: This figure shows the numerical solution to the constrained investment threshold under the parameters in Table 2.2. The top left graph shows the investment threshold when the value of the launched project is 0 and therefore the solution shows the same characteristics as the one in Section 2.2. The remaining graphs show the optimal investment policy when $V_{A}$ is equal to 67,141 and 200 .

investment first occurs. In order to prove that the investment without divestment constraint is binding and the use of grids leads to a lower investment threshold, first consider the intuitive solution. It has four distinct parts depending on the firm's level of cash as illustrated in Figure 2.8. When $X$ is in the range labelled $X_{1}$, the investment threshold binds on Equation (2.17). This occurs because $V_{B}$ is sufficiently high that the firm is willing to divest whatever amount is required in order to fund the investment. The risk of future shortfalls combined with the high project value leads to investment, although the constrained firm under invests when compared to the unconstrained firm. In region $X_{2}$, the investment threshold is decreasing in cash but at a much lower rate than in $X_{1}$. Within this range neither of the investment constraints are binding and the firm chooses to divest assets in order to raise capital to fund the investment. The threshold is decreasing in cash as more cash means they 


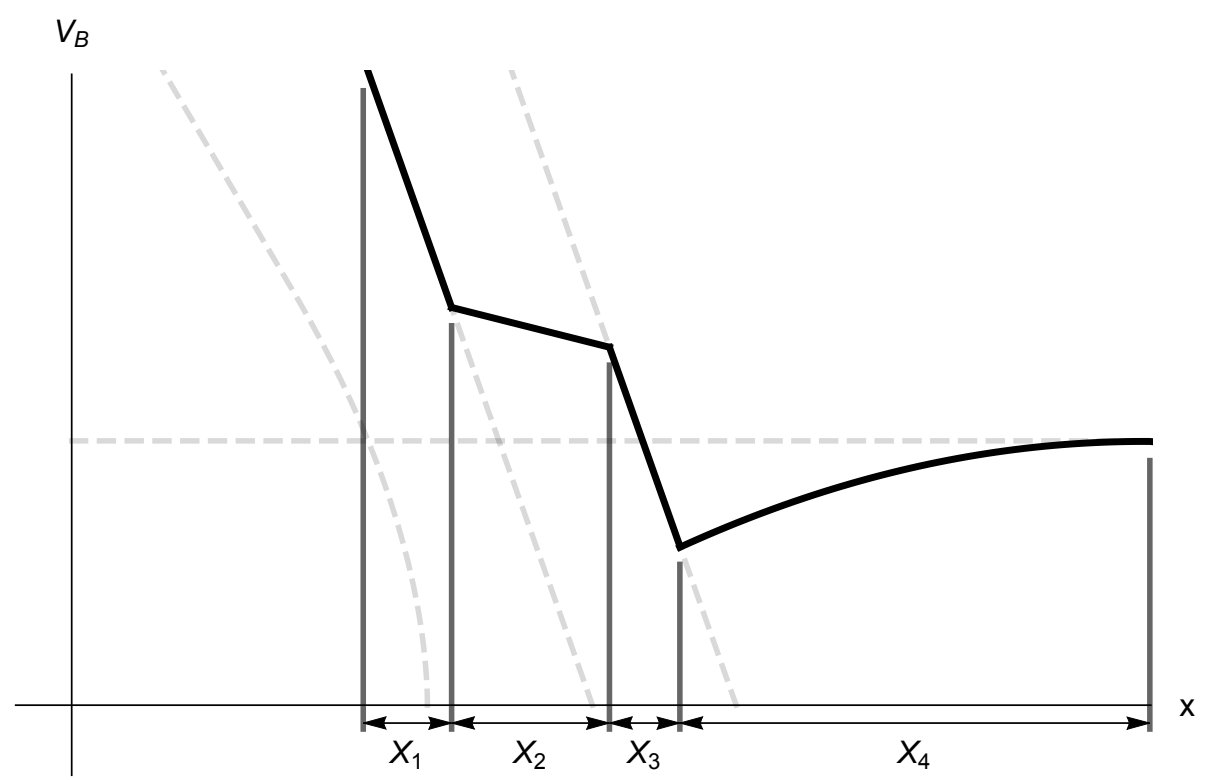

Figure 2.8: This figure shows the intuitive solution to the investment threshold and the four distinct ranges of cash where the threshold behaviour has certain characteristics. When $X$ lies within the range illustrated by $X_{1}$, Equation (2.17) is binding in the threshold. In the ranges $X_{2}$ and $X_{4}$ no constraints are binding. Within the $X_{3}$ range the investment without divestment constraint is binding.

can divest a lower proportion of assets in order to fund investment and therefore are willing to undertake investment for a lower level of $V_{B}$. For the $X_{3}$ range the investment without divestment constraint is binding on the threshold. Perhaps the most interesting feature of the threshold is that it shows that the constrained firm is willing to delay or accelerate investment in order to avoid selling any assets in place. In the final region $X_{4}$ the investment threshold begins lower than the unconstrained threshold and increases with cash as the firm becomes less and less constrained.

In order to further investigate what is happening at the investment boundary it is worth understanding the slope of the investment payoff function. To illustrate the ideas as simply as possible, imagine that the investment option is not perpetual and the firm must immediately decide whether to invest or let the option expire and receive nothing, a "now-or-never" scenario. This situation bears a striking resemblance to a European call option at maturity. The difference comes in whether the firm needs to raise capital from selling assets to fund investment. Consider Figure 2.9, which shows the value of the "now-or-never" investment for a range of arbitrary cash balances. 
Firstly focus on the top left graph, for low levels of $V_{B}$, the firm does not have the resources to invest so they must let the option expire. When $V_{B}$ reaches a moderate level, the firm can invest but only by selling some assets in place. Within the selling region, as $V_{B}$ increases the firm not only receives a more valuable project but also reduces the loss on selling as the borrowing capacity of the project increases. These two effects work in tandem and the option value increases steeply with $V_{B}$. When $V_{B}$ is high enough to be out of the selling region, only the former effect operates and the option value increases one for one with increases in $V_{B}$.

Moving from the top left to the top right to the bottom left and finally the bottom right graph the cash balance is increasing in size. Accordingly, the regions where the firm is able to invest by selling some of project A or invest without selling occur for lower and lower values of $V_{B}$. Eventually the cash balance is of such a magnitude that the "now-or-never" payoff resembles that of a textbook European call at maturity as divestment is never required.

To further build on the intuition of the "now-or-never" payoff imagine now that the firm can additionally delay investment until a later date. The option value will now more closely resemble that of an American call prior to maturity. Refer to Figure 2.10 for the relevant intricacies where the black curves of each graph indicate the option value when the firm optimally delays investment. For the top left graph the level of cash corresponds to that of the range $X_{1}$ of Figure 2.8. It is in this range that the divestment constraint is binding and for low levels of $V_{B}$ the firm is forced to delay. ${ }^{15}$ As the constraint binds the firm is unable to choose a better investment policy and the option value is not smoothly pasted. This also results in the option value being less than the investment payoff for certain levels of $B$. Moving into the $X_{2}$ region and subsequently the top right graph of Figure 2.10, the option value increases and becomes smoothly pasted to the divestment payoff. It is here that the firm is able to choose the most effective investment policy accounting for the fact that investment will be costly.

\footnotetext{
${ }^{15}$ The firm may also be liquidated for sufficiently low cash balances as indicated by the top left graph of Figure 2.10.
} 

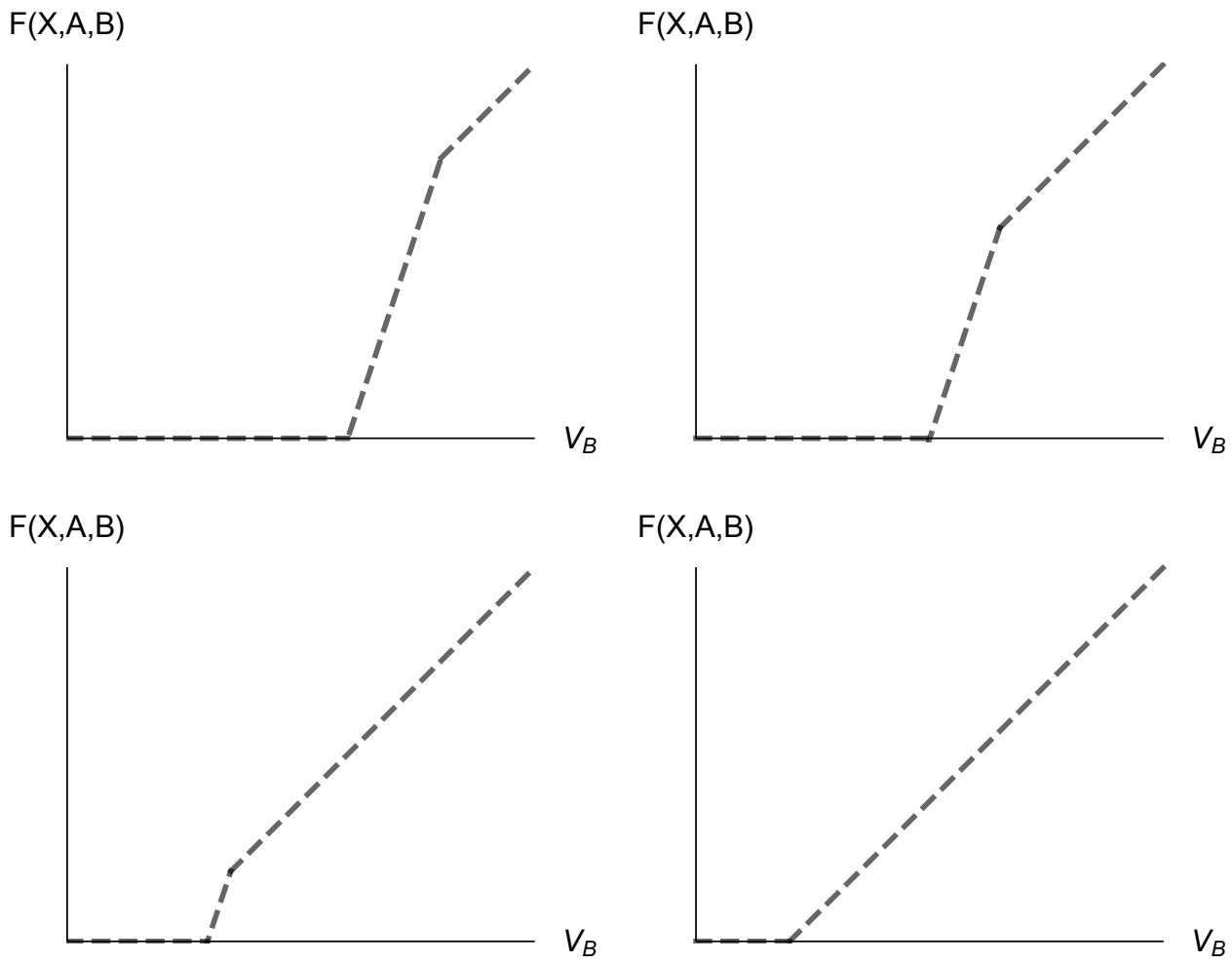

Figure 2.9: This figure shows the stopping payoff for the firms opportunity to invest in project B for arbitrary levels of cash. Cash is increasing moving from the top left to top right to bottom left to bottom right). When the firm is forced to wait the option is worthless. When they are able to invest via divestment the payoff value steeply increases with $V_{B}$. When the firm can invest without divestment the payoff value increases one to one with increases in $V_{B}$.

Increasing cash and moving into the $X_{3}$ region and therefore the bottom left graph of Figure 2.10 reveals an interesting and informative anomaly of the option value. As cash increases through $X_{3}$ the waiting value shifts from being smoothly pasted to the divestment payoff in $X_{2}$ to smoothly pasted to the regular investment payoff in $X_{4}$. During this movement the option value "gets stuck" at the vertex between these payoffs and therefore the regular investment constraint binds confirming earlier intuition. ${ }^{16}$ Finally within the $X_{4}$ region the option value is smoothly pasted to the general investment payoff.

\footnotetext{
${ }^{16}$ Constraints will bind when the option value is not smoothly pasted.
} 

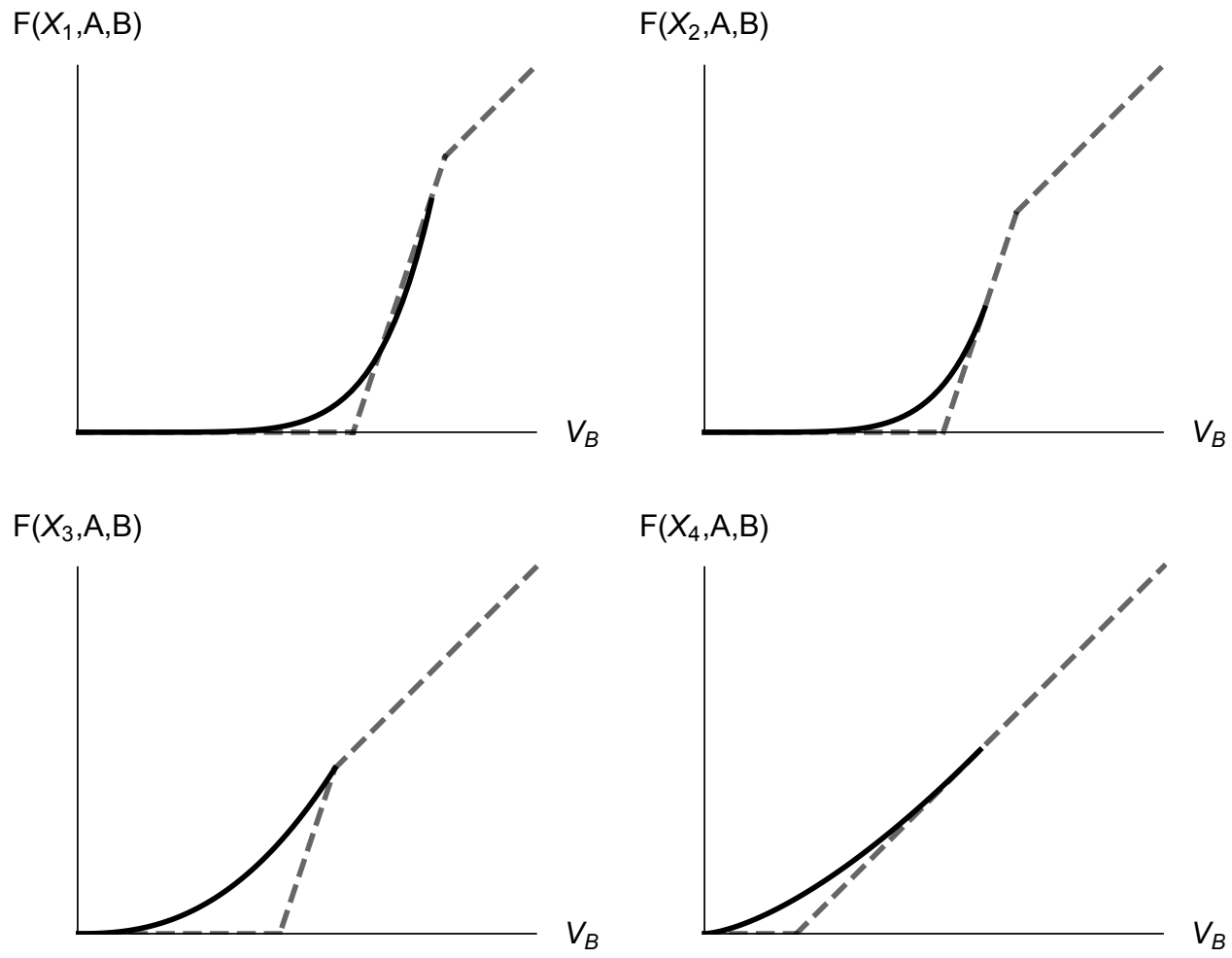

Figure 2.10: This figure shows the value of the waiting option for arbitrary levels of cash (cash is increasing moving from the top left to top right to bottom left to bottom right. Each of these four graphs correspond to the $X_{1}, X_{2}, X_{3}$ and $X_{4}$ cash ranges of Figure 2.8 respectively.

\subsection{Two Investments: None Launched, Two Op- portunities}

Finally, consider the case where the firm has perpetual rights to two projects, project A and project B, with no existing assets other than $G$. Once initiated the investment opportunities will generate cash flow that evolve according to the following Geometric Brownian Motions,

$$
d A=\mu_{A} A d t+\sigma_{A} A d \xi_{A, t}
$$

and

$$
d B=\mu_{B} B d t+\sigma_{B} B d \xi_{B, t}
$$

respectively where $\mu_{A}, \mu_{B}$ are constants that specify each project's drift, $\sigma_{A}, \sigma_{B}$ are constants that specify each project's volatility and $\xi_{A, t}, \xi_{B, t}$ are the increments to 
Weiner processes that satisfy $d \xi_{A, t} d \xi_{B, t}=\rho_{A B} d t$. As detailed previously, project A and project $\mathrm{B}$ will have present values of $A / \delta_{A}$ and $B / \delta_{B}$ respectively once completed.

The cash balance of the firm evolves in a manner identical to that of Section 2.2,

$$
d X=r X d t+\nu d t+\phi d \zeta
$$

and as such $X$ may become negative. When the deficit reaches a significant magnitude so as to be larger than the realisable value of the firm's assets forced liquidation occurs. In states where liquidation occurs the investment rights to projects A and B are sold for $F^{U A}\left(\gamma_{A} A\right)$ and $F^{U B}\left(\gamma_{B} B\right)$ respectively. ${ }^{17}$ This is analogous to the condition used in the single-project case as the buyer of the individual project rights will be an unconstrained firm.

\subsubsection{The Unconstrained Firm}

The solution to the unconstrained case is an amalgamation of two single-project solutions. Because the firm has sufficient cash to invest in either project in any state there will be no interdependence between the projects. The option value to the firm will be

$$
F^{U}(X, A, B)= \begin{cases}\left(V_{A}-I_{A}\right)+\left(V_{B}-I_{B}\right) & \text { if } A \geq \hat{A}^{u} \& B \geq \hat{B}^{u} \\ \left(V_{A}-I_{A}\right)+\left(V_{\hat{B}^{u}}-I_{B}\right)\left(\frac{V_{B}}{V_{\hat{B}^{u}}}\right)^{\beta_{B}} & \text { if } A \geq \hat{A}^{u} \& B<\hat{B}^{u} \\ \left(V_{\hat{A}^{u}}-I_{A}\right)\left(\frac{V_{A}}{V_{\hat{A}^{u}}}\right)^{\beta_{A}}+\left(V_{B}-I_{B}\right) & \text { if } A<\hat{A}^{u} \& B \geq \hat{B}^{u} \\ \left(V_{\hat{A}^{u}}-I_{A}\right)\left(\frac{V_{A}}{V_{\hat{A}^{u}}}\right)^{\beta_{A}}+\left(V_{\hat{B}^{u}}-I_{B}\right)\left(\frac{V_{B}}{V_{\hat{B}^{u}}}\right)^{\beta_{B}} & \text { if } A<\hat{A}^{u} \& B<\hat{B}^{u}\end{cases}
$$

where

$$
\hat{A}^{u}=\frac{\beta_{A} I_{A} \delta_{A}}{\beta_{A}-1}
$$

and

$$
\hat{B}^{u}=\frac{\beta_{B} I_{B} \delta_{B}}{\beta_{B}-1} .
$$

\footnotetext{
${ }^{17}$ Forced liquidation occurs when $X+G+F^{U A}\left(\gamma_{A} A\right)+F^{U B}\left(\gamma_{B} B\right) \leq 0$
} 


\subsubsection{The Constrained Firm}

The constrained firm does not have the luxury of being able to invest whenever it wants. Instead, there will exist many states where the firm must choose between projects. Investment in a given project will occur if the cash flow from that project is above some minimum threshold, $\hat{A}(X, B)$ and $\hat{B}(X, A)$ for projects $\mathrm{A}$ and $\mathrm{B}$ respectively. The investment thresholds of each project are non-constant and depend on the cash balance and the potential cash flow of the other project. The payoff to exercising will now depend on which (or both) project is being launched. ${ }^{18}$ When investing in both projects simultaneously the option value is the combination of both exercise payoffs

$$
\left(V_{A}-I_{A}\right)+\left(V_{B}-I_{B}\right)
$$

Upon investment in $\mathrm{A}$ and delay in $\mathrm{B}$, the option will be worth the exercise payoff of A plus the option value of $\mathrm{B}$ given that $\mathrm{A}$ has been launched and $I_{A}$ has been spent,

$$
\left(V_{A}-I_{A}\right)+F^{B A}\left(X-I_{A}, A, B\right) .
$$

The reverse is true for the payoff to investment in B and delay in A, namely the exercise payoff of $\mathrm{B}$ plus the option to invest in $\mathrm{A}$ given that $\mathrm{B}$ has been launched and $I_{B}$ has been spent

$$
\left(V_{B}-I_{B}\right)+F^{A B}\left(X-I_{B}, A, B\right) .
$$

It is worth noting that divestment is not relevant in this case because neither project has been launched. Prior to investment the option value will satisfy the following

\footnotetext{
${ }^{18}$ In addition to exercising the options the firm may, in any state, voluntarily liquidate and sell the rights to project $\mathrm{A}$ and $\mathrm{B}$ for $F^{U A}\left(\gamma_{A} A\right)$ and $F^{U B}\left(\gamma_{B} B\right)$ respectively.
} 
partial differential equation

$$
\begin{aligned}
\frac{1}{2} \sigma_{A}^{2} A^{2} F_{A A}+ & \frac{1}{2} \sigma_{B}^{2} B^{2} F_{B B}+\left(r-\delta_{A}\right) A F_{A}+\left(r-\delta_{B}\right) B F_{B}+r(X+G) F_{X}+\frac{1}{2} \phi^{2} F_{X X} \\
& +A B \rho_{A B} \sigma_{A} \sigma_{B} F_{A B}+B \rho_{X B} \sigma_{B} \phi F_{X B}+A \rho_{X A} \sigma_{A} \phi F_{X A}-r F=0
\end{aligned}
$$

where subscripts on $F$ indicate partial derivatives. The complexity of the equation prevents an analytical solution so numerical methods based on finite differences and successive over-relaxation are used to find an approximate solution, the details of which can be found in the Appendix. The following conditions are implemented in the solution procedure. At each investment threshold the option has a value equal to the exercise payoff,

$$
\begin{gathered}
F(X, \hat{A}(X, B), B)=\left(V_{\hat{A}}-I_{A}\right)+F^{B A}\left(X-I_{A}, \hat{A}, B\right), \\
F(X, A, \hat{B}(X, A))=\left(V_{\hat{B}}-I_{B}\right)+F^{A B}\left(X-I_{B}, A, \hat{B}\right), \\
F\left(X, A^{*}(X), B^{*}(X)\right)=\left(V_{\hat{A}}-I_{A}\right)+\left(V_{\hat{B}}-I_{B}\right),
\end{gathered}
$$

where $A^{*}(X)=\hat{A}\left(X, B^{*}(X)\right)$ and $B^{*}(X)=\hat{B}\left(X, A^{*}(X)\right)$. When the cash flow of either project hits zero it acts as an absorbing barrier and the project is forever worthless. In such a scenario the problem simplifies down to the one discussed in Section 2.2,

$$
\begin{gathered}
F(X, 0, B)=F^{B}(X, B), \\
F(X, A, 0)=F^{A}(X, A), \\
F(X, 0,0)=0 .
\end{gathered}
$$

In addition, as the cash balance increases, the financing constraint is relaxed and the value of the option will approach that of the unconstrained firm,

$$
\lim _{X \rightarrow \infty} F(X, A, B)=F^{U A}(A)+F^{U B}(B) .
$$


As the potential cash flow generated by project A increases, the financing constraint is relaxed, and the value of the option will approach that of the unconstrained firm

$$
\lim _{A \rightarrow \infty} F(X, A, B)=F^{U A}(A)+F^{U B}(B) .
$$

As the potential cash flow generated by project B increases, the financing constraint is relaxed, and the value of the option will approach that of the unconstrained firm

$$
\lim _{B \rightarrow \infty} F(X, A, B)=F^{U A}(A)+F^{U B}(B) .
$$

Due to the complexity of having two investment opportunities, the firm may now find itself in one of nine situations including liquidation depending on the following investment constraints as well as the liquidation constraint,

$$
\begin{gathered}
I_{A}+I_{B} \leq X+G+\gamma_{A} \theta_{A} V_{A}+\gamma_{B} \theta_{B} V_{B}, \\
I_{A} \leq X+G+\gamma_{A} \theta_{A} V_{A}, \\
I_{B} \leq X+G+\gamma_{B} \theta_{B} V_{B} .
\end{gathered}
$$

When the first constraint is satisfied, the firm has enough resources to invest simultaneously in both projects. The second and third constraints show when the firm is able to invest in just project $\mathrm{A}$ or just project $\mathrm{B}$ respectively. It is worth noting that within Equations (2.50) and (2.51) the firm does not borrow against one project in order to fund the another. This assumption is consistent with the idea that financial institutions will make lending decisions based on realisable cash flow. When the firm invests in project $\mathrm{A}$ and delays project $\mathrm{B}$, the bank will not lend any money against project B as it will not generate any cash until initialised. It is additionally assumed that there are no economies of scale when investing in both projects, to launch both projects will require a lump sump outflow of $I_{A}+I_{B}$. The nine states are as follows: 
- Able to invest in both projects simultaneously but not individually ${ }^{19}$

- Able to invest in both projects simultaneously as well as individually ${ }^{20}$

- Able to invest in both projects simultaneously but only project A individually ${ }^{21}$

- Able to invest in both projects simultaneously but only project B individually $^{22}$

- Able to invest in either project but not both simultaneously ${ }^{23}$

- Only able to invest in project $\mathrm{A}$ but not $\mathrm{B}$ or both ${ }^{24}$

- Only able to invest in project B but not $\mathbf{A}$ or both ${ }^{25}$

- Forced to delay investment in either project ${ }^{26}$

- Forced to liquidate

It is clear that the addition of another investment opportunity vastly increases the complexity of the investment decision. In order to better understand the investment states and the interaction between them refer to Figure 2.11, which has been created under the parameters in Table 2.3. It is worth noting that when $\gamma_{B} \theta_{B} V_{B}<I_{B}$, the borrowing capacity of project $B$ is less than its investment cost. In this situation, if the firm is able to invest in both projects simultaneously, then it must also be such that the firm is able to invest in project $\mathrm{A}$ on its own. However, if $\gamma_{B} \theta_{B} V_{B}>I_{B}$, the borrowing capacity of project $B$ is greater than its investment cost and therefore if the firm is able to invest in project A then it must also be able to do both simultaneously. Consider the graph on the left where $V_{B}=96 .{ }^{27}$ In this case $\gamma_{B} \theta_{B} V_{B}<I_{B}$ and as such the investment constraint for investing in only project $A$, as represented by

\footnotetext{
${ }^{19}$ Equation (2.49) is satisfied but Equations (2.50) and (2.51) are not.

${ }^{20}$ Equations (2.49), (2.50) and (2.51) are satisfied.

${ }^{21}$ Equations (2.49) and (2.50) are satisfied but Equation (2.51) is not.

${ }^{22}$ Equations (2.49) and (2.51) are satisfied but Equation (2.50) is not.

${ }^{23}$ Equations (2.50) and (2.51) are satisfied but Equation (2.49) is not.

${ }^{24}$ Equation (2.50) is satisfied but Equations (2.49) and (2.51) are not.

${ }^{25}$ Equation (2.51) is satisfied but Equations (2.49) and (2.50) are not.

${ }^{26}$ Equations (2.49), (2.50) and (2.51) are not satisfied.

${ }^{27}$ The graphs are shown under $V_{B}=96$ and $V_{B}=148$ in order to best illustrate the underlying behaviour of the problem.
} 
Table 2.3: This table outlines the parameter values used to numerically solve Equation (2.39) for the optimal investment timing policy. The parameters of each project are identical and are where possible similar to those of Boyle and Guthrie (2003).

\begin{tabular}{lcc}
\hline \hline & Project A & Project B \\
\cline { 2 - 3 } Project investment cost $(\$)$ & $I_{A}=100$ & $I_{B}=100$ \\
Project cash flow volatility & $\sigma_{A}=0.20$ & $\sigma_{B}=0.20$ \\
Project dividend yield & $\delta_{A}=0.03$ & $\delta_{B}=0.03$ \\
Information asymmetry & $\gamma_{A}=0.80$ & $\gamma_{B}=0.80$ \\
Control friction & $\theta_{A}=0.40$ & $\theta_{A}=0.40$ \\
\cline { 2 - 2 } Risk free interest rate & $r=0.03$ \\
Firm cash flow-Project A cash flow correlation & $\rho_{X A}=0.5$ \\
Firm cash flow-Project B cash flow correlation & $\rho_{X B}=0.5$ \\
Project A cash flow-Project B cash flow correlation & $\rho_{A B}=0.5$ \\
Firm cash flow volatility & $\phi=60$ \\
Market value of existing assets & $G=100$ \\
\hline \hline
\end{tabular}

the solid, negative-sloping line, binds for lower levels of cash than the constraint for both projects, as represented by the dashed line. This is because in order to do both projects, the firm's net assets (excluding funds raised from using project B as collateral) need to be sufficiently greater than $I_{A}$ in order to make up the shortfall of $I_{B}-\gamma_{B} \theta_{B} V_{B}$. The investment constraint for launching project $\mathrm{B}$ is represented by the vertical line as the firm's ability to invest in B on its own does not depend on $\mathrm{A}$. The curve plots the liquidation constraint. In region 1 the firm has negative net assets and is forced to liquidate. As either cash or $V_{A}$ increase, the firm moves into region 2 and their net assets are large enough to avoid forced liquidation however they are still unable to invest. In region 3 the firm is only able to invest in project A. As cash and $V_{A}$ increase the firm moves into region 4 and can invest in $\mathrm{A}$ as well as both projects simultaneously. Here project $\mathrm{A}$ is now valuable enough that the extra borrowing capacity associated with it, over and above that required to invest only in $A$, can be used to subsidise the investment cost of B that otherwise could not be undertaken. Should cash increase even further and the firm find itself in region 5, it will no longer be constrained by opportunities (yet it is still constrained in cash) and can invest in either $\mathrm{A}$ or $\mathrm{B}$ or both. In region 6 the firm is able to do either $\mathrm{A}$ or $\mathrm{B}$ 

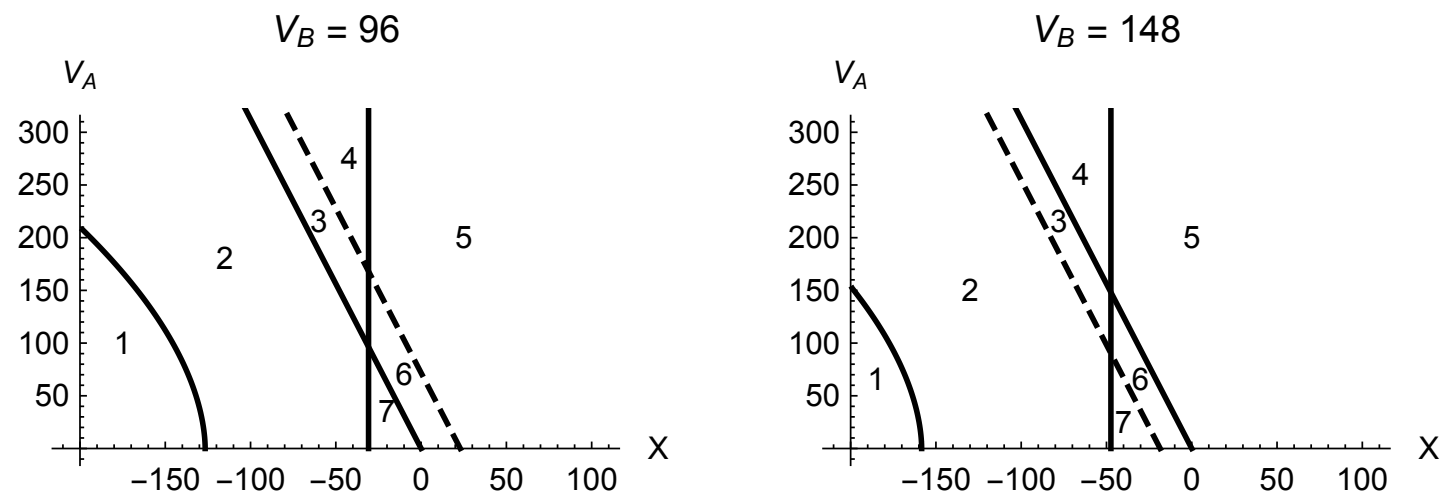

Figure 2.11: This figure shows some of the regions the constrained firm will find itself in. The sloped black line represents the investment constraint for launching only project A and the sloped dashed black line represents the investment constraint for launching both projects simultaneously. The vertical black line represents the constraint for investing in only project B and the remaining black curve is the liquidation constraint. For the graph on the left: In region 1, the firm is forced to liquidate. In region 2 , the firm is solvent but unable to invest in any capacity. In region 3 , the firm can invest in project A only. In region 4, the firm can invest in both projects simultaneously but only A individually. In region 5, the firm can invest in both projects either simultaneously or individually. In region 6 , the firm can invest in either project but not both. In region 7 , the firm can only invest in project B. For the graph on the right: In region 1, the firm is forced to liquidate. In region 2 , the firm is solvent but unable to invest in any capacity. In region 3 , the firm can invest in both projects simultaneously but neither individually. In region 4 , the firm can invest in both projects simultaneously but only a individually. In region 5, the firm can invest in both projects either simultaneously or individually. In region 6 , the firm can invest in both projects simultaneously but only $\mathrm{B}$ individually. In region 7 , the firm can only invest in project B.

but not both. When in region 7 the firm is only able to invest in project B.

Now consider the case where $V_{B}=148$ and as such $I_{B}>\gamma_{B} \theta_{B} V_{B}$. Instead, the investment constraint for both projects now binds for lower levels of cash than the constraint for just A. In regions 1 and 2 the firm is forced to liquidate and wait respectively. In region 3 the firm is forced to do both projects if it chooses to invest. In region 4 the firm can invest in either $\mathrm{A}$ or both projects. In region 5 the firm can do either A, B or both projects. For relatively low levels of $V_{A}$, as cash decreases the firm moves into region 6 and is able to either $\mathrm{B}$ or both projects but not $\mathrm{A}$ on its own. In region 7 the firm can only do B.

The addition of an extra project to the model of Boyle and Guthrie (2003) is a fairly simple extension to the setup of the model. However, it greatly increases the number of decisions the firm is able to make and the situations it may find itself in. The following section illustrates the resulting optimal investment policy for the 
constrained firm.

\subsubsection{A Numerical Solution}

The constrained firm will at times find itself in states where although it would like to invest it lacks the capital to do so. When faced with similar investment opportunities the unconstrained firm will undertake investment when it is optimal, as such

$$
F(X, A, B) \leq F^{U A}(A)+F^{U B}(B)
$$

When subject to the financing frictions as described earlier, the constrained firm will either postpone (under invest) or accelerate (over invest) in a specific project when compared to the benchmark case of the unconstrained firm. Keeping in line with previous analysis, the investment policy of project A will be explored in detail, although the logic can easily be applied to that of project B. Figure 2.12 displays the optimal investment policy for the unconstrained firm for a variety of $V_{B} \cdot{ }^{28}$ First consider the case where $V_{B}=0$. In this situation the firm will invest in project A for any combination of $X$ and $V_{A}$ that lies above the red line. This is the same result as described earlier where the firm has access to only one project. For low levels of cash the investment constraint is binding and the firm invests as soon as possible to avoid future shortfalls. As cash increases and the investment constraint no longer binds the firm reduces the level of investment acceleration and the threshold approaches that of the unconstrained firm.

The effect of having an extra investment opportunity on the policy of project A can be seen in the remaining graphs. When $V_{B}=170$, the firm does not change its behaviour very much. The investment constraint still binds to the left where the risk of future funding shortfalls is largest. However, for levels of cash where the constraint does not bind, investment is delayed slightly. The inclusion of B makes the firm delay

\footnotetext{
${ }^{28}$ The model is solved on a grid with asymmetric grid spacing, further details of which can be found in Chapter 4 and the Appendix. All graphs contained within this thesis have been plotted for values of $V_{B}$ that show the general behaviour of the constrained firm.
} 

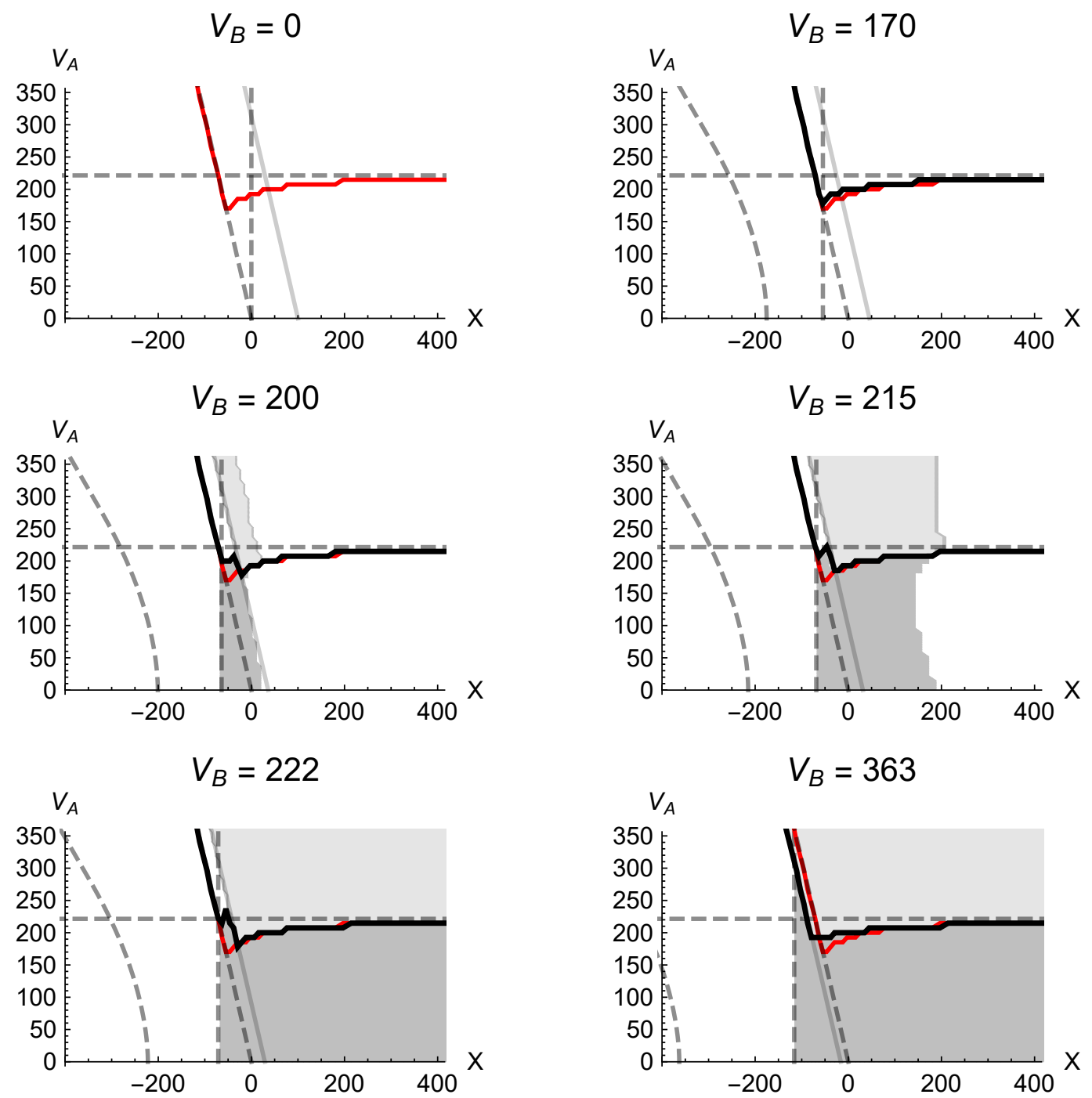

Figure 2.12: This graph shows the optimal constrained investment policy for a variety of $V_{B}$ under the parameters in Table 2.3. The red curve is the single-project investment threshold for project A. The black curve is the investment threshold for project A given that the firm also has access to project B. The dark grey region shows states where project B is launched but not project A and the light grey region shows states where both projects are launched simultaneously.

A slightly longer because investment is irreversible. Launching A will reduce the cash balance by $I_{A}$. Therefore, if B turns out to be a good project ex-post, the firm would rather have the cash available to invest than have to wait and build up reserves. It is worth noting that when $V_{B}=170$, for the range of $X$ and $V_{A}$ shown the firm does not invest in B. In this case the delay is entirely caused by the fact the firm may want to do $\mathrm{B}$ in the near future.

Eventually $V_{B}$ will be of such a magnitude that project $\mathrm{A}$ is delayed because the 
firm chooses instead to invest in project B. Refer to the graph where $V_{B}=200$ for a scenario where this happens. In this case the dark grey region represents states where investment in B occurs and the light grey region where investment in both $\mathrm{A}$ and $\mathrm{B}$ occurs. Here it can be seen that the investment constraint for doing only A still binds for low cash. However, for levels of cash that are just below zero the existence of project B causes investment in A to be considerably delayed. Examining the dark grey region shows that for low cash and low $V_{A}$ the firm invests in $\mathrm{B}$ as soon as possible. This is the same story as before, where the firm invests now in order to avoid losing the opportunity to invest in the future. The project choice question is easily answered as B is considerably better than $\mathrm{A}$. As $V_{A}$ increases, and the firm moves into the dark grey area above the single-project threshold (red) and below the multi-project threshold (black) the firm still chooses B. The inclusion of B now causes a large adjustment in the policy for A. Cash is low enough that the firm must invest in something, else it risks losing the ability to invest in anything in the future. In this case when $V_{A}<V_{B}=200$ the firm optimally chooses B and further delays A. If $V_{A}>V_{B}=200$ then instead it does the opposite and delays B. As cash increases from this area, the threshold to do both investments simultaneously binds and the delay in A relative to the single-project threshold reduces until it no longer exists. In this case the choice between investments is no longer the driving factor in the A policy. Instead both projects are launched as soon as possible as they are both relatively valuable. This is similar to earlier where investment occurs because the firm does not want to lose options in the future. However, it is now a matter of losing the ability to do both that drives the decision. For high levels of cash, B is delayed for the entire range of $V_{A}$ as the likelihood of not being able to invest is low.

As $V_{B}$ increases further the grey regions expand as waiting is less valuable for higher levels of cash due to the high value of $\mathrm{B}$. When $V_{B}=215$ the investment policy for A displays the same behaviour as when $V_{B}=200$ however the delay is slightly larger when compared to the single-project case. Consider the right hand boundary of the region where the firm only invests in $\mathrm{B}$. When $V_{A}=0, \mathrm{~B}$ will be launched up until cash is just below 200. As $V_{A}$ increases, this boundary shifts 
inwards. This occurs because as the value of A increases, the firm is willing to wait longer before deploying $\mathrm{B}$ to make sure it picks the correct investment. When $V_{A}$ reaches a moderate level this effect reverses and the dark grey boundary shifts to the right. Now, both projects are sufficiently valuable so the firm does not need to delay B because it is likely they will still be able to do $\mathrm{A}$ in the near future. When $V_{B}=222$ the firm invests in B as soon as possible and for the entire range of cash shown.

As soon as $\gamma_{B} \theta_{B} V_{B}>I_{B}$, the "just-A" and "both" constraints cross over and the investment policy returns to the $u$-shape as first described in Boyle and Guthrie (2003). In such a scenario $V_{B}$ is large enough that it can be funded entirely by its own borrowing capacity. ${ }^{29}$ This, in combination with the fact that B is launched as soon as possible, means that effectively project B just increments the firm's assets in place. That is to say, B has a similar effect to that associated with increasing $G$ in the single-project model.

The standard NPV rule for investment states that if a project has a positive NPV then it should be undertaken as it provides a net increase in value for the firm. Standard real-options analysis shows that there are many states where the value to waiting is greater than the NPV of a project, even when the NPV is positive, and therefore opposes the standard NPV rule. The addition of an exogenous financing constraint in Boyle and Guthrie (2003) further develops the standard real-options argument by showing that due to the risk of future funding shortfalls the constrained firm may invest earlier than its unconstrained counterpart. Additionally, when the firm is sufficiently constrained it may invest later than the unconstrained firm due to a lack of sufficient resources for investment. Extending their model to include two investment opportunities provides even further insights into the constrained investment decision. There still exists states where (1): the firm accelerates investment for fear of losing the ability to do so in the future and (2): the firm delays investment due to insufficient funds; however, it also shows that the firm will delay investment in a specific project due to other investment opportunities. This occurs either due to the fact that (1): investment in the other project reduces resources such that the firm no longer

\footnotetext{
${ }^{29}$ So long as the value of the firm's remaining assets is not too low.
} 
has enough resources for the investment in question and must therefore wait or (2): although investment in the other project has not occurred, it may occur in the near future and therefore the firm delays the project in question in order to avoid losing the ability to do the other project in the future.

In general, the introduction of another investment opportunity leads the firm to delay investment in its current opportunity because it wants to make sure it chooses the right one. This choice decision is relatively simple under the baseline parameters as the projects are symmetric is all aspects other than present value. It has been shown that investment policies are distorted towards the more valuable project. The following chapter introduces projects that are asymmetric in nature and shows that delay relative to the single-project situation is not always optimal. 


\section{Chapter 3}

\section{Model Applications}

\subsection{Overview}

The baseline projects explored in the preceding chapter had the same yield, growth rate, debt capacity and volatility. Their only point of differentiation was the level of their cash flow and accordingly their present value, both of which vary stochastically. These symmetric investments showed that the addition of an extra opportunity causes the firm to delay their original investment. Intuitively, the added complexity of the firm's problem, due to adding a second project, is minimised when both investments are symmetric. This is because it largely becomes a matter of picking the project that is more valuable at the time, subject to the financing constraints. Both baseline projects have the same yield and the same funding capacity constraints, therefore the decision is relatively simple. Prior to investment in either project, the delay, relative to the single-project case, is most severe when each project has a similar NPV and the firm has low cash. In this chapter the interaction of asymmetric investments is introduced. The model of Chapter 2 is applied to three main areas of interest. First, the optimal investment policy is explored in the context of quick payback projects and high pledgeability projects. Second, the value of cash is explored for both of these types of projects. This includes both the trade-off between spending cash now and earning cash for the future, as well as the marginal value of cash now. Third, the 
model is used to investigate the decision to spin-off each project from a single firm and operate them under separate, stand-alone firms. This setting explores which firm should receive the majority of the merged firm resources in a spin-off.

\subsection{Asymmetric Investment Policies}

There exists a growing pool of literature that investigates the various drivers behind firms' investment strategies. A sizeable proportion of this literature suggests that

firms that face financing constraints will prefer investments with a specific set of characteristics, the two most common being investments with short payback periods and high pledgeability. The intuition is simple. Projects with shorter payback periods will generate cash over and above their investment cost earlier than those with longer payback periods. This extra cash helps to relax future financial constraints and therefore assists investment in the future. The same logic applies for high-pledgeability investments where debt can be raised to fund the project which will then generate cash that helps to relax future financial constraints associated with low-pledgeability projects. Additionally, when debt is used to initiate a project with high-pledgeability, it frees up scarce cash reserves for low-pledgeability projects that require cash for completion. This section looks at how either a fast payback or high-pledgeability project alters the policy results of the previous Chapter. Intuitively a downwards shift in the preferred project investment curve relative to the single-project case is expected as investment in the desirable project is accelerated.

\subsubsection{Literature}

A recent study looking at investment preference is that of Almeida et al. (2011), who use a three stage, high or low state model of investment. In the first stage the firm must allocate funds across three types of investments. Cash-generating investments generate cash in the period directly following the investment date. Collateralizable investments also generate cash in the period directly following investment; however, 
a proportion of their cash flow can be used as collateral for investment in the period prior to generation. ${ }^{1}$ Risky investments are more valuable in expectation than nonrisky investments; however, they produce less cash flow in the low state than their non-risky counterparts. In the second stage the firm has a new investment opportunity and must invest either a high or low amount. Almeida et al. (2011) confirm earlier intuition and suggest that constrained firms prefer projects that have short payback periods with front-loaded cash flow. Additionally, they find that firms distort their investment policy towards projects that generate collateralizable cash flow when faced with future financing constraints. Although similar in some respects to the model presented in this thesis, their model does not investigate the optimal time to invest, instead it looks at the relative levels of investment.

Clementi and Hopenhayn (2006) also suggest that collateral is an important factor related to the investment dynamics of a firm. Through their use of a discrete-time, contracting model, they suggest that, in the extreme case, collateral constraints can cause investment opportunities to become financially infeasible. This suggests that when the collateral of a project is low, other investment opportunities can provide additional benefits over and above their NPV as the cash they generate helps to relax future collateral and financing constraints. This notion is empirically shown in Hennessy and Whited (2005), who investigate the costs associated with external financing. Gan (2007) also shows empirically that a reduction in asset collateral values leads to a reduction in investment. He uses a unique dataset of Japanese manufacturing firms that faced an exogenous shock to collateral values during the Japan asset price bubble of 1986-1991. The exogenous nature of this reduction in collateral solves the endogeneity problem generally associated with similar studies.

In addition to the aforementioned, the analysis completed by Thakor (1990) also suggests that a firm will prefer projects that have short payback periods. This preference is strongest when it is anticipated that future investments will need to be financed internally. Almeida and Campello (2007) also investigate the effect of asset

\footnotetext{
${ }^{1}$ It is worth noting that the literature uses both collateralizability and pledgeability interchangeably in reference to the amount of an asset's value that can be raised prior to investment by using the asset as collateral (pledging the asset).
} 
pledgeability on investment. They find that the investment of constrained firms that have assets with low pledgeability will have a low sensitivity to cash flow.

In terms of investment choice and timing, Dixit (1993a) presents a model where the firm must choose between projects of differing scale. The value of each project is a linear function of a single Geometric Brownian Motion and there is no follow-up investment. He suggests that as soon as the firm reaches the investment region for any single investment it will choose that project over the others. However, this conclusion is flawed as when investing in one project, the waiting value of some other project could be higher and therefore investment should be delayed. Décamps et al. (2006) address this problem and derive an optimal investment rule for a firm that must choose one investment out of a possible two. Investment scale is also of importance in Nishihara and Shibata (2013), who show that for a moderate level of cash it is optimal to expand production on a smaller scale to avoid the costly financing of large scale expansions.

The literature identified above largely supports the hypothesis that quick payback and high-pledgeability projects are the most desirable and therefore investment in them should be accelerated. Before implementing these project types in the model of Chapter 2, the deterministic case is used to illustrate how the addition of an extra investment opportunity can cause such an acceleration of investment.

\subsubsection{The Deterministic Case}

As mentioned above, intuition suggests that investment in a specific project will occur earlier if that project can help to relax future financial constraints. First consider the deterministic case where the firm has access to one project $(\mathrm{A})$ with a current present value of $V_{A}$ and must choose when to invest. ${ }^{2}$ The firm will choose the time to invest, $t_{A}$, such that the present value of investment is maximised. If the firm chooses $t_{A}$,

\footnotetext{
${ }^{2}$ Further details on the deterministic case set up and solution can be found on page 138 of Dixit and Pindyck (1994).
} 
the present value of investment at date 0 will equal

$$
Q_{A}\left(t_{A}\right)=e^{-r t_{A}}\left(V_{A} e^{\left(r-\delta_{A}\right) t_{A}}-I_{A}\right)
$$

where $r$ is the riskfree rate, $\delta_{A}$ the dividend yield and $I_{A}$ the investment cost. Rearranging the first order condition for the objective function in Equation (3.1) with respect to $t_{A}$ provides the optimal investment timing of

$$
t_{A}^{*}=\frac{\log \left(r I_{A} / A\right)}{r-\delta_{A}} .
$$

Now consider that the firm has access to an additional project with a present value of $V_{B}$. If there are no constraints, investment is optimally undertaken at $t_{A}^{*}$ and $t_{B}^{*}$ for projects $\mathrm{A}$ and $\mathrm{B}$ respectively where $t_{B}^{*}$ is given by a function analogous to the one in Equation (3.2). However, the constrained firm will be unable to undertake both projects initially and as such it must choose one to do first. The constrained timing of investment in this first project will shortly be shown to be accelerated relative to the unconstrained timing. Without loss of generality, it is assumed that project $\mathrm{A}$ is undertaken first.

After initiating the first project, the firm must wait a fixed amount of time before it can invest in the second as it requires time to generate sufficient cash. ${ }^{3}$ Therefore, investment in the second project will occur at date $t_{A}+\Delta t$ for some fixed $\Delta t>0$. It is assumed that due to the constrained nature of the firm, once the first project is initiated, investment in the second project is delayed longer than optimal. That is to say $t_{B}^{*}<t_{A}^{*}+\Delta t$.

If $t_{A}^{*}$ and $t_{B}^{*}$ are the optimal investment dates when the firm only has one of either

\footnotetext{
${ }^{3}$ In this case, cash generated could either mean cash literally generated by the first project or cash that can be raised by pledging the first project as collateral.
} 
project $\mathrm{A}$ or project $\mathrm{B}$ then it must be such that

$$
\begin{gathered}
Q_{A}^{\prime}\left(t_{A}^{*}\right)=Q_{B}^{\prime}\left(t_{B}^{*}\right)=0 \\
Q_{A}^{\prime}\left(t_{B}^{*}\right)<0 \\
Q_{B}^{\prime}\left(t_{A}^{*}\right)>0
\end{gathered}
$$

where $Q_{A}\left(t_{A}\right)$ and $Q_{B}\left(t_{B}\right)$ are the NPV functions for the first and second investments respectively. Let the combined NPV of completing both projects be denoted by $Q_{A B}\left(t_{A}, t_{B}\right)$ where

$$
Q_{A B}\left(t_{A}, t_{B}\right)=Q_{A}\left(t_{A}\right)+Q_{B}\left(t_{B}\right) .
$$

As both $Q_{A}$ and $Q_{B}$ are concave functions it must be such that $Q_{A B}$ is maximised when $t_{A}=t_{A}^{*}$ and $t_{B}=t_{B}^{*}$. However, for the constrained firm $t_{B}=t_{A}+\Delta t$. The objective function of the constrained firm is therefore to maximise $Q_{A B}\left(t_{A}, t_{A}+\Delta t\right)$ by choosing the investment timing of the first project $t_{A}$. A first order condition of $Q_{A B}$ evaluated at $t_{A}^{*}$ shows that

$$
\left.\frac{\partial}{\partial t_{A}} Q_{A B}\left(t_{A}, t_{A}+\Delta t\right)\right|_{t_{A}=t_{A}^{*}}=Q_{A}^{\prime}\left(t_{A}^{*}\right)+Q_{B}^{\prime}\left(t_{A}^{*}+\Delta t\right)<0
$$

as $Q_{A}^{\prime}\left(t_{A}^{*}\right)=0$ and $Q_{B}^{\prime}\left(t_{A}^{*}+\Delta t\right)<0$. Therefore, it is optimal for the firm to invest in project $\mathrm{A}$ before $t_{A}^{*}$. Refer to Figure 3.1 for a further intuitive description of the result. This figure plots the optimal investment timing of both investments in $\left(t_{A}, t_{B}\right)$ space. At the centre of the plot is the optimal unconstrained policy of $t_{A}^{*}$ and $t_{B}^{*}$. The dashed curves indicate contour lines associated with $Q_{A B}$. Due to the concavity of both $Q_{A}$ and $Q_{B}$, moving further from the unconstrained optimum results in a lower combined NPV value. The timing constraint of the constrained firm, $t_{B} \geq t_{A}+\Delta_{t}$, is illustrated by the black line. Due to the time required to build up cash reserves for the second project, following investment in the first project, the constrained firm is only able to pick a combination of $t_{A}$ and $t_{B}$ that lies on or above the black line. The optimal constrained policy will occur when the timing constraint meets tangentially with the contour curve that is as close to the unconstrained policy as possible. This 


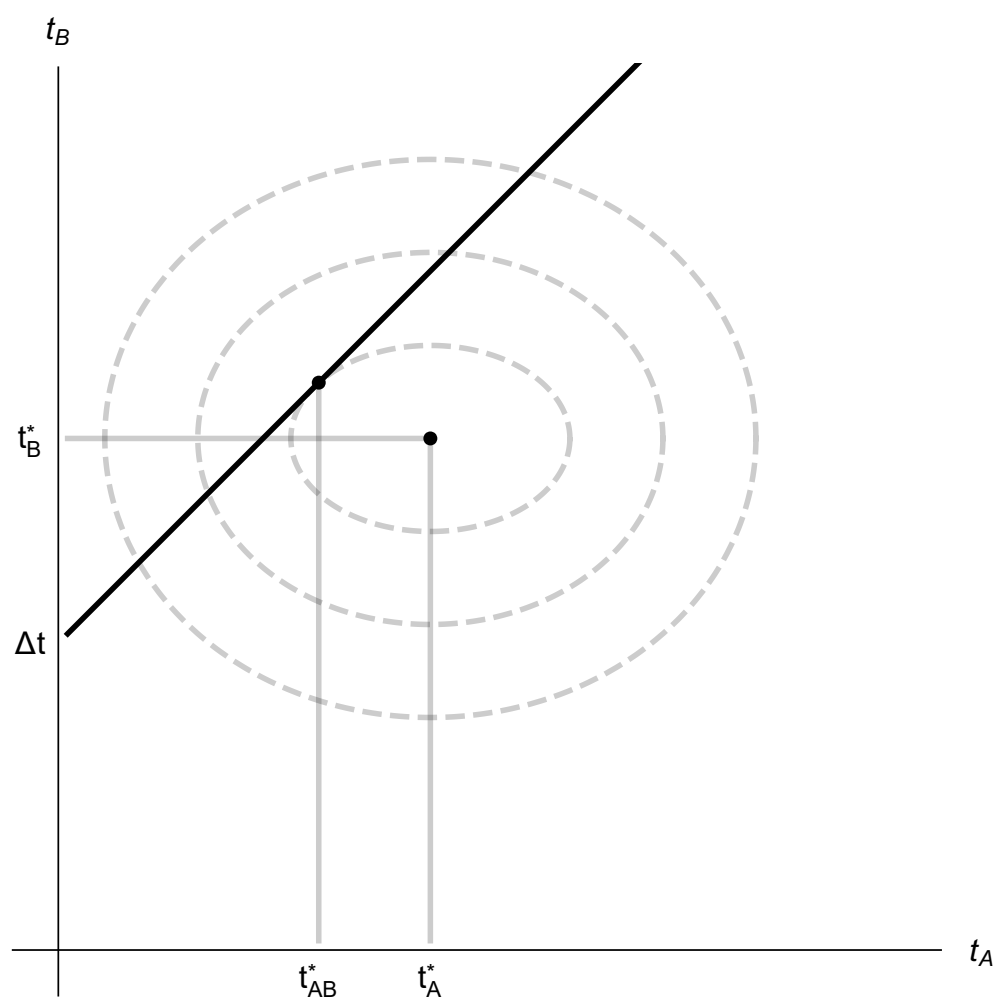

Figure 3.1: This graph shows how the introduction of project $\mathrm{B}$ accelerates the investment timing in project A for the constrained firm in the deterministic case. At the centre of the plot is the optimal unconstrained policy of $t_{A}^{*}$ and $t_{B}^{*}$. The dashed curves indicate contour lines associated with $Q_{A B}$. The black line represents the timing constraint of $t_{B} \geq t_{A}+\Delta_{t}$. The constrained firm must choose an investment policy that lies on or above this constraint. The optimal solution is the policy where the timing constraint meets tangentially with the highest contour curve possible at $t_{A B}^{*}$.

occurs when $t_{A}=t_{A B}^{*}$ where $t_{A B}^{*}$ is the new accelerated policy for project A.

The remainder of this section will investigate the optimal investment policy when the firm has access to either a fast payback or highly pledgeable project. A preference for such projects would imply that, for a firm that currently has access to either a fast payback or high-pledgeability project, the introduction of an additional opportunity without these characteristics will cause a downwards shift of the investment threshold for the preferred project so that the "investment test" is less demanding (and investment occurs earlier). ${ }^{4}$ This effect was not shown in the symmetric case of the preceding chapter except for situations where $V_{B}$ was of such a magnitude that it increased the state space where investment in project $\mathrm{A}$ was possible. ${ }^{5}$ The increase

\footnotetext{
${ }^{4}$ This corresponds to a two-project threshold below the single-project threshold.

${ }^{5}$ In Figure 2.12, when $V_{B}=200$ there is a hint of acceleration relative to the single-project case however it arises due to the numerical grid-based nature of the solution procedure. For further
} 
in states where investment is possible occurs when the simultaneous-investment constraint "crosses-over" the "only A" investment constraint. That is, it happens when the debt that can be raised on project B exceeds the lump-sum investment cost of initiating $\mathrm{B}, I_{B}<\gamma_{B} \theta_{B} V_{B}$. Here, the extra debt capacity can be used to subsidise the investment cost of project $\mathrm{A}$ and allows investment in states where investment without project B was not possible.

\subsubsection{Fast Payback Projects}

The payback period of an investment measures the time it takes for that investment to generate a cumulative amount of cash equal to the initial cost of investment. Traditionally payback period as an investment analysis tool has been doubted as it does not consider the cash flows after payback (Boardman et al., 1982). However, in general, the sooner a project is able to pay back its initial investment cost, the sooner it can begin to generate cash that can help relax the financing constraints of a firm. Boyle and Guthrie (2006) discuss the merits of payback as a capital budgeting technique and show that longer payback projects will require a larger NPV to justify investment. However, their argument is based around the option value of waiting and not driven by a financing constraint. As discussed previously, a large amount of literature suggests that constrained firms will prefer projects with short paybacks.

The model presented within this thesis allows the analysis of investment policies for a variety of different investment opportunities. Under the setup of Chapter 2, a high payback project will be one that has a high implicit yield as represented by $\delta_{A}$ and $\delta_{B}$ for projects $\mathrm{A}$ and $\mathrm{B}$ respectively. To investigate how the addition of an extra investment opportunity influences the optimal timing policy of a high yield project the parameters found in Table 3.1 are used to solve the investment timing model. These parameters are the same as detailed in the symmetric case of the previous chapter with the exception of the dividend yield of project A. Instead the yield of this project has been doubled from $\delta_{A}=0.03$ to $\delta_{A}=0.06$. Refer to Figure 3.2,

information of the solution procedure refer to Chapter 4 and the Appendix. 
Table 3.1: This table outlines the parameter values used to numerically solve Equation (2.39) for the optimal investment timing policy when project A has a quick payback period. The parameters are the same as those shown in Table 2.3 except the implicit dividend yield of project $\mathrm{A}$ has been increased from $\delta_{A}=0.03$ to $\delta_{A}=0.06$.

\begin{tabular}{lcc}
\hline \hline & Project A & Project B \\
\cline { 2 - 3 } Project investment cost $(\$)$ & $I_{A}=100$ & $I_{B}=100$ \\
Project cash flow volatility & $\sigma_{A}=0.20$ & $\sigma_{B}=0.20$ \\
Project dividend yield & $\delta_{A}=0.06$ & $\delta_{B}=0.03$ \\
Information asymmetry & $\gamma_{A}=0.80$ & $\gamma_{B}=0.80$ \\
Control friction & $\theta_{A}=0.40$ & $\theta_{A}=0.40$ \\
\cline { 2 - 2 } Riskless interest rate & $r=0.03$ \\
Firm cash flow-Project A cash flow correlation & $\rho_{X A}=0.5$ \\
Firm cash flow-Project B cash flow correlation & $\rho_{X B}=0.5$ \\
Project A cash flow-Project B cash flow correlation & $\rho_{A B}=0.5$ \\
Firm cash flow volatility & $\phi=60$ \\
Market value of existing assets & $G=100$ \\
\hline \hline
\end{tabular}

which plots the new policy results under these parameters. The red curve is the single-project investment threshold for project A. The black curve is the investment threshold for project A given that the firm also has the right to invest in project B. The dark grey region shows states where project B is launched but not project A and the light grey region shows states where both projects are launched simultaneously.

When $V_{B}=0$, the standard single-project result applies and the investment threshold for project $\mathrm{A}$ is $\mathrm{u}$-shaped in cash reserves. ${ }^{6}$ Relative to the unconstrained firm, investment is accelerated for moderate to high levels of cash in order to avoid losing the opportunity to invest. Investment is delayed for low levels as the firm invests as soon as possible. As $V_{B}$ increases to 133 there are minor changes in the investment policy. For moderate levels of cash, investment is fractionally delayed when compared to the case of $V_{B}=0$. This occurs as the firm is willing to delay investment slightly in order to avoid the case where cash is spent on project A and shortly afterwards project B is highly valuable but unobtainable.

The traditional u-shaped investment threshold no longer holds as $V_{B}$ increases

\footnotetext{
${ }^{6}$ Project $\mathrm{B}$ generates cash flow that follows a GBM process and therefore if $B=0$ now, then at all times in the future $B=0$ and the firm can be treated as if it only has access to project A.
} 

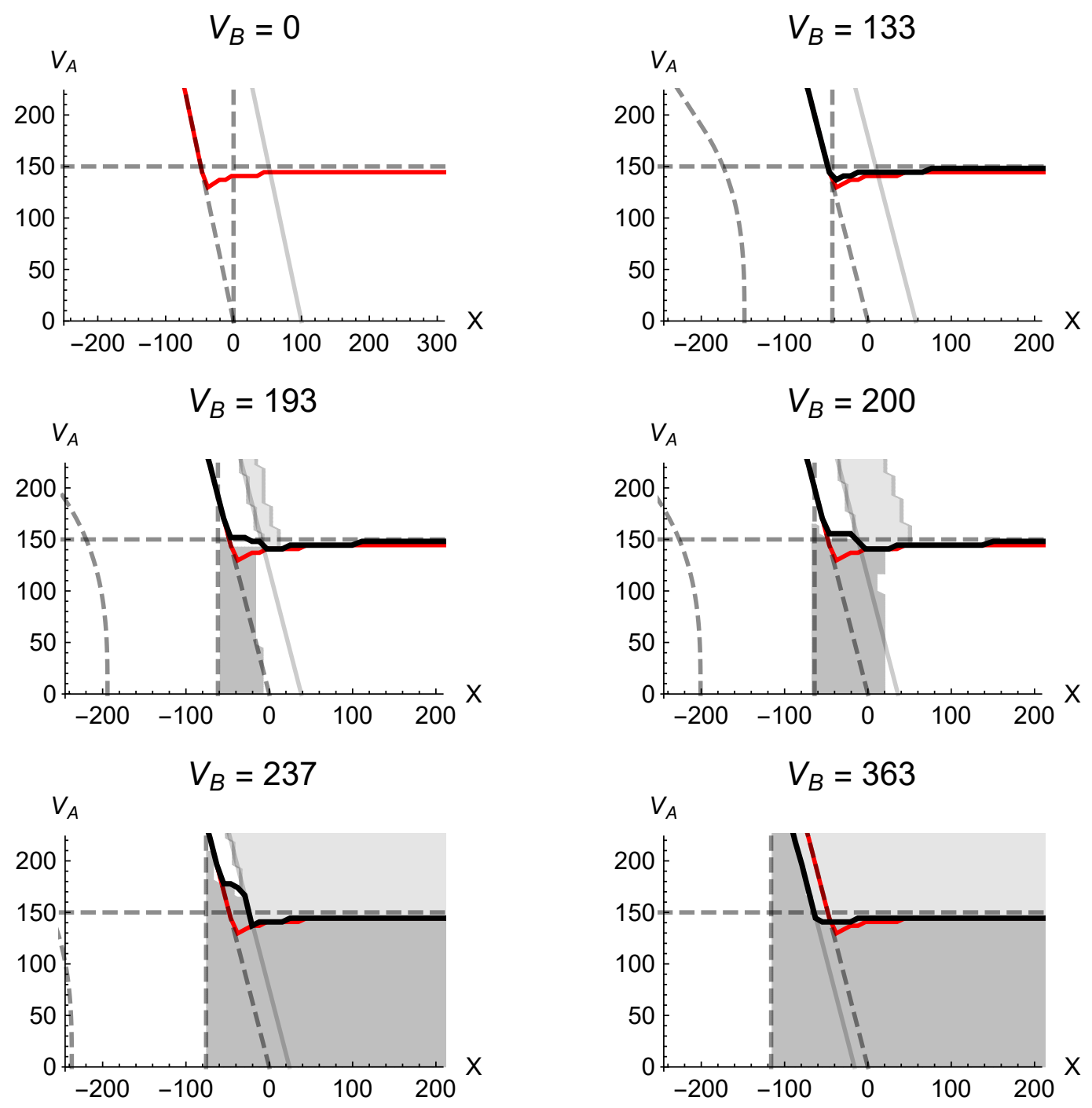

Figure 3.2: This figure shows the investment policy when project $\mathrm{A}$ is a fast payback project under the parameters in Table 3.1. The red curve is the single-project investment threshold for project A. The black curve is the investment threshold for project A given that the firm also has the right to invest in project B. The dark grey region shows states where project B is launched but not project A and the light grey region shows states where both projects are launched simultaneously.

further and reaches a level of 193 . Now $V_{B}$ is of such value that the constrained firm will launch project $\mathrm{B}$ in some states. For a moderate level of cash and low $V_{A}$, project $\mathrm{B}$ is launched as soon as possible, as indicated by the dark grey region. However, for the same moderate level of cash when $V_{A}$ is high, instead project $\mathrm{A}$ is launched. Relative to the single-project case, the timing delay of project $\mathrm{A}$ is largest in this moderate range of cash. Here the firm is sufficiently constrained and unable to do both projects and therefore initiates the project that is more valuable. It is worth 
noting that an intermediate region exists within the area above the single-project (red curve) and below the multi-project (black curve) policies for project A. Within this region in some cases the firm chooses to delay investment in both projects. This is in contrast to the symmetric case where the firm implements a strict "A or B" policy and chooses the best project without delay. The delay seen in Figure 3.2 is driven by the increased dividend yield of project A. As $V_{A}$ increases, instead of investing in B up until hitting the A threshold the firm will stop investing in $\mathrm{B}$ when $V_{A}$ is sufficiently large and wait to see whether $V_{A}$ will increase in the future. In this case the loss of potential cash that would have been generated by $\mathrm{B}$ is offset by the potential for larger magnitudes of cash to be generated by A.

As $V_{B}$ increases further and reaches 200, the resulting policies maintain the general shape as above. However, the small interim waiting region described earlier is almost non-existent. It is worth noting that in the moderate range of cash, the policy switch from project $\mathrm{B}$ to project $\mathrm{A}$ occurs when $V_{A}$ is around 155 . When projects are symmetric in Figure 2.12 and $V_{B}=200$, the switch occurs when both investments have the same present value, that is when $V_{A}$ is also equal to 200 . This is logical as the two projects have the same characteristics, their only point of differentiation being the current cash flow generated and therefore the present value of each project. As such, it is simple to see that the firm chooses to invest in the project with the higher NPV as neither project provides significant benefits relative to the other project except in differences in NPV. However, when project A has a higher yield, the switch will occur when $V_{A}<V_{B}$. This shows that when the constrained firm has a level of cash that puts it close to the investment constraints, in some states, it will be willing to choose project A over project B even though project A has a lower NPV. This is in direct violation of the standard NPV rule and occurs because the high yield project is able to provide additional benefits, over and above its NPV. These benefits come in the form of its ability to relax the future financial constraints on follow-up investment. This result supports and provides further insight into the intuition described in Thakor (1990) and Almeida et al. (2011) where firms will have a preference for short payback projects that can relax future financial constraints. 
The behaviour described above persists as $V_{B}$ increases further. Eventually $V_{B}$ is so large that investment occurs regardless of state and the policy for project A returns to the u-shape of Boyle and Guthrie (2003). ${ }^{7}$ Interestingly, and contrary to intuition, for all levels of cash, the introduction of project B for a firm that holds the higher yielding project A does not cause an acceleration of investment in project A relative to if the firm only had project A. This would suggest that although in some states project $\mathrm{A}$ is picked over project $\mathrm{B}$, the effect of having cash in the future is outweighed by the cost of spending cash now. ${ }^{8}$

\subsubsection{High Pledgeability Projects}

The pledgeability of an asset refers to the amount of the asset's value that can be used as collateral for debt. The model's financing frictions include an assumption that the collateral value of an asset is lower than the true value of that asset. Asset pledgeability in the model is represented through the financing frictions $\gamma_{A}, \gamma_{B}, \theta_{A}$ and $\theta_{B}$. The level of debt that can be raised on an uninitiated project is equal to $\gamma_{A} \theta_{A} V_{A}$ and $\gamma_{B} \theta_{B} V_{B}$ for projects $\mathrm{A}$ and $\mathrm{B}$ respectively. Therefore, the higher the parameter value, the higher the pledgeability of the project. Pledgeable assets support more borrowing, and in turn facilitate further investment in other assets (Almeida and Campello, 2007) and therefore should be preferred by the constrained firm.

To investigate how the addition of an extra investment opportunity influences the optimal timing policy of a high-pledgeability project, the parameters found in Table 3.2 are used to solve the investment timing model of Chapter 2. These parameters are the same as detailed in the symmetric case of the previous chapter with the exception of the information asymmetry and control frictions of project A. The information asymmetry friction of this project has been decreased from $\gamma_{A}=0.8$ to $\gamma_{A}=0.95$ (a friction decrease is the same as a parameter increase) and the control friction decreased from $\theta_{A}=0.4$ to $\theta_{A}=0.95$. Refer to Figure 3.3 which plots the new policy

\footnotetext{
${ }^{7}$ As discussed earlier this is because project B is so large that it effectively becomes equivalent to assets in place.

${ }^{8}$ In this case, cash in the future refers to cash that would be generated by Project $\mathrm{A}$ if it was launched.
} 
Table 3.2: This table outlines the parameter values used to numerically solve Equation (2.39) for the optimal investment timing policy when project $\mathrm{A}$ is a high-pledgeability project. The parameters are the same as shown in Table 2.3 except the information asymmetry of project A has changed from $\gamma_{A}=0.8$ to $\gamma_{A}=0.95$ and the control discount has changed from $\theta_{A}=0.4$ to $\theta_{A}=0.95$.

\begin{tabular}{lcc}
\hline \hline & Project A & Project B \\
\cline { 2 - 3 } Project investment cost $(\$)$ & $I_{A}=100$ & $I_{B}=100$ \\
Project cash flow volatility & $\sigma_{A}=0.20$ & $\sigma_{B}=0.20$ \\
Project dividend yield & $\delta_{A}=0.03$ & $\delta_{B}=0.03$ \\
Information asymmetry & $\gamma_{A}=0.95$ & $\gamma_{B}=0.80$ \\
Control friction & $\theta_{A}=0.95$ & $\theta_{B}=0.40$ \\
\cline { 2 - 2 } Riskless interest rate & $r=0.03$ \\
Firm cash flow-Project A cash flow correlation & $\rho_{X A}=0.5$ \\
Firm cash flow-Project B cash flow correlation & $\rho_{X B}=0.5$ \\
Project A cash flow-Project B cash flow correlation & $\rho_{A B}=0.5$ \\
Firm cash flow volatility & $\phi=60$ \\
Market value of existing assets & $G=100$ \\
\hline \hline
\end{tabular}

results under these parameters. As before, when $V_{B}$ is equal to zero, the standard single-project policy shape applies and a u-shaped investment threshold is shown. Depending on the level of cash and project value, the firm will either accelerate or delay investment relative to the unconstrained firm. It is worth noting that for high project values, the gap between the liquidation constraint and investment constraint is small. This occurs because when $V_{A}$ is large, in liquidation the buyer of the project will pay $\gamma_{A} V_{A}-I_{A}$ and therefore the liquidation constraint becomes $X+G+\gamma_{A} V_{A}-I_{A} \leq 0$. The investment constraint is $I_{A} \leq X+G+\gamma_{A} \theta_{A} V_{A}$ and as such the size of the forced waiting region is determined by the control discount $\theta_{A}$. A high control discount (low parameter value) increases the waiting region and a low discount (high parameter value) reduces it. As $V_{B}$ increases to 141, the investment policy maintains the ushape; however, investment is marginally delayed. In this case the delay occurs as the firm does not want to invest in project $\mathrm{A}$ to find out that it would rather launch project B ex-post.

Further increasing $V_{B}$ until $V_{B}=178$ leads to a change in the shape of the investment policy. Instead of the traditional u-shape, the investment policy for project A 

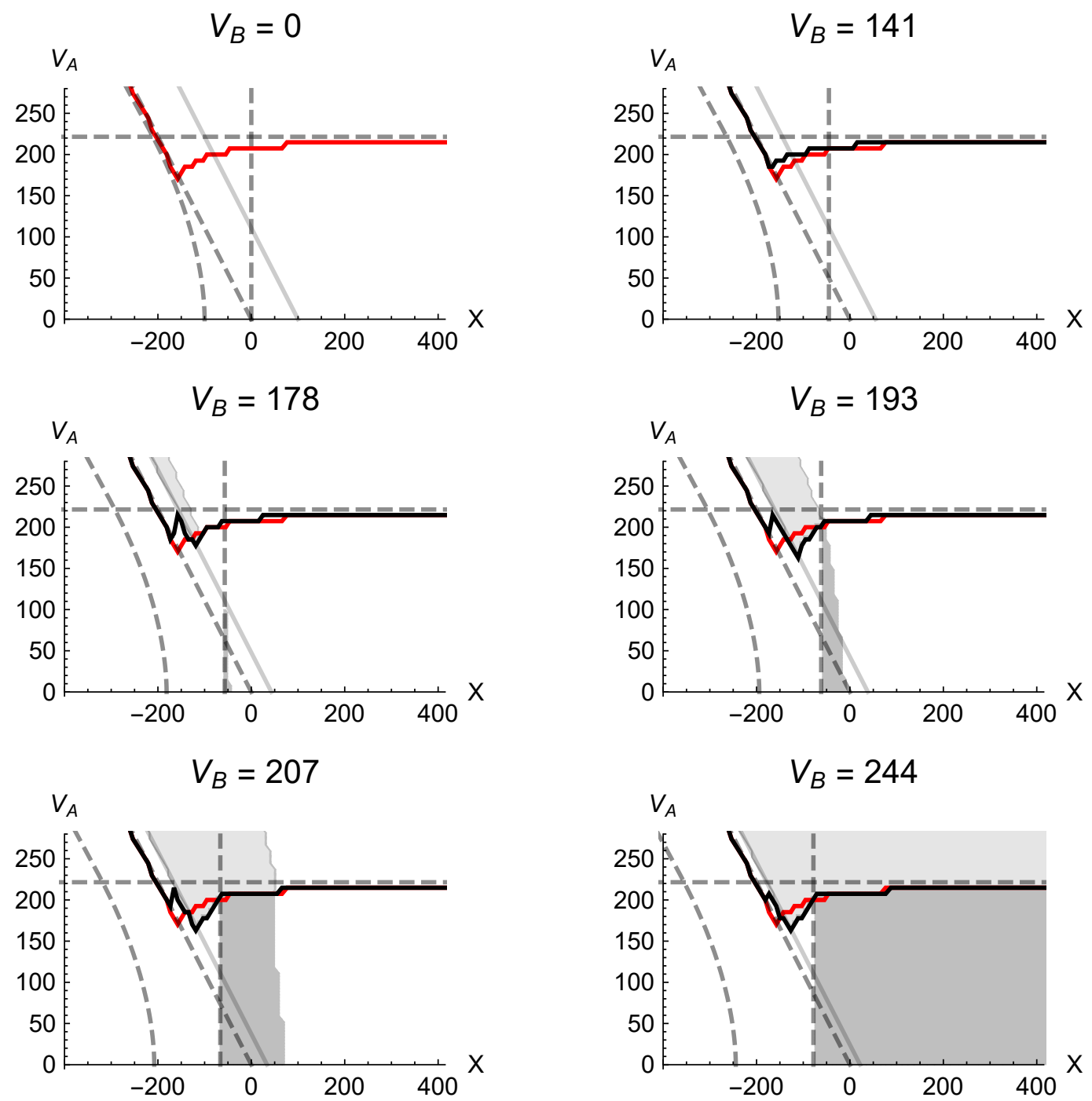

Figure 3.3: This figure shows the investment policy when project A is a high-pledgeability project under the parameters in Table 3.2. The red curve is the single-project investment threshold for project A. The black curve is the investment threshold for project A given that the firm also has access to project B. The dark grey region shows states where project B is launched but not project A and the light grey region shows states where both projects are launched simultaneously.

now takes on a distinct w-shape. When the firm has low cash reserves, the investment constraint is binding and investment in A is undertaken as soon as possible. Eventually, cash reaches a sufficient level where the likelihood of losing the ability to invest in the future is small enough that the investment policy jumps upwards quickly with $X$. In this case, due to the comparatively low-pledgeability of $\mathrm{B}$, the firm is considerably far away from being able to invest in project B. This means that the only feasible way investment in $\mathrm{B}$ will occur is through the help of project $\mathrm{A}$. If the firm is unable 
to invest in both projects simultaneously, then should the firm invest in A on its own there are three ways the constraint on B as a follow up investment is relaxed. First, project A will generate cash that can be used to fund future investment. Second, a proportion of the asset can be sold to raise capital that can be used to finance investment. Third, the firm may raise debt on a proportion of the project provided that proportion has not been sold. The dividend yield is not particularly large so the effect of cash generated is negligible, an idea that will be explored further in the following section. Additionally, it is costly for the firm to invest in project A and subsequently sell off part of the project as a capital-raising strategy. Also debt financing can be raised at any time for the firm. Therefore, the firm chooses to delay investment in A until such a time when $V_{A}$ is sufficiently large to facilitate simultaneous investment in both projects. In this case the upwards jump in threshold occurs as a result of the difficulty surrounding investment in project B.

Following the threshold jump, the policy function binds to the simultaneousinvestment constraint as cash increases. This leads to the investment threshold of project A decreasing in cash. For higher and higher levels of cash the firm is able to invest in both projects for a lower and lower value of $V_{A}$. Here the firm is launching both projects as soon as possible due to the fear of losing the ability to do both in the future. Eventually the simultaneous-investment constraint no longer binds and the firm begins to reduce the level of acceleration relative to the unconstrained firm as cash increases, thus completing the w-shaped investment threshold of project A. In regards to investment in project $\mathrm{B}$ it is worth noting that when $V_{B}=178$, in most states where $\mathrm{B}$ is initiated it is done so in conjunction with project $\mathrm{A}$. There is only a small set of states where project B is launched and project A delayed, which can be seen along the financing constraint for project B.

When $V_{B}$ is equal to 193 the w-shaped investment curve persists. There are now more states where investment in B occurs as soon as possible without the initiation of project A. Interestingly, where the simultaneous-investment constraint binds the policy shifts from being above the single-project policy to below it. ${ }^{9}$ Here the intro-

\footnotetext{
${ }^{9}$ Although much smaller, this region is also seen when $V_{B}=178$.
} 
duction of an additional project opportunity can cause the constrained firm to invest earlier in a highly pledgeable project than they would otherwise. This result is consistent with the work of Almeida et al. (2011), who suggest that investment policies will distort towards collateralizable projects. The model used however extends this result to show that the level of distortion, and states where distortion occur, will be highly dependent on the firm's cash reserves and financial position.

The w-shape is maintained in the remaining graphs of Figure 3.3 as $V_{B}$ increases to 207 followed by 244 . It is worth noting that the policy acceleration relative to the single-project case is seen only in the region where project B is unobtainable on its own. Intuitively, this makes sense as it is in this region where the firm needs to use the resources of project A to "cross subsidise" the investment in project B. Acceleration would require the firm to be in a state where it chooses to delay project $\mathrm{A}$ if this project was all it had.

\subsubsection{Summary}

This section began by hypothesising that a firm with the rights to either a quick payback or high-pledgeability project would alter their investment policy for this project if another opportunity without these characteristics was also available. Specifically, initial intuition suggests that the alteration would come in the form of a downwards shift of the investment policy indicating an increase in investment. Instead, the downwards shift is only present for a firm that holds the perpetual option to a highpledgeability project and does not occur for a constrained firm with a quick payback project. $^{10}$

However, in the quick payback case, in some states the firm is willing to undertake the faster payback project A even though it has a lower NPV than that of the slower payback project B. This suggests that although there is not a downwards shift of the threshold, the firm is engaging in a project-picking strategy. In the high pledgeability case, investment is accelerated relative to the single-project case when the firm has

\footnotetext{
${ }^{10}$ Other than in states where $V_{B}$ is of such a magnitude so as to increase the number of states where investment in project $\mathrm{A}$ is possible.
} 
low cash reserves. The low cash reserves coupled with the low pledgeability of project $\mathrm{B}$ means that the only way project $\mathrm{B}$ can be completed is by completing project A and using the excess debt capacity. This means that the constrained firm accelerates investment in project $\mathrm{A}$ in order to complete B as well.

\subsection{The Value of Cash}

In the previous section it was shown that for a firm with access to a fast payback project, the introduction of an additional project that is identical in all respects except that it has a slower payback will lead to a change in the optimal investment policy. Interestingly, for all values of the new project, the constrained firm does not accelerate its investment in the fast payback project relative to the case where it only has the fast payback project available. This would suggest that the value of cash generated by investing in the project is more than offset by the cash spent on initiating the high payback project. But this needs to be investigated further if we are to fully understand these results. Also, the study of the marginal value of cash is important and interesting in its own right. As such, this section looks at the tradeoff that occurs when investing in a project where investment decreases the capital available for other projects but also generates cash that increases available capital. Following this, the marginal value of cash is explored for both fast payback and high-

pledgeability projects in the two-project model described in Chapter 2. First, the existing literature on the marginal value of cash to a firm is briefly summarised.

\subsubsection{Literature}

There is a considerable amount of literature that looks at the value of cash holdings; however, the majority looks at the value of an extra dollar of cash now and not the trade-off between cash spent now and cash earned later. Initial intuition may suggest that the marginal value of cash is equal to $\$ 1$, that is an extra dollar is worth its face value to the firm. However, such intuition ignores a variety of other 
factors. One side of the theory suggests that the marginal value should be greater than $\$ 1$ as additional cash increases financial flexibility which is valuable to the firm. For example, an additional dollar may allow the constrained firm to invest where it otherwise is unable to. The other side of the theory suggests that the marginal value of cash will be less than $\$ 1$. One simple explanation of this is that taxes reduce the amount received by shareholders and therefore one dollar at the firm level is worth less than its face value at the shareholder level. Further to this argument is the idea that agency costs between shareholders and managers decrease the value of cash.

Pinkowitz and Williamson (2002) look at the value of cash in an empirical study and find that on average the marginal value of cash is greater than $\$ 1$. They also find that cash will be valued less in firms that are close to financial distress. They reason that this is because the agency conflict between stockholders and bondholders is larger for these distressed firms. Assuming that a financially distressed firm is one with a low cash balance, then the work of Faulkender and Wang (2006) suggests the opposite. In their paper they show that the marginal value of cash decreases with the cash balance of a firm and therefore is greater for firms that are close to financial distress. This occurs because a firm that has lower cash is more likely to be in a position where costly external capital is required to fund investment. As cash increases, the need for external finance is reduced, and accordingly so is the marginal value of that cash. A similar result is discussed in Denis and Sibilkov (2009), where cash constrained firms place a higher value on cash than unconstrained firms. They suggest two reasons for this. First, cash allows constrained firms to increase investment and, second, the marginal investment of constrained firms has a stronger relation to value than for unconstrained firms.

Although a larger cash balance reduces the need for external finance, it also increases the magnitude of perquisites received by a manager who instead of paying out cash to shareholders engages in empire building investments. This is the moral hazard problem as described in Jensen (1986). Both Pinkowitz et al. (2006) and Dittmar and Mahrt-Smith (2007) expand on this theory and further explore the agency costs of free cash flow. The former looks at variations in the value of cash across coun- 
tries where the level of investor protection varies country to country. In support of the agency costs associated with free cash flow, they show that cash is valued at a discount in countries that have comparatively weak investor protection. Controlling shareholders in these countries prefer holding cash reserves as it provides them with an added level of flexibility. ${ }^{11}$ This means that high cash reserves should be valued at a discount as outside investors' value is diluted by the private benefits received by controlling shareholders. Dittmar and Mahrt-Smith (2007) looks at how the value of cash is influenced by the quality of governance. Their results show that a firm with poor governance is more likely to spend limited cash reserves on a poor performing investment than a firm with good governance. In fact, good governance is shown to roughly double the value of cash in the eyes of the investor. Drobetz et al. (2010) looks at how the value of cash changes with information asymmetry. The free cash flow theory of Jensen (1986) is supported in their findings as the value of cash decreases as the level of information asymmetry increases.

The aforementioned look at the value of cash now in an essentially static setting. Keefe and Tate (2013) look at the relationship between investment and cash flow volatility using a conditional volatility measure. This volatility measure allows them to identify unexpected changes in a firm's cash flow growth. Their results show that financially constrained firms will decrease investment when cash flow volatility is persistently high, cash is low and cash flow growth is negative. Hirth and Viswanatha (2011) develop a two-period model to investigate how the investment threshold is influenced by financing costs now. In their model the firm has access to an investment opportunity that can either be launched in the first period or the second period. Their results mirror the u-shaped investment policies of Boyle and Guthrie (2003), Shibata and Nishihara (2012) and Hirth and Uhrig-Homburg (2010b). The two period nature of their model shows that the optimal investment policy is driven by the trade-off between financing costs today and financing costs tomorrow. Their main findings suggest that financing costs today are more important than financing costs in the

\footnotetext{
${ }^{11}$ In this case, flexibility refers to the fact that cash can either be siphoned to controlling shareholders or used to initiate investments that provide perks to the investor.
} 
future. Therefore, constrained firms with low cash now are reluctant to invest if it is likely that they will not face financing constraints in the future. To expand on this area, the following sections look at the trade-off between financing costs today, which decrease the cash balance/restrict future investment and cash generated by a project

after investment, which increases/encourages future investment. This analysis helps to provide insights into the value of cash generated by a project. Following this, the increase in option value when the firm has an additional $\$ 1$ of cash is explored. Such analysis helps to describe the states where cash is valuable and when it is not, thus helping to tie together the conflicting empirical results.

\subsubsection{Cash Now vs Cash Later}

When the firm has the rights to a quick payback project, the introduction of a similar but slow payback project does not elicit accelerated investment in the quick payback opportunity. The benefit of early investment is the realisation of cash produced by the project being received earlier. This is the "Cash Later" effect where a launched project generates cash after investment that helps to relax future financial constraints. This is the same result described in Hennessy and Whited (2005) where firms can benefit from investing now because the current investment's cash flow reduces future capital constraints. The cost of early investment is the decrease in the cash balance due to the lump sum expenditure associated with investment. This is the "Cash Now" effect where cash is used up now to fund investment. Figure 3.2 suggests that the first effect outweighs the second for quick payback projects.

In order to better understand how each of these effects interact and understand their relative importance, the impact of cash generated by a launched project is isolated from the impact of cash spent on investment. Consider that project A has been launched and B delayed. The firm's cash balance will evolve according to the following process

$$
d X=r X d t+\nu d t+\phi d \zeta+A d t
$$

where the cash generated by project $\mathrm{A}$ is captured by $A d t$. Omitting this term will 
eliminate the effect of any cash that is generated by the project after completion. One way to interpret this is to imagine that all of the cash flow generated by project A is paid out to shareholders as soon as it is generated. Thus, shareholders still receive the direct benefit of the cash generated by the asset, but not the indirect benefit that comes from relaxing the cash constraint. Therefore, when the timing model is solved, the firm will now make its investment decisions based only on the cash spent on investment without the benefit of cash generated. The cash balance will now evolve according to the following process

$$
d X=r X d t+\nu d t+\phi d \zeta .
$$

The same conditions and solution procedure used previously apply; however, prior to investment in project $\mathrm{B}$, given that project $\mathrm{A}$ has been launched, the investment option value will now satisfy the following partial differential equation

$$
\begin{aligned}
& \frac{1}{2} \sigma_{A}^{2} A^{2} F_{A A}^{B A}+\frac{1}{2} \sigma_{B}^{2} B^{2} F_{B B}^{B A}+\left(r-\delta_{A}\right) A F_{A}^{B A}+\left(r-\delta_{B}\right) B F_{B}^{B A}+r(X+G) F_{X}^{B A} \\
& \quad+\frac{1}{2} \phi^{2} F_{X X}^{B A}+A B \rho_{A B} \sigma_{A} \sigma_{B} F_{A B}^{B A}+\rho_{X B} \sigma_{B} B \phi F_{X B}^{B A}+\rho_{X A} \sigma_{A} A \phi F_{X A}^{B A}-r F^{B A}=0 .
\end{aligned}
$$

When compared to Equation (2.28), the only difference is the coefficient on $F_{X}^{B A}$ which has changed from $r(X+G)+A$ to $r(X+G)$. The equivalent PDE for the case where investment in project $B$ has been undertaken and the firm is yet to invest in project $\mathrm{A}$ is as follows

$$
\begin{aligned}
& \frac{1}{2} \sigma_{A}^{2} A^{2} F_{A A}^{A B}+\frac{1}{2} \sigma_{B}^{2} B^{2} F_{B B}^{A B}+\left(r-\delta_{A}\right) A F_{A}^{A B}+\left(r-\delta_{B}\right) B F_{B}^{A B}+r(X+G) F_{X}^{A B} \\
& \quad+\frac{1}{2} \phi^{2} F_{X X}^{A B}+A B \rho_{A B} \sigma_{A} \sigma_{B} F_{A B}^{A B}+\rho_{X B} \sigma_{B} B \phi F_{X B}^{A B}+\rho_{X A} \sigma_{A} A \phi F_{X A}^{A B}-r F^{A B}=0 .
\end{aligned}
$$

It is worth noting that the PDEs for the single-project case and the two-project case where neither has been launched do not change as cash is only generated (outside of the cash generated by assets in place $G$ ) when a project has been launched. 

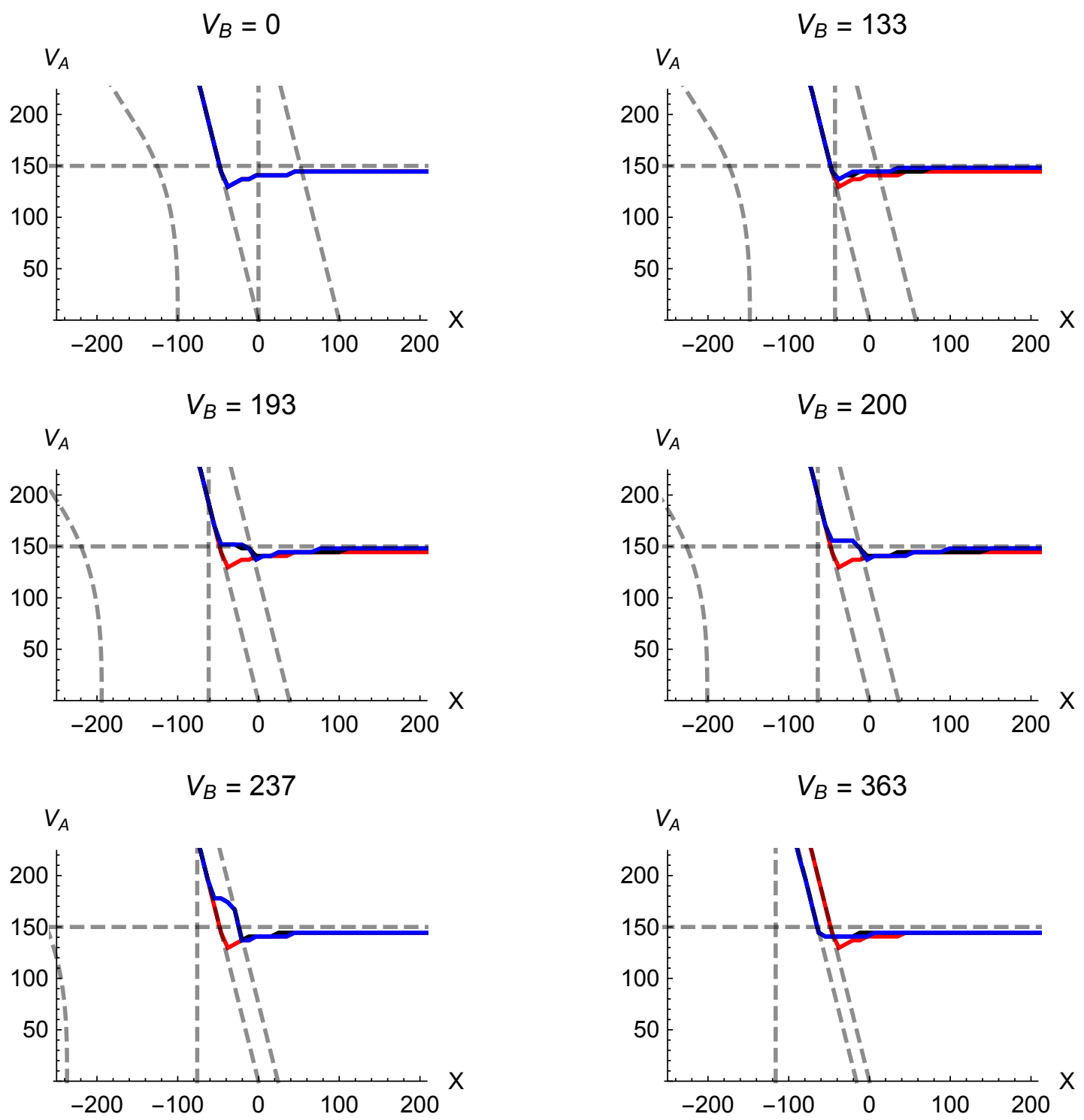

Figure 3.4: This figure plots the investment threshold for project A when project $\mathrm{A}$ is a fast payback project under the parameters in Table 3.1. The red curve is the single-project investment threshold for project A. The black curve is the investment threshold for project A given that the firm also has access to project $\mathrm{B}$. The blue curve is the investment threshold for project $\mathrm{A}$ given that the firm also has access to project B and that all cash generated by project A after being launched is paid out to shareholders.

Now refer to Figure 3.4, which plots the investment thresholds that apply when Equations (3.8) and (3.9) are used where appropriate in the solution procedure. The investment regions for project B have been excluded from this figure in order to keep the graphs manageable. The blue curve on each graph depicts the investment policy for project A given that, once launched, the cash it generates is not added to the firm's 
cash stock. As before, the black curve plots the investment threshold for project A in the traditional setup where a project generates cash according to its implicit dividend yield and the red curve plots the single-project threshold. Intuitively the two effects described earlier will have opposing impacts on the investment threshold for a given project. Spending cash to launch one of the opportunities means that there is less cash available for the other project, which therefore shifts the threshold upwards. However, the cash generated by an in-place asset increases the cash available for the other project and therefore leads to a downwards shift in the threshold.

For all levels of $V_{B}$ shown in Figure 3.4 the threshold for project A without the effect of cash generated coincides with the threshold shown in the previous section. This shows that the cash generated by project A upon investment does not have an impact on the overall investment policy. If the "Cash Now" effect outweighed the "Cash Later" effect then it would be expected that the new threshold would be above the original one calculated. In this sense spending cash now would jump the threshold upwards and the potential of generated cash would pull it downwards. However, there is no difference in the two policy functions, other than differences attributable to the numerical nature of the solution procedure. This shows that the cash generated by project $\mathrm{A}$ has a negligible effect on the optimal constrained investment policy. Instead, the change in investment policy for project A when project B is introduced is driven by the lump sum cost of initiating the project. This provides an interesting insight into how multiple projects interact and affect investment policies.

In contrast to the quick payback situation, the threshold for a high-pledgeability project is shown to be accelerated in some states when an additional low-pledgeability project is introduced to the firm. As mentioned previously, this occurs when the high-pledgeability project is used to subsidise the investment in the low-pledgeability project and both are launched simultaneously. To confirm that the cash generated by the high-pledgeability project does not account for the acceleration, the same procedure above is implemented. Refer to Figure 3.5 for the resulting investment policy. The graphs show that there is no difference in the two policies when the acceleration occurs and therefore confirms that, as expected, cash generated does not 

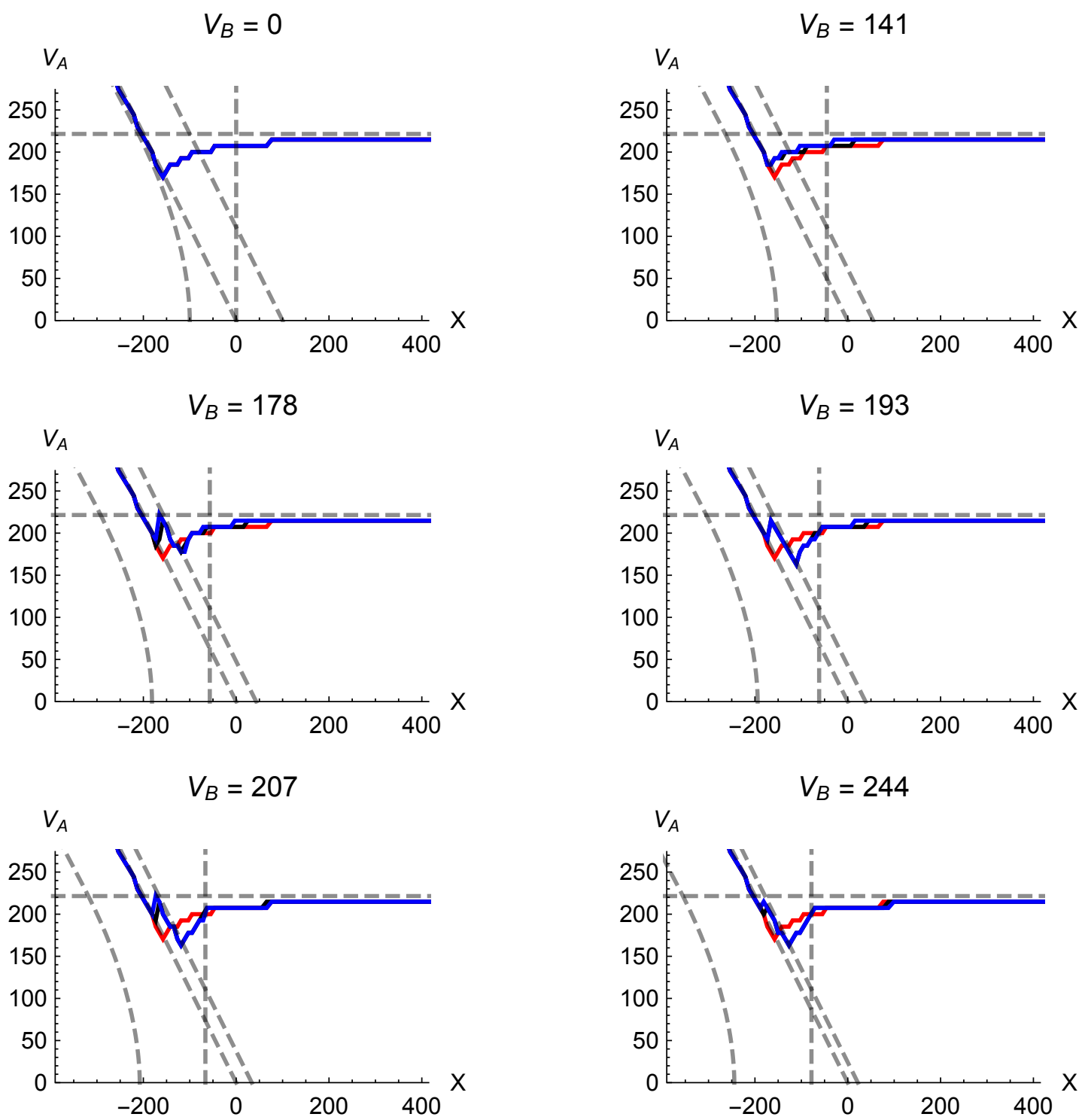

Figure 3.5: This figure plots the investment threshold for project $\mathrm{A}$ when project A is a highpledgeability project under the parameters in Table 3.2. The red curve is the single-project investment threshold for project A. The black curve is the investment threshold for project A given that the firm also has access to project B. The blue curve is the investment threshold for project A given that the firm also has access to project $\mathrm{B}$ and that all cash generated by project $\mathrm{A}$ after being launched is paid out to shareholders.

drive the acceleration. Interestingly, it appears that there is a slight difference in the thresholds when cash is low enough that only project A can be launched. This is in the region where the policy jumps upwards sharply from binding to the only A constraint to the simultaneous-investment constraint. It is likely that the difference is purely numerical in nature due to the policy solution being solved on a grid. Further 
evidence in this regard is seen on the plot where $V_{B}=193$ and no difference is shown although the policy has the same features as when $V_{B}=178$ and $V_{B}=207$. Further details on the numerical procedure can be found in Chapter 4 and the Appendix.

\subsubsection{The Marginal Value of Cash}

It has been shown that the trade-off between spending cash now and earning cash in the future has a negligible, if any, effect on the optimal investment timing. It is the upfront cost of investment that matters the most. The analysis completed above implicitly looks at the relative value of cash between now and the future and not the actual value of cash now. It is, however, straightforward to extract the value of an extra $\$ 1$ of cash from the model presented in this thesis. The value of the firm with access to both projects is equal to

$$
X+G+F(X, A, B)
$$

and therefore the marginal value of cash from the shareholders' point of view is equal to

$$
\frac{\partial}{\partial X}(X+G+F(X, A, B))=1+\frac{\partial F}{\partial X}
$$

There are no taxes in the investment model of Chapter 2 and as such the direct value

of adding one dollar to the firm's cash reserves is equal to one. The term $\frac{\partial F}{\partial X}$ captures how the option value increases as an additional dollar is added to the cash balance. This increase is driven by the fact that a firm with an extra dollar of cash is able to either delay investment longer until a more profitable state occurs or invest in a project that would otherwise be unavailable. Refer to Figure 3.6 which plots the option's marginal value of cash alongside the corresponding threshold under the quick payback parameters found in Table 3.1. The marginal value of cash is shown with contour lines in order to highlight the general behaviour and the changes in value that occur as $V_{B}$ increases. The white region is the lowest contour and represents states 

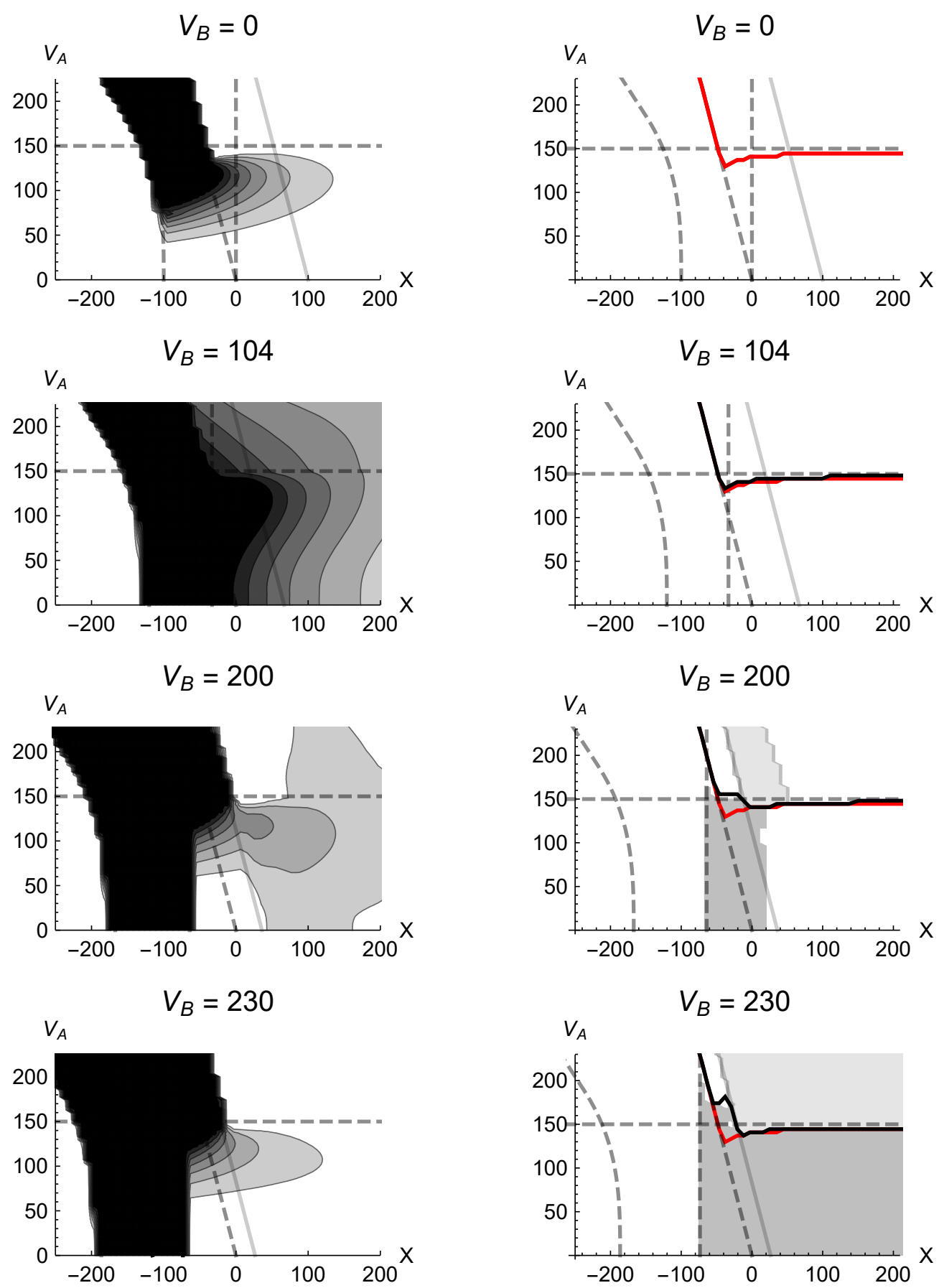

Figure 3.6: This figure shows the marginal value of cash and the constrained investment policy when project $\mathrm{A}$ is a quick payback project under the parameters in Table 3.1. The marginal value of cash is shown on the left hand graph of each row with contour lines. The white region is the lowest contour representing states where the value of cash is between $\$ 0$ and $\$ 2$. Each subsequent contour is shown by a progressively darker grey and illustrates a $\$ 2$ increase in the value of cash. The black region indicates the maximum contour and is applied where the value of cash is equal or greater that $\$ 15$. The constrained investment policy is shown on the right hand side graph for each row in the same manner as Figure 3.2. 
where the marginal value of cash is between $\$ 0$ and $\$ 2 .{ }^{12}$ Each subsequent contour is shown by a progressively darker grey and illustrates a $\$ 2$ increase in the marginal value of cash. The black region indicates the maximum contour and is applied where the marginal value of cash is equal to $\$ 15$ or more. This maximum contour of $\$ 15$ is implemented in order to ensure the regions where the most interesting behaviour occurs are easily visible. ${ }^{13}$

When $V_{B}=0$, the single-project case applies and the marginal value of cash is largest when the firm is in the forced waiting region and $V_{A}$ is high as more cash in this state increases the likelihood of being able to launch a valuable project in the future. Cash has a low marginal value when $V_{A}$ is low. Here, even though more cash will either put the firm closer to being able to invest or further from being unable to invest, the low project value and therefore NPV means that even with more cash, investment will not occur. Outside of the maximum contour, extra cash is most valuable for a moderate level of cash and moderate value of $V_{A}$. Intuitively, this should be expected as this is when (i) cash is low enough that investment in both projects is not possible and therefore extra cash increases the firm's flexibility and (ii) the NPV of project $\mathrm{A}$ is low enough that investment is delayed and therefore extra cash decreases the likelihood of being unable to invest in the future when the NPV is high.

The relative simplicity of the single-project model is illustrated as $V_{B}$ increases to 104. Project B now has a slightly positive NPV. The marginal value of cash in the forced waiting region when $V_{A}$ is low is now very large. Even though investment does not occur in either project and is unlikely for project $A$ in the near future, investment in $\mathrm{B}$ is likely in the near future. Therefore, each extra dollar that brings the firm closer to being able to invest is highly valued. This is the same reason why cash is valuable to the right of the forced waiting region when $V_{A}$ is high. In this region when $V_{B}=0$, cash was not very valuable because investment in project A would occur regardless

\footnotetext{
${ }^{12}$ The contours are drawn for the option's marginal value of cash, $\frac{\partial F}{\partial X}$, and therefore it is possible for them to be less than $\$ 1$.

${ }^{13}$ For an example of an uninteresting result, consider a firm that is just inside the forced waiting region and only requires $\$ 1$ more of cash to be able to invest. If the launched project has an NPV of $\$ 200$ then of course the marginal value of cash in this state is equal to $\$ 200$.
} 
of additions to the cash balance and project $\mathrm{B}$ was worthless so there was no follow up investment value. However, when $V_{B}=104$, investment in project A still occurs regardless of any increments to the cash balance but now project $B$ is valuable as a follow-up investment in the future. Therefore, additional cash is valuable as it relaxes the constraints associated with investing in project B in the future.

Further increasing $V_{B}$ to 200 leads to changes in the value of cash with similar intuitive explanations to those above. Project $B$ is now a highly valuable project with a large NPV which means that it is launched in some states. First, consider the situation where both A and B are initiated simultaneously. As both projects have been undertaken and there are no additional investments, cash has a low marginal value here. Second, when $V_{A}$ is low and project $\mathrm{B}$ is launched, the value of cash is low, the same result that was seen when $V_{B}=0$. The low probability of investment in project A, due to a low NPV, coupled with the fact that B has already been launched means that extra cash is not very valuable. Outside of the forced waiting regions where $\mathrm{B}$ is not launched, cash is moderately valuable.

As $V_{B}$ increases further to 230 , the contour plot shows the same general behaviour as when $V_{B}=0$. However, because project B is no longer worthless, cash is highly valuable in the entire forced waiting region. Even when project A has a low NPV, the firm would still like to launch B and that drives the value.

For completeness, the marginal value of cash has also been calculated under the high-pledgeability parameters of Table 3.2 and is shown in Figure 3.7. The general behaviour under these parameters is similar to the quick payback scenario with slight changes occurring due to the shape of the constraints. As discussed earlier, due to the relative high pledgeability of project $\mathrm{A}$, there are many states where the firm is able to invest in A but still be a long way from being able to invest in project $\mathrm{B}$ on its own. This is highlighted when $V_{B}=200, V_{A}$ is high and cash is around 100. In a similar situation under the fast payback parameters, the value of cash is between $\$ 2$ and $\$ 4$. However, here cash is worth between $\$ 0$ and $\$ 2$. The high pledgeability of project $\mathrm{A}$ in this case means that the firm is relatively far away from the forced 

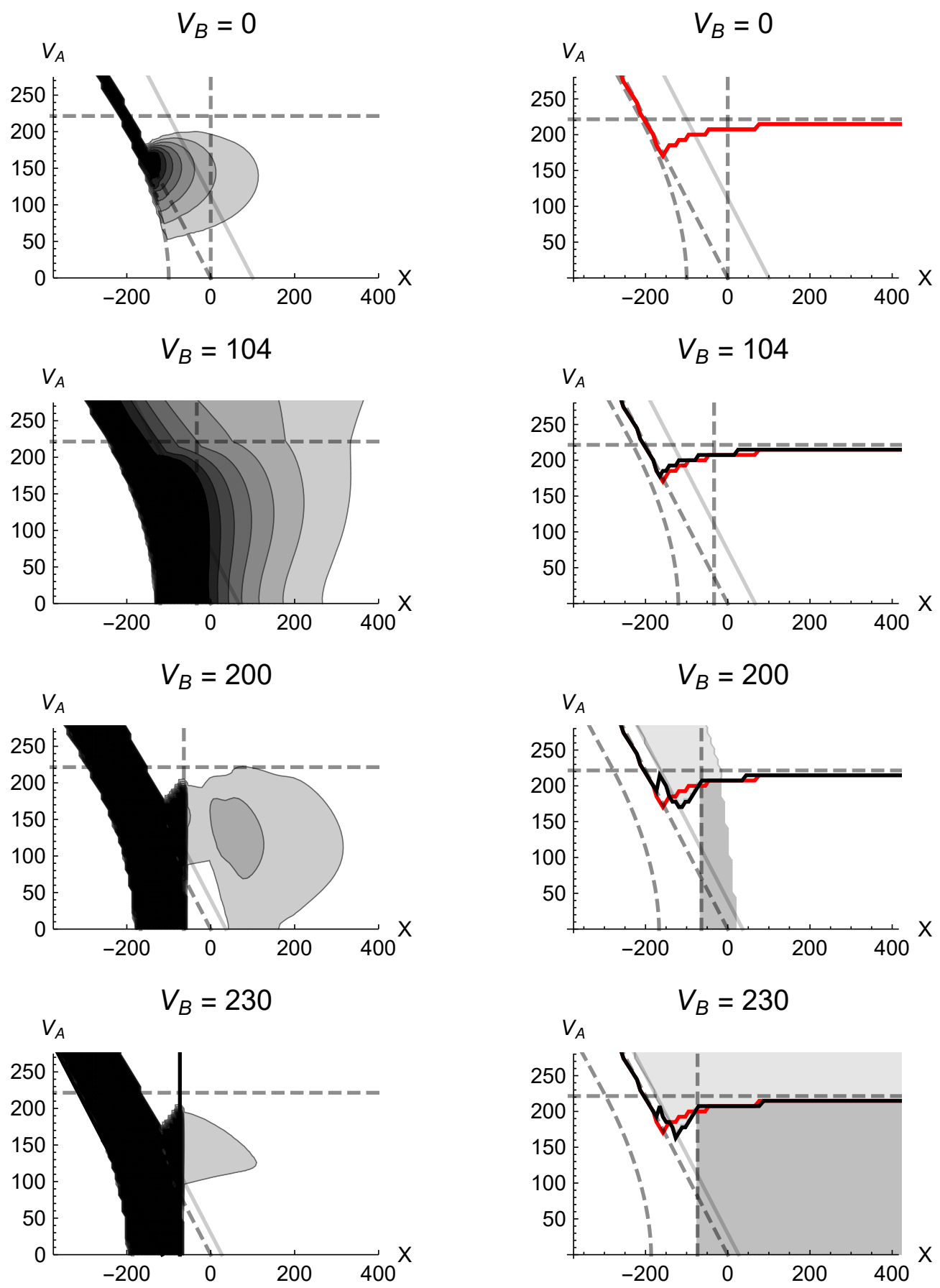

Figure 3.7: This figure shows the marginal value of cash and the constrained investment policy when project $\mathrm{A}$ is a high-pledgeability project under the parameters in Table 3.2. The marginal value of cash is shown on the left hand graph of each row with contour lines. The white region is the lowest contour representing states where the value of cash is between $\$ 0$ and $\$ 2$. Each subsequent contour is shown by a progressively darker grey and illustrates a $\$ 2$ increase in the value of cash. The black region indicates the maximum contour and is applied where the value of cash is equal or greater that $\$ 15$. The constrained investment policy is shown on the right hand side graph for each row in the same manner as Figure 3.3. 
waiting region and as such the value of extra cash is lower.

\subsubsection{Summary}

This section began with the conjecture that when one of the available projects had a high dividend yield, the cost of spending cash now to initiate this project outweighed the future benefits associated with a high yield. To show this, the effect of cash spent on investment is separated from the effect of cash generated post-investment and the optimal investment policy solved. The firm does not change its investment timing when it pays out all of the cash generated and therefore confirms that even though cash generated eases future constraints as discussed by Thakor (1990) and Almeida et al. (2011), it is more costly to initiate the project earlier due to lump sum investment costs.

All of this suggests that cash on hand is highly valuable to the constrained firm. In order to confirm this, the marginal value of cash is calculated for both scenarios when the firm has a fast payback and highly pledgeable project. As expected, the marginal value of cash is of a large magnitude in the forced waiting region when each extra dollar brings the firm closer to being able to do a positive NPV project. Additionally, the relative simplicity of the single-project model is highlighted where in the vast majority of states cash has a low value. However, the introduction of a second project shows that the true value of cash largely depends on the interaction of both projects. When one project has a low NPV and the other a high NPV cash will be valuable even though not useful in regards to the low NPV project. In general the results show that an extra dollar of cash can be highly valuable due to the increased flexibility it provides the constrained firm around investment timing.

\subsection{Mergers and Spin-offs}

The model presented in this thesis arises from adding an additional investment opportunity to the model of Boyle and Guthrie (2003), a non trivial extension. Each 
of the previous sections within this chapter have shown that this extra investment can considerably alter the conclusions under the single-project model. In addition to the insights into how a constrained firm chooses between multiple investments, with minor additions, the model of Chapter 2 can also be used to illustrate how and when the firm should spin-off and run the projects separately as separate firms. By way of symmetry it can also be used to show the value of merging two firms that each have access to one project. A merged firm is able to allocate the cumulative cash balance to either, or both, projects as it sees fit. This internal capital market can allow positive NPV projects to be launched that otherwise would have not been undertaken. The remainder of this section first summarises the relevant literature and then subsequently investigates the details around which division should receive a majority proportion of the parent firm resources in a spin-off situation.

\subsubsection{Literature}

There has been a steady flow of literature exploring whether firms should consolidate investments and run them under a joint firm as opposed to separately. However, there is no general consensus as to which is optimal. One side suggests that merged (diversified) firms will be undervalued when compared to the cumulative value of similar single segment firms, that is they suggest a diversification discount. ${ }^{14}$ On the other hand, a diversification premium has also been shown in a variety of cases.

Theoretical studies rely on agency problems in order to suggest a diversification discount. Financial conglomerates are shown to have lower values than if they were split up in the research conducted by Laeven and Levine (2007). They suggest that by engaging in multiple activities conglomerates exacerbate agency problems and thus destroy value. The economies of scale enjoyed by large conglomerates are found to be outweighed by the increased agency problem. Hund et al. (2010) use the rational learning model of Pástor and Pietro (2003) to show a discount. In the learning model, as investors learn about profitability, the market value of a firm converges to

\footnotetext{
${ }^{14}$ The analysis completed in the following section looks at spin-offs; however, it is simple to show that the same logic applies for mergers except in reverse.
} 
its book value. Their analysis shows that merged firms have lower uncertainty about mean profitability and therefore under the learning model a diversification discount is proved.

There is also a range of theoretical research to support a diversification premium. Lewellen (1971) suggests that there are financial synergies associated with mergers when the target and acquirer have low correlated cash flows. Leland (2007) expands on this by using a simple two-period model to investigate the optimal firm structure. His setup follows a firm with two projects that can either incorporate the projects into separate firms and leverage each firm accordingly, or merge the projects into one firm and leverage the merged firm. Under the base case, with identical projects, the financial synergies of merging are limited and diminish as cash flow correlation increases. Outside of the base case, financial synergies are negative when the projects have vastly different volatility. The two-project approach is similar to the one presented in this thesis; however, instead of focusing on leverage, the application at the end of this section looks at the optimal allocation of existing cash reserves. A two period, two investment, merge or spin-off model is also explored in Inderst and Müller (2003) where they find that merging is optimal when homogeneous projects have low expected returns.

In support of the theoretical discount is Lang and Stulz (1993). They show that diversified firms have lower values of Tobin's $q$, a proxy for value and investment opportunities, than comparable standalone firms. Empirical data is also used by Berger and Ofek (1995) to show an average diversification discount of $13-15 \%$ for firms within the Compustat database. This discount is greatly reduced for firms where diversification occurs across the same industry. A similar magnitude discount is found by Lins and Servaes (1999) in Japan and the United Kingdom; however, no such discount is found in Germany.

Recent empirical studies have also challenged the idea of diversification discounts. A lot of the discount implying literature focuses on firms during the late 1980s to the early 1990s. In contrast, Mazur and Zhang (2015) use empirical data ranging 
from 1976 to 2013 and show that the discount diminishes after 1990. They reason that increases in the efficiency of capital allocation in recent times has led to a better management of diversified firms and thus a lower discount. Graham et al. (2002) show that the excess value of an acquiring firm declines after merging with another firm. However, they attribute this to the fact that firms within their sample acquire already discounted firms and not to value destroying diversification.

Using a different approach to challenge the discount, Villalonga (2004) and Custodio (2014) show that measurement errors associated with Tobin's $q$ can overestimate the difference between merged firms and comparable spin-offs. The former uses the Business Information Tracking Series to develop a data-set that is not limited by relaxed reporting rules and therefore covers the full range of diversified firms. Measurement under this new data-set suggests that instead of a discount there is in fact a premium associated with combining single segment firms. While the latter shows that due to purchase accounting, where merged assets are reported at their inflated transaction value instead of book value, the $q$ of consolidated firms is significantly understated. Whited (2001) and Çolak and Whited (2007) also address the problem of measurement error by using the error consistent estimators of Erickson and Whited (2002). Both studies find no evidence of inefficient allocation of investment and subsequently no diversification discount associated with either merged firms or single investment spin-offs.

One explanation of a merged firm premium is the existence of a valuable internal capital market. An internal capital market can create value by reallocating resources across divisions. Billett and Mauer (2003) show that the use of efficient subsidies between different firm segments can increase excess firm value. However, firm value is only increased when the subsidy shifts resources to a financially constrained segment. Efficient subsidies to unconstrained segments do not increase excess firm value. This suggests that the main value of an internal capital market is its ability to shift money and facilitate investment in projects that otherwise would be unable to be undertaken.

Stein (1995) looks at internal capital markets through a model where investment 
opportunities can either have a "good" or "bad" state. When the firm has multiple investment opportunities they will engage in winner picking by shifting funds to the

opportunity in the good state. The internal capital market provides more resources to the good investment and therefore capitalises on it being in the good state. A caveat with winner picking is loser sticking where a bad performing division has funds moved away from it and is therefore stuck with low resources. The loser division would be better off if it was spun-off and operated on its own.

It should be clear now that there is a range of opposing views within academic circles. The following section uses the model of Chapter 2 to describe two situations where both diversification discounts and premiums are plausible. From here, given that in some states a spin-off will be preferred, the optimal allocation of resources between spun off firms is explored.

\subsubsection{Spin-Offs}

The firm with two unlaunched projects in Section 2.4 had a single consolidated pool of cash which it could draw upon to invest. Under this scenario, the cash surplus/deficit is essentially shared by both projects. The remainder of this section will investigate the costs and benefits associated with spinning-off a multi-project firm into separate entities. This is followed by a look at how the existing cash balance should be allocated between the separate firms in a spin-off situation.

Imagine that the firm described in Section 2.4 chooses to split apart such that the two projects are now maintained as separate entities. In order to keep the initial analysis simple, assets are split equally. Therefore, firm A, with the rights to project A, has cash of $X_{A}=0.5 X$ and assets in place of $G_{A}=0.5 G$ while firm B, with the rights to project $\mathrm{B}$, has cash of $X_{B}=0.5 X$ and assets in place of $G_{B}=0.5 G$. As such, the cash balance of firm A will evolve according to the following process,

$$
d X_{A}=r X_{A} d t+0.5 \nu d t+0.5 \phi d \zeta
$$


while the cash balance of firm B will evolve according to the following process,

$$
d X_{B}=r X_{B} d t+0.5 \nu d t+0.5 \phi d \zeta
$$

The option value for both firm A and firm B can be solved in the same manner as shown in Section 2.2 in the standard single-project case with the appropriate parameters substituted. Let $F_{S A}(X, A)$ be the option value for firm $\mathrm{A}$ and $F_{S B}(X, B)$ the option value for firm $B$ where the subscript denotes each firm is a spin-off. ${ }^{15}$ The value of the combined (merged) firm will equal

$$
X+G+F(X, A, B)
$$

The value of the spun-off firm with Project A will equal

$$
0.5 X+0.5 G+F_{S A}\left(X_{A}, A\right)
$$

and the value of the spun-off firm with project $B$ will equal

$$
0.5 X+0.5 G+F_{S B}\left(X_{B}, B\right) .
$$

Therefore it will be optimal to split and the run projects in separate firms when

$$
F(X, A, B)<F_{S A}\left(X_{A}, A\right)+F_{S B}\left(X_{B}, B\right) .
$$

Initial intuition would suggest that, in the absence of agency problems, the merged firm will always be more valuable than the split firm. This intuition stems from the idea that the merged firm can make any investment decision a split firm is able to make while also having increased flexibility due to a larger cash balance. A simple nowor-never numerical example illustrates the added value a merged firm can provide.

\footnotetext{
${ }^{15}$ The value of firm $\mathrm{B}$ does not depend on the value of project $\mathrm{A}$ as it has no control over this project once the spin-off occurs. It will not pay the cost of investment when project A is initiated and also will not receive the cash generated by project A post-investment. The same logic applies where the value of firm A does not depend on the value of project B.
} 
Consider that firm A has a cash balance of $X_{A}=40$, assets in place of $G_{A}=0$ and an investment worth $V_{A}=200$ with a cost of $I_{A}=100$ that must either be launched or left to expire. In a world with no investment frictions, the firm is able to invest and receives a payoff of $V_{A}-I_{A}=100$. However, consider that the information asymmetry discount is $\gamma_{A}=0.5$ and the control discount is $\theta_{A}=0.5$. The firm is now only able to borrow $\gamma_{A} \theta_{A} V_{A}=50$ and as such is unable to invest. The value of the firm under this scenario is 40 as it must let the option expire. If firm A was able to merge with an identical firm $\mathrm{B}$, then the merged firm would have cash of $X=80$, assets in place of $G=0$ and two investment opportunities worth $V_{A}=V_{B}=200$ and investment $\operatorname{costs} I_{A}=I_{B}=100$. Although the merged firm can not invest in both projects it can launch one of them. As such the value of the merged firm is 180 which is considerably larger than the sum of the separate firms of 80 .

The above example provides a straightforward look at how merging can increase value by relaxing the investment constraints. However, it is important to understand that in some cases merging can also destroy value. Another simple example can help to explain the situation. Consider the case where one of the projects is "Good" and the other "Bad". If the merged firm has a relatively low level of cash then it can find itself close to the liquidation region. If liquidated it will be forced to give up the rights to the "Good" project even though it knows it is good and thus wants to keep it. However, by spinning-off the projects into separate firms, the value of the "Good" project can be preserved. Refer to Figure 3.8 for a further intuitive explanation. This figure plots the liquidation constraints for both the merged and split firms for an arbitrary cash balance. The merged graph indicates a point where although the firm is liquid, it is close to the liquidation region and therefore there is a chance it will lose the ability to undertake the profitable project. ${ }^{16}$ The split firm graph shows that by spinning off the projects, the firm with the "Good" project is much further from the liquidation constraint. In contrast, the firm with the "Bad" project is forced into liquidation due to the projects low value. The effect of moving further from the liquidation region for the "Good" project outweighs the cost of losing the ability to

\footnotetext{
${ }^{16}$ The "Good" project value is on the $\mathrm{x}$-axis and the "Bad" project on the $\mathrm{y}$-axis.
} 

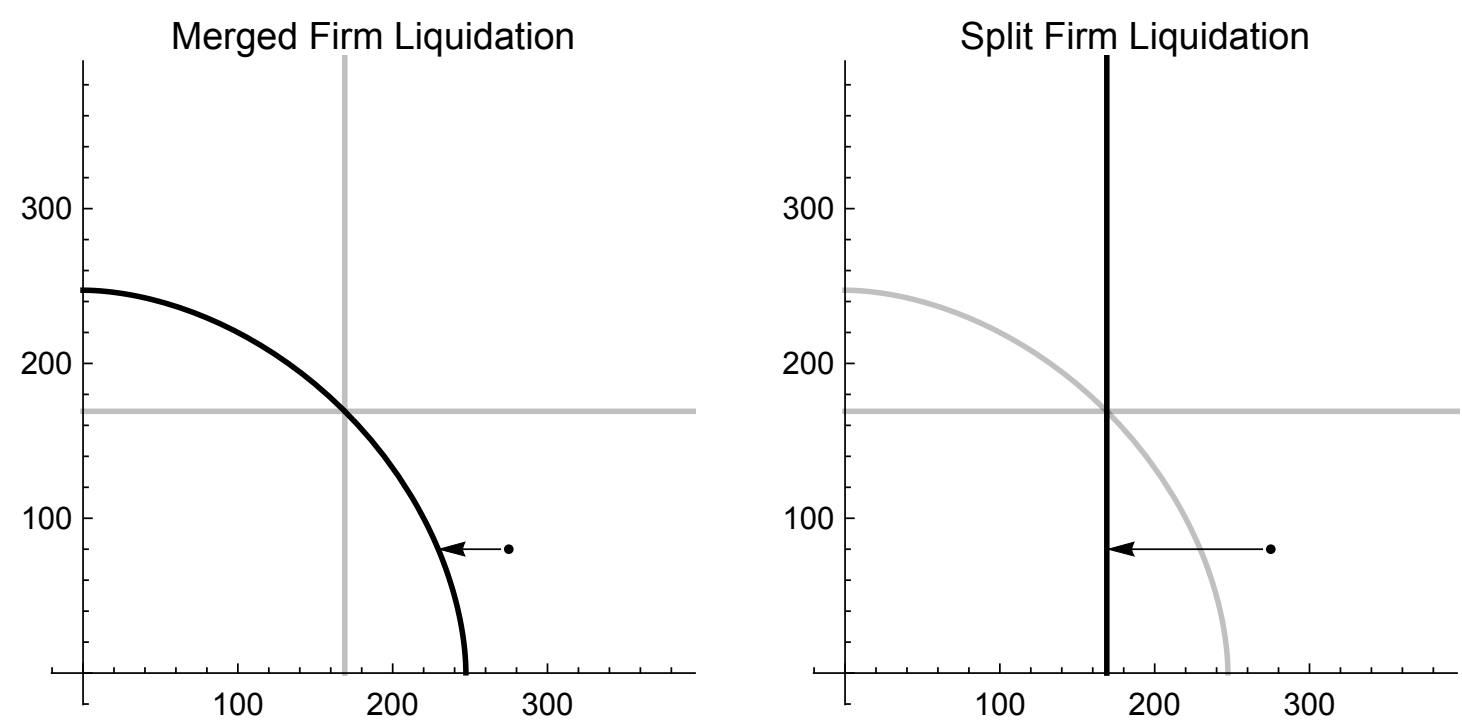

Figure 3.8: This figure plots the liquidation constraints for both the merged and split firms for an arbitrary cash balance. Each axis plots the value of one of the projects. The curve on each graph is the liquidation constraint for the merged firm. The vertical line on each graph is the liquidation constraint for the project on the x-axis ("Good" project) and the horizontal line is the liquidation constraint for the project on the y-axis ("Bad" project). The graphs show that spinning off into separate firms can make it less likely that a "Good" project is lost in liquidation of the merged firm.

do the "Bad" one. This occurs as it is unlikely that the "Bad" project would be completed in the near future due to its low NPV.

These two basic examples have shown that the decision to spin-off will largely be influenced by the state. In some cases a spin-off is preferable while in others a combined firm is optimal. It is easy to see why there is no general consensus in the literature. The above examples only provide a basic insight into the problem as it is assumed that each spin-off will receive exactly half of the cash and assets in place of the merged firm. In reality, a larger proportion of the resources should be allocated to the division with the highest marginal value of cash.

In order to fully explore the cash allocation and spin-off decision it would be beneficial to endogenise the spin-off decision when solving the model. However, this is a non-trivial task and is beyond the scope of this thesis. The model can however provide an insight into which of the spin-offs should receive the larger portion of resources. In Section 3.3.3 the marginal value of cash was discussed in regards to the merged firm with both projects. When the cash is split evenly between firms A and 
$\mathrm{B}$ it is likely that the cumulative firm value could be increased by shifting some cash from one firm to the other. A simple way to understand which firm should receive more cash can be found via the marginal value of cash. The marginal value of cash to firm A will be equal to

$$
\frac{\partial}{\partial X_{A}}\left(X_{A}+G_{A}+F_{S A}\left(X_{A}, A\right)\right)=1+\frac{\partial F_{S A}}{\partial X_{A}}
$$

and the marginal value of cash to firm B will equal

$$
\frac{\partial}{\partial X_{B}}\left(X_{B}+G_{B}+F_{S B}\left(X_{B}, B\right)\right)=1+\frac{\partial F_{S B}}{\partial X_{B}}
$$

Therefore the change in cumulative value when moving $\$ 1$ of cash from firm A to firm $\mathrm{B}$ is

$$
-1-\frac{\partial F_{S A}}{\partial X_{A}}+1+\frac{\partial F_{S B}}{\partial X_{B}}
$$

and as such it is optimal to allocate more cash to firm B in a spin-off situation when

$$
\frac{\partial F_{S B}}{\partial X_{B}}>\frac{\partial F_{S A}}{\partial X_{A}}
$$

Therefore, the firm that has the higher marginal value of cash for a given state should be allocated more cash than the other in a spin-off situation. Refer to Figure 3.9 , generated using the symmetric parameters of Table 2.3, which plots the difference in $\frac{\partial F_{S A}}{\partial X_{A}}$ and $\frac{\partial F_{S B}}{\partial X_{B}}$ and therefore the states where it is locally optimal to allocate the majority of cash to either firm A or B. The white region on each graph represents states where the marginal cash values for each firm are equal and thus an even split of the firm resources is locally optimal. The black regions show states where the marginal value of cash for firm $\mathrm{A}$ is higher and therefore in a spin-off more cash should be allocated to firm A than firm B. In contrast the grey regions show states where firm B should receive more cash in a spin-off than firm A.

It is worth noting that the graphs do not show how much value can be gained by moving from an even split. Instead, they show which firm should receive the majority 

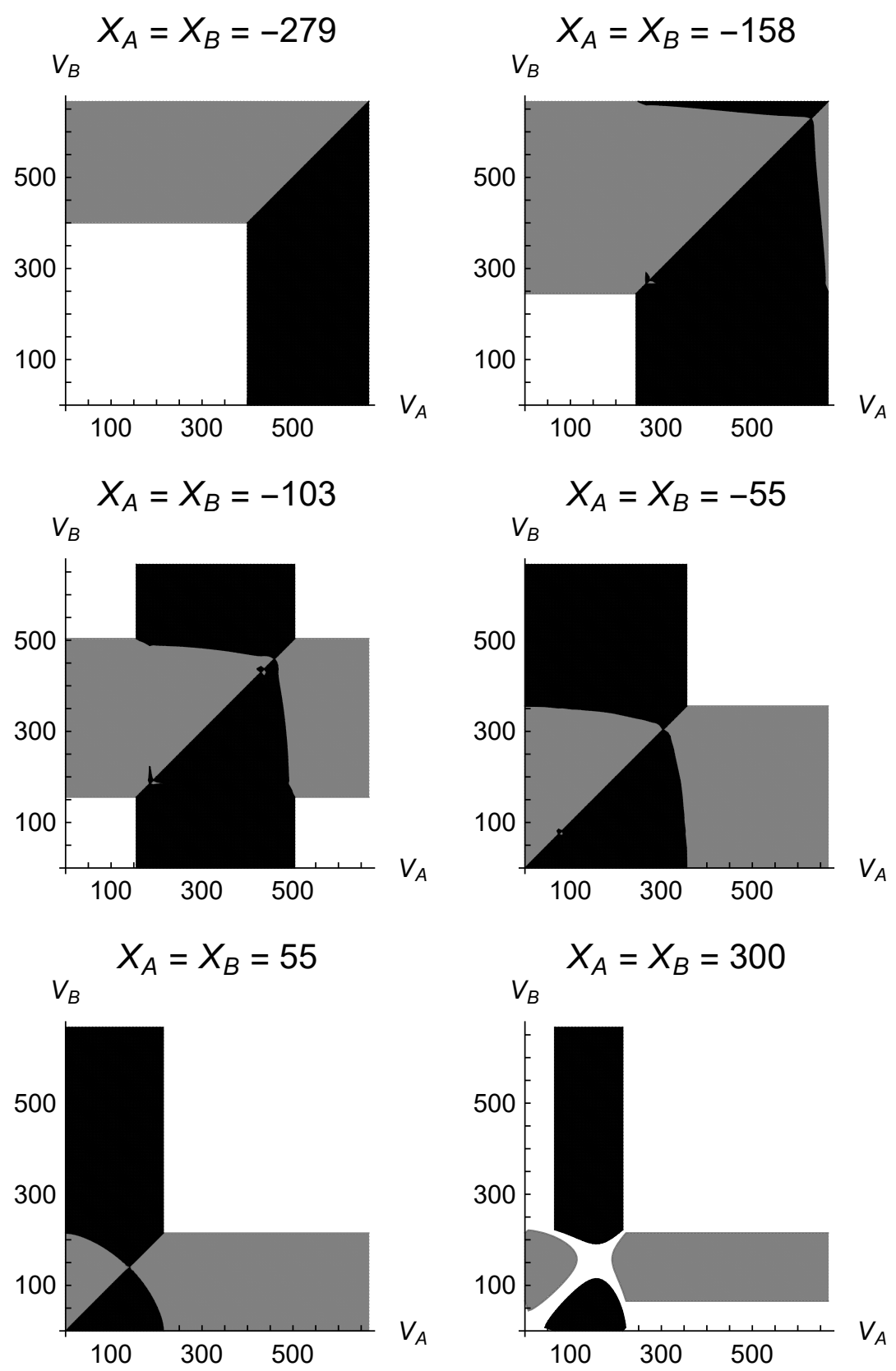

Figure 3.9: This figure shows the difference in the marginal value of cash for firm A and firm B under the symmetric parameters shown in Table 2.3 when the resources of the merged firm are split evenly. The black region shows states where the value of cash is higher in firm A than firm B and therefore where it is locally optimal for firm A to receive the larger proportion of resources in a spin-off. The grey region shows states where the value of cash is higher in firm B than firm A and therefore where it is locally optimal for firm B to receive the larger proportion of resources in a spin-off. The white regions show states where the marginal value of cash for each firm is equal and an even resource split is optimal.

proportion of assets when a split occurs. However, simple intuition shows that the value gained by reallocating cash will be largest when the cash balance is moderate. 
If cash is low, then both firms are unlikely to be able to invest regardless of the cash allocation. If cash is high, then both firms are likely to be able to invest regardless and therefore the penalty for an incorrect allocation is small. When cash is moderate, in general the firms will be close to the investment threshold and as such a misallocation of cash can prevent otherwise valuable investment opportunities occurring.

When $X_{A}=X_{B}=-279$ and both $V_{A}$ and $V_{B}$ are low, the split firms are both liquidated and therefore there is no value to be added by changing the cash split. ${ }^{17}$ Here the white region depicts states where both firms are forced to liquidate. If $V_{A}$ is high and $V_{B}$ low, then firm A should receive a larger proportion of cash as this extra cash helps to prevent it from being forced into liquidation in the future. The reduction in cash for firm $\mathrm{B}$ has little effect as it has rights to a project that is not very valuable and therefore unlikely to be launched anyway. ${ }^{18}$ The reverse is true when $V_{B}$ is high and $V_{A}$ low as more cash should be allocated to firm B, thus allowing the good project a better chance of being launched in the future. When both projects have large NPVs and neither will be liquidated in an even split (the top right hand corner) then it is optimal to provide a larger proportion of resources to the firm with the higher NPV project. This is shown where the grey and black regions meet each other along a 45-degree line from the origin. Providing more resources to the better project increases the likelihood of it being launched in the future.

Much of the same general behaviour is shown as $X_{A}$ and $X_{B}$ increase to -158 . The increase in available resources leads to a decrease in the white region where both firms are forced to liquidate. Interestingly, now when both projects are highly valuable, in the top right hand corner, there is a switch in the optimal cash allocation. Consider the case where both $V_{A}$ and $V_{B}$ are very large and $V_{A}$ is larger then $V_{B}$. When cash was equal to -279 , in this region it would be optimal to allocate the larger proportion of the merged firms resources to firm A in a spin-off. However, when cash is equal to -158 , instead, it is now optimal to allocate the larger proportion to firm

\footnotetext{
${ }^{17}$ As each firm has a negative cash balance, increasing the proportion of resources for one firm is the same as reducing the level of negative cash i.e. debt that it holds whilst increasing the level of debt for the other firm.

${ }^{18}$ In fact, without further resources firm $\mathrm{B}$ will be forced to liquidate.
} 
B. The switch occurs because when $X=-279$, cash was low enough that the firm with the better project receives more cash in order to increase the chance that this better project can be launched in the future. As cash for each firm increases to -158 , the total resources to be allocated are sufficient that the better project is likely to be launched in the future even without access to the larger proportion of resources. Therefore cash is allocated to the firm with the slightly worse project in order to increase the chance of it being launched in the future.

Further increasing $X_{A}$ and $X_{B}$ to -103 maintains the behaviour described above in the regions where $V_{A}$ and $V_{B}$ are around 500 or less. When either project has a value around 500 or greater the respective firm is able to invest in the project it holds. In the top left corner when firm B can invest and firm $\mathrm{A}$ is liquidated there is no value to be gained by moving from an even split. As firm B is already able to invest and has a highly valuable project, the marginal value of cash is low as investment is likely to occur regardless of additional resources. The opposite applies in the bottom right corner where firm B is liquidated and firm A able to invest. In the top right corner both firms are able to invest and both projects are highly valuable so there is no value to be gained by altering the even split.

When $X_{A}$ and $X_{B}$ are both further increased to -55 , neither firm A nor firm B are forced into liquidation for any value of $V_{A}$ or $V_{B}$ respectively. This means there are no longer any white regions where, due to either one or both firms being liquidated, there is no value to be created by changing from an even resource split. There still exists the white region where both firms are able to invest for the same reasons as above. It is straightforward to see that the graph shows the same behaviour as when $X_{A}=X_{B}=-103$ and $V_{A}$ and $V_{B}$ were greater than 150 . The same inwards shift of the regions occurs when moving from $X_{A}=X_{B}=-55$ to $X_{A}=X_{B}=55$. The top right white region has expanded as each firm is able to invest for lower levels of $V_{A}$ and $V_{B}$. In fact, when each firm has a cash balance of 55 , it is able to invest for any levels of its respective project as its also has assets in place of 50. Therefore when one of the projects is high and the other low the low project firm should receive the larger proportion of resources as the firm with the high project does not value them 
as much. When both projects are low, instead the firm with the higher value project should receive the larger proportion. This is because when both project values are low the firms delay investment as the payoff, $V_{A}-I_{A}$ for firm $\mathrm{A}$ and $V_{B}-I_{B}$ for firm $B$, are relatively low. Therefore, the more valuable project receives more cash in order to avoid losing the opportunity to invest in the future should the payoff be higher.

When the cash stock is large enough that each firm can invest no matter which state they find themselves in, further increases in cash will be worth less and less. Therefore the value to be gained by altering the even split in a spin-off decreases with cash. This can be seen when $X_{A}=X_{B}=300$ where the cash held by each firm is so large that in most states there is no benefit to an asymmetric split of resources. Eventually, when cash is of such a level that each firm is effectively unconstrained there will be no states where it is beneficial to alter the split.

\subsubsection{Summary}

This section began by contextualizing the two sides of the merger/spin-off literature. One side states that a merged firm is more valuable than the cumulative value of similar single segment firms, whilst the other states that spinning off a diversified firm into multiple segments will lead to an increase in cumulative value. After establishing the driving factors for each argument, two simple examples are provided in order to show that both sides can be correct and that the optimal strategy is largely dependent on the state in which the firm finds itself.

Following these examples the spin-off decision is further investigated in the context of the resource split between firms. Once again the identity of the firm that should receive the largest proportion of resources is going to be heavily dependent on the state. That is to say, it is more complex than just providing the firm that owns the larger NPV project with the majority share of resources. This is most easily demonstrated when one of the projects is highly valuable and the other not. In this case when each firm, under an even split, has relatively low cash then it is better 
to shift the majority of resources to the firm with the better project. As a result, investment in the better project is more likely to occur in the future and thus the firm avoids missing out. However, if each firm instead had a high level of cash then the majority of resources should go the firm with the lower NPV project. Now that cash is higher, the risk of losing the opportunity to complete the good project is reduced, and as such it is outweighed by the benefit of increasing (decreasing) the likelihood of investment (forced liquidation) in the bad project. 


\section{Chapter 4}

\section{Numerical Methods}

\subsection{Overview}

The analysis presented in the preceding chapters provides various insights into how a constrained firm's investment policy can be influenced by an additional project. In Chapter 2 the underlying model was introduced and the optimal investment policy under symmetric projects discussed. Chapter 3 examined the implications of the model in much more detail. First, the optimal investment policy under asymmetric projects where one of the projects is either a fast-payback or high-pledgeability project is explored. Second, the model is used to look at the value of cash regarding both the trade-off between spending cash now and earning cash in the future, as well as the marginal value of an additional dollar today. Third, the merge/spin-off decision for a firm with symmetric projects is discussed and the firm that should receive the majority of cash identified. What might not be apparent in Chapters 2 and 3 is that the analysis involved solving complicated high-dimensional systems of partial differential equations with free boundaries. The complexity of the problem meant that standard finite difference methods would not have been fast enough for systematic analysis to be feasible. For example, the final analysis used numerical grids with $91^{3}=753,571$ grid points, and involved interrelated systems of equations with five

dependent variables. Therefore, the analysis in those chapters required the use of 


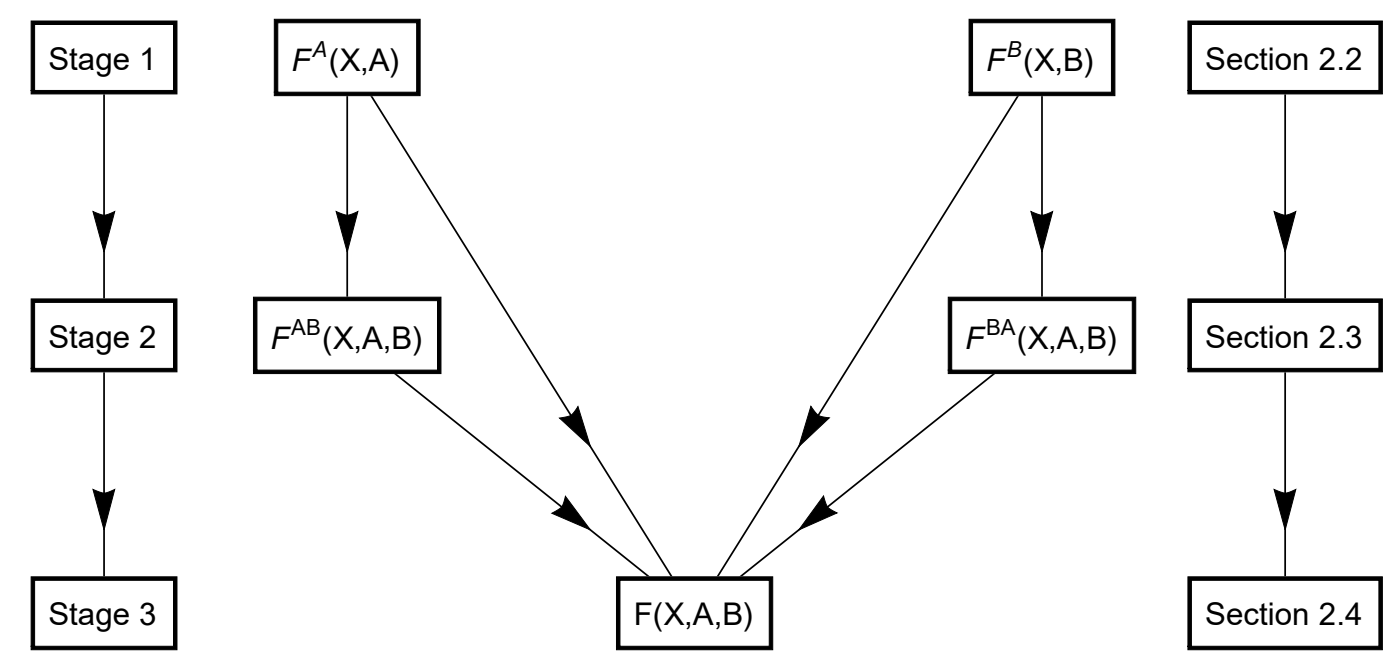

Figure 4.1: This figure details the steps required to solve the underlying model. Firstly, the singleproject option pricing model of Section 2.2 is solved for both projects. Secondly, the resulting solutions are used as inputs in order to solve the two-project model of Section 2.3 where one of the projects has been initiated. Lastly, the results from solving the option pricing models of Sections 2.2 and 2.3 are used as inputs in the solution procedure for the two-project model where neither has been launched of Section 2.4.

sophistical numerical methods. This chapter presents a high-level description of the numerical challenges and the main modifications used in this thesis to overcome these challenges. Further details on the solution procedure can be found in the appendix.

\subsection{The Solution Algorithm}

The underlying model where the firm has access to two projects, neither of which has been launched, as described in Section 2.4 requires solutions to the options discussed in Sections 2.2 and 2.3. This is because the model must be solved backwards in "project-time". ${ }^{1}$ In order to know whether or not investing in project A and delaying project $\mathrm{B}$ is optimal, the firm needs to know how the value of the option to invest in B changes when A is launched. Subsequently, in order to solve for the value of the option to do B when A is launched, the value of the option when only A is available is required. Refer to Figure 4.1 for a description of the solution stages. The first step

\footnotetext{
${ }^{1}$ Project-time refers to the order in which projects are launched as the explicit timing of each project is irrelevant.
} 
is to solve the single-project case of Section 2.2 for each project A and B. Once completed, the option values, $F^{A}(X, A)$ and $F^{B}(X, B)$, are then used within the solution procedure to solve the two-project model where one of the projects has been launched from Section 2.3 for both variations. That is, the option value to invest in A when $\mathrm{B}$ has been launched and the option value to invest in B when A has been launched. The last step is to use the option values $F^{A}(X, A), F^{B}(X, B), F^{A B}(X, A, B)$ and $F^{B A}(X, A, B)$ in the solution procedure to solve the value of the option when the firm has two investment opportunities that are both yet to be initiated.

During the solution algorithm, $F^{A B}(X, A, B)$ and $F^{B A}(X, A, B)$ are needed to calculate $F(X, A, B)$ as they are included in the investment payoffs. When investing in $\mathrm{A}$ and delaying $\mathrm{B}$ the payoff is

$$
V_{A}-I_{A}+F^{B A}\left(X-I_{A}, A, B\right)
$$

and the payoff to investing in $\mathrm{B}$ and delaying $\mathrm{A}$ is

$$
V_{B}-I_{B}+F^{A B}\left(X-I_{B}, A, B\right)
$$

In addition, $F(X, A)$ and $F(X, B)$ are required to calculate $F^{A B}(X, A, B)$ and $F^{B A}(X, A, B)$ respectively as they are used within the following boundary conditions

$$
\begin{aligned}
& F(X, A, 0)=F^{A}(X, A), \\
& F(X, 0, B)=F^{B}(X, B) .
\end{aligned}
$$

\subsection{Transformation of Coordinates}

As detailed above, the procedure for solving the underlying model requires solving five separate and distinct option values each with their own associated partial differential equation. These equations are each solved on a 3 -dimensional grid in $X, A, B$ space. $^{2}$ A grid with an equal amount of grid points, with equal spacing, in each

\footnotetext{
${ }^{2}$ In the single-project case the model is solved in $(X, A)$ or $(X, B)$ space. The non-linear transformation described below is still applied here.
} 
dimension therefore increases as the cube of the length. In order to have sufficiently high resolution solutions for inference, the grid size must be as large as possible. In addition, the value of the state variables at the grid limit must be large enough so as to not influence the behaviour inside the boundaries. In particular, the lower limit for $X$ needs to be within or close to the forced liquidation region. The upper limit for $X$ needs to be sufficiently high that the firm is approximately unconstrained. In addition, the lower limits for $A$ and $B$ are set at 0 . The upper limits for $A$ and $B$ will also need to be sufficiently high so as to make the firm approximately unconstrained.

As such, solving the model is computationally intensive and requires limits to be placed on the grid size in the interest of feasibility. In order to reduce the impact of the grid size on resolution, a transformation of coordinates in the $X$ direction was undertaken. This transformation clusters grid points in the middle of the $X$ region and therefore increases resolution within the interesting regions whilst ensuring the boundaries are sufficiently far away.

\subsubsection{New Partial Differential Equations}

The transformation requires the derivation of a new partial differential equation for each of the five options outlined above. Consider the single-project case of Section 2.2. Prior to investment the option value will satisfy

$$
\frac{1}{2} \sigma_{A}^{2} A^{2} F_{A A}+\rho_{X A} \sigma_{A} \phi A F_{X A}+\frac{1}{2} \phi^{2} F_{X X}+\left(r-\delta_{A}\right) A F_{A}+r(X+G) F_{X}-r F=0
$$

where subscripts on $F$ denote partial derivatives. In this case the solution to the option value prior to investment, $F(X, A)$, is a function of both $X$ and $A$. Any transformations on $X$ will lead to new coefficients and subsequently a new equation, which can be derived as follows. Let $F(X, A)=S(h(X), A)$ for some strictly increasing function $h$. The new independent, transformed variable will be $Z=h(X)$ and $S$ will be the solution for the option value when it is written as a function of $Z$ instead of $X$. Now that $F$ is effectively a function of $Z$, the next step is to calculate the derivatives 
of $F$ as functions of $Z$. The first order derivative of $F$ with respect to $X$ will be

$$
F_{X}(X, A)=S_{Z}(h(X), A) h_{X}(X)
$$

where subscripts on $F, S$ and $h$ denote derivatives. If $m$ is the inverse function of $h$ such that $m(h(X))=X$ for all $X$, then differentiating with respect to $X$ shows that

$$
m_{Z}(h(X)) h_{X}(X)=1
$$

and therefore

$$
h_{X}(X)=\frac{1}{m_{Z}(h(X))}
$$

where subscripts on $m$ denote derivatives. Substituting this expression back into $F_{X}(X, A)$ shows that

$$
F_{X}(X, A)=S_{Z}(h(X), A) \frac{1}{m_{Z}(h(X))}=S_{Z}(Z, A) \frac{1}{m_{Z}(Z)} .
$$

Applying this same process to the remaining $F$ derivatives, substituting into Equation (4.4) and rearranging, results in the following transformed PDE that is satisfied prior to investment,

$$
\begin{gathered}
\frac{1}{2} \sigma_{A}^{2} A^{2} S_{A A}+\frac{\rho_{X A} \sigma_{A} \phi A}{m_{Z}(Z)} S_{Z A}+\frac{\phi^{2}}{2 m_{Z}(Z)^{2}} S_{Z Z}+\left(r-\delta_{A}\right) A S_{A} \\
+\left(\frac{r(S+m(Z))}{m_{Z}(Z)}-\frac{\phi^{2} m_{Z Z}(Z)}{2 m_{Z}(Z)^{3}}\right) S_{Z}-r S=0 .
\end{gathered}
$$

The single-project case where the firm has access to project B will have the same equation where each $\mathrm{A}$ is swapped with $\mathrm{B}$.

Prior to investment, the option value to invest in $\mathrm{B}$ when project $\mathrm{A}$ has been 
launched will satisfy the following transformed PDE

$$
\begin{gathered}
\frac{1}{2} \sigma_{A}^{2} A^{2} S_{A A}^{B A}+\frac{1}{2} \sigma_{B}^{2} B^{2} S_{B B}^{B A}+\left(r-\delta_{A}\right) A S_{A}^{B A}+\left(r-\delta_{B}\right) B S_{B}^{B A} \\
+\frac{1}{2 m_{Z}(Z)^{3}}\left(2(B+r(S+m(Z))) m_{Z}(Z)^{2}-\phi^{2} M_{Z Z}(Z)\right)+\frac{\phi^{2}}{2 m_{Z}(Z)^{2}} \\
+\rho_{A B} \sigma_{A} \sigma_{B} A B S_{A B}^{B A}+\frac{B \rho_{X B} \sigma_{B} \phi}{m_{Z}(Z)} S_{X B}^{B A}+\frac{A \rho_{X A} \sigma_{A} \phi}{m_{Z}(Z)} S_{X A}^{B A}-r S^{B A}=0
\end{gathered}
$$

where subscripts on $S$ and $m$ denote partial derivatives and $S^{B A}$ is the value of the option to invest in project $\mathrm{B}$ given that project $\mathrm{A}$ has been launched. The option value to invest in A given that B has been launched will have the same form where each $\mathrm{A}$ is replaced with a $\mathrm{B}$ and vice versa.

The same logic and transformation process can be applied to the two-project model where neither project has been initiated. In this case the investment option prior to investment will satisfy the following transformed PDE

$$
\begin{gathered}
\frac{1}{2} \sigma_{A}^{2} A^{2} S_{A A}+\frac{1}{2} \sigma_{B}^{2} B^{2} S_{B B}+\left(r-\delta_{A}\right) A S_{A}+\left(r-\delta_{B}\right) B S_{B} \\
+\frac{2 r(S+m(Z)) m_{Z}(Z)^{2}-\phi^{2} m_{Z Z}(Z)}{2 m_{Z}(Z)^{3}} S_{Z}+\frac{\phi^{2}}{2 m_{Z}(Z)^{2}} S_{Z Z} \\
+A B \rho_{A B} \sigma_{A} \sigma_{B} S_{A B}+\frac{B \rho_{X B} \sigma_{B} \phi}{m_{Z}(Z)} S_{X B}+\frac{A \rho_{X A} \sigma_{A} \phi}{m_{Z}(Z)} S_{X A}-r S=0
\end{gathered}
$$

where subscripts on $S$ denote partial derivatives.

It is worth noting that within the solution procedure constraints and boundaries are now functions of $Z$ and not $X$. For example in order to invest in project $\mathrm{A}$ in the single-project case it must be such that

$$
I_{A} \leq m(Z)+G+\gamma_{A} \theta_{A} V_{A} .
$$




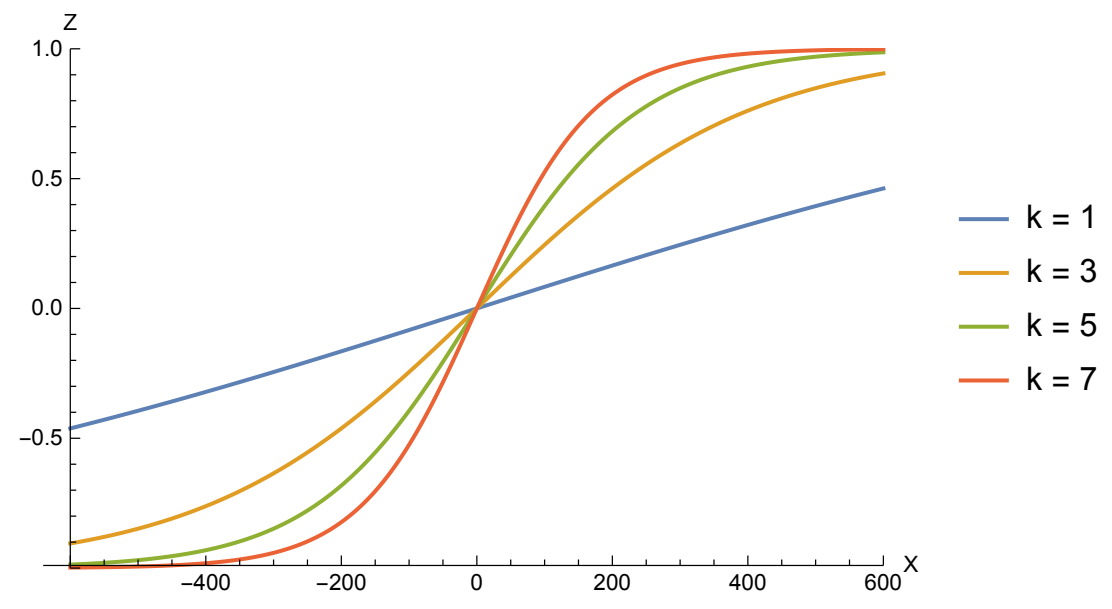

Figure 4.2: This figure shows the functional form of the transformation applied to the cash variable for a variety of concentration parameters. When $k=1$, the transformation is approximately linear and there is no clustering of grid-points. However, as $k$ increases above 1 the grid-points will begin to cluster towards the middle of the $X$ range.

\subsubsection{Functional Form}

The specific transformation used on the cash variable $X$ is as follows,

$$
Z_{i}=\tanh \left(k\left(\frac{X_{i}-X_{\min }}{X_{\max }-X_{\min }}-0.5\right)\right)
$$

where $Z_{i}$ is the transformed variable at grid-point $i, X_{i}$ is the level of cash at grid point $i, X_{\min }$ the value of cash at the lower boundary, $X_{\max }$ the value of cash at the upper boundary and $k$ a parameter that determines the level of concentration within the grid points. Figure 4.2 shows the transformation for various levels of $k$. When $k=1$, the function is approximately linear and the grid points are evenly spaced in both the $X$ and $Z$ ranges. As $k$ increases above 1, the level of concentration increases and evenly spaced grid points in $Z$ space will lead to grid points that are clustered within the middle of the $X$ range.

Refer to Figure 4.3 for an example of how changes in the level of $k$ change the make-up of the grid. In this figure, the solved option value for the single-project case of Section 2.2 is shown for multiple levels of $k$. The parameters used are the same as in the baseline case and there are 21 grid-points in each direction. ${ }^{3}$ As stated above,

\footnotetext{
${ }^{3}$ In this case 21 grid points are used in order to illustrate how the grid changes with $k$. In practice, when solving the model for inference, 91 grid points are used in each direction.
} 

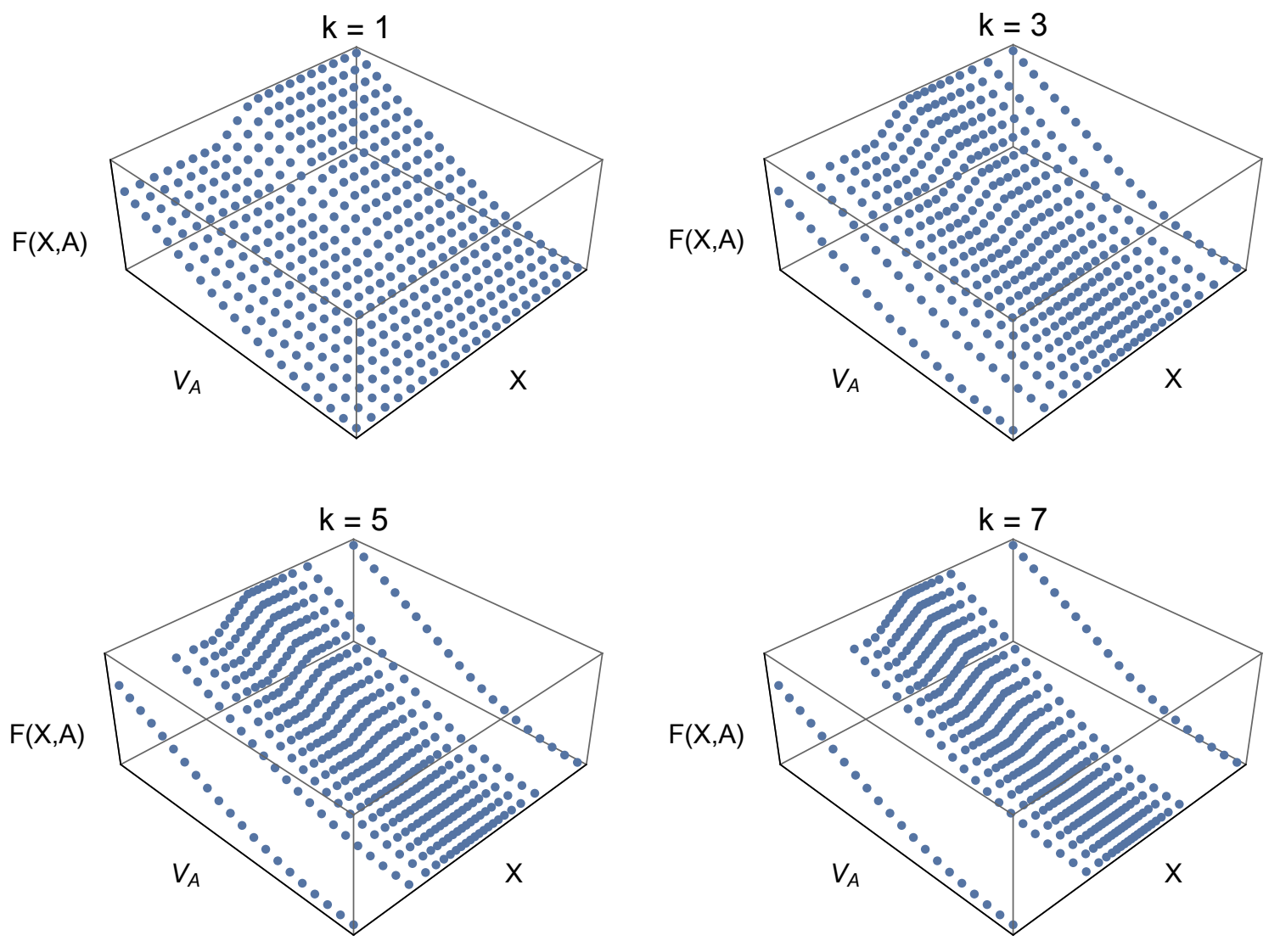

Figure 4.3: This figure shows the option value of the single-project model of Section 2.2 under the symmetric parameters of Table 2.3 for a variety of concentration parameters. When $k=1$, the grid points are even spaced in all directions. As $k$ increases the grid points become more and more clustered towards the middle of the $X$ range. The points are highly clustered when $k=7$.

when $k=1$ the grid points are evenly spaced in all directions. As $k$ increases to 3 , there is a moderate change in the number of grid points within the middle of the graph. When $k$ increases further to 5 , there is a clear gap between the $X_{\min } / X_{\max }$ option values and the inner points. This is further exacerbated when $k=7$ and suggests that for levels of $k$ above 5 the behaviour within the middle of the grid will be heavily influenced by the imposed boundary conditions. As such for all analysis completed within this thesis a value of $k=3.5$ was used as it provides a high level of resolution within the interesting regions, whilst preventing the associated interesting behaviour from being tainted by the boundaries. 


\section{Chapter 5}

\section{Concluding Remarks}

It is a well-known fact that financing constraints restrict the investment decisions available and can therefore lead to a suboptimal investment policy when compared with firms that do not face such constraints. Boyle and Guthrie (2003) use an endogenous liquidity constraint to show that the constrained firm will either invest earlier or later than the unconstrained firm depending on the constrained firm's cash balance. Early investment occurs when the risk of future funding shortfalls (and therefore losing the ability to invest) outweighs the benefits of waiting. Delayed investment occurs when the firm does not have sufficient resources to invest and is forced to wait until such a time that it does. The addition of a second investment opportunity to the model of Boyle and Guthrie (2003) allows the model to explore not only the constrained investment timing decision, but also provides insights into how the choice between multiple projects is made. The principal conclusions outlined within this thesis are as follows:

1. Due to information asymmetry, assets in place can only sell at a discount. Therefore, the constrained firm with insufficient resources to invest will resist selling existing assets to fund investment and as such will willingly delay investment past the unconstrained optimum.

2. For the constrained firm with access to one project, the introduction of a second project with symmetrical characteristics will raise the threshold required to 
invest in the first project as the firm does not want to invest in one project to find out ex-post that it would rather have invested in the other (or find itself unable to invest in the remaining project in the future although it would like to).

3. A project with a higher implicit dividend yield is able to provide benefits over and above its NPV as the cash it generates can relax future financial constraints. When choosing between projects, these additional benefits can lead the constrained firm to choose a lower NPV project instead of higher NPV alternatives as it can better facilitate future investment.

4. A project that can pledge a high proportion of its value as collateral for borrowing is able to free up cash reserves for remaining projects with lower collateral capacity. This can reduce the threshold for investment in the high pledgeability project relative to if the firm only had access to a single-project.

5. The capital expenditure in a project reduces the cash available for remaining projects and must therefore be weighed against the cash generating benefits of investing. When the constrained firm has either a high implicit yield or high pledgeability project coupled with a similar project without these characteristics, the benefit of cash generated post-investment by these two project types is outweighed by the cost of investing and therefore decreasing the cash balance.

6. The marginal value of cash is greatest when the constrained firm has insufficient resources for investment. This is because more cash can bring the firm closer to investment. If the constrained firm only has one investment opportunity with a low (or negative) NPV then the value of cash is low as investment is unlikely regardless. However, when the firm has access to more than one investment opportunity, the value of cash is high so long as one of the opportunities has at least a moderate value.

7. In a spin-off scenario where projects are run as separate firms, if the total cash balance is low, then it is optimal to shift the majority of resources to the firm with the higher NPV project. This is because this project is most likely to be launched in the future as the firm with the lower NPV project is unlikely to be 
able to invest regardless of the amount of resources it has. In contrast, when the total cash balance is high, then it is optimal to shift the majority of resources to the firm with the lower NPV project. This is because the higher NPV project is likely to be launched regardless, and therefore the resources should be allocated to the firm that requires them for investment.

The analysis in this thesis has been completed by looking at a cash-constrained firm with access to two investment opportunities. It is unlikely that additional investment opportunities would provide material insights into the problem of the constrained firm. However, there are multiple extensions that can be added to the twoproject model to gain further insights into the behaviour of the constrained firm. Perhaps the most interesting area for expansion relates to the role of an internal capital market within a cash-constrained firm. The spin-off decision could first be made endogenous in order to allow the firm to run the projects separately. This is likely to yield further insights regarding when an internal capital market is valuable and when it is not. Further, the cash allocation mechanism in a spin-off situation could be enhanced by introducing self-interested divisional managers. In the presence of asymmetric information, a divisional manager must choose how to represent their divisions prospects to the party that allocates budgets. Understating performance is likely to leave "cash on the table" for other divisions to take, while overstating performance is likely to have consequences of its own. 


\section{Appendix A}

\section{Derivations and Solution}

\section{Procedures}

\section{A.1 Equation Derivations}

\section{A.1.1 Derivation of Equation (2.28)}

It is assumed that the risks inherent in $A, B$ and $X$ are spanned by the market of existing securities. Specifically, suppose that there are traded assets or portfolios with prices $a, b$ and $x$ that evolve according to

$$
\begin{gathered}
d v_{a}=\mu_{a} a d t+\sigma_{a} v d \epsilon_{1} \\
d v_{b}=\mu_{b} b d t+\sigma_{b} v d \epsilon_{2} \\
d x=\mu_{x} x d t+\sigma_{x} v d \zeta
\end{gathered}
$$

Then a long position in the investment option can be combined with a short position of $\sigma_{A} A F_{A} /\left(\sigma_{a} a\right)$ units of asset $a$, a short position of $\sigma_{B} B F_{B} /\left(\sigma_{b} b\right)$ units of asset $b$ and $\phi F_{X} /\left(\sigma_{x} x\right)$ units of asset $x$ to produce a total return $d R$ over the time interval 
$d t$ such that

$$
d R=d F-\left(\frac{\sigma_{A} A F_{A}}{\sigma_{a} a}\right) d a-\left(\frac{\sigma_{B} B F_{B}}{\sigma_{b} b}\right) d b-\left(\frac{\phi F_{X}}{\sigma_{x} x}\right) d x
$$

Using Ito's Lemma to obtain an expression for $d F$, substituting (A.1), (A.2) and (A.3) for $d a, d b$ and $d x$, respectively, and simplifying, $d R$ becomes

$$
\begin{aligned}
d R & =\left(\frac{1}{2} \sigma_{A}^{2} A^{2} F_{A A}+\frac{1}{2} \sigma_{B}^{2} B^{2} F_{B B}+\frac{1}{2} \phi^{2} F_{X X}+\rho_{A B} \sigma_{A} \sigma_{B} A B F_{A B}\right. \\
& +\rho_{X B} \sigma_{B} \phi B F_{X B}+\rho_{X A} \sigma_{A} \phi A F_{X A}+\left(\mu_{A}-\frac{\mu_{a} \sigma_{A}}{\sigma_{a}}\right) A F_{A} \\
& \left.+\left(\mu_{B}-\frac{\mu_{b} \sigma_{B}}{\sigma_{b}}\right) B F_{B}+\left(r X+\nu+A-\frac{\mu_{x} \phi}{\sigma_{x}}\right) F_{X}\right) d t .
\end{aligned}
$$

It is worth noting that the coefficient on $F_{X}$ reflects the fact that project $\mathrm{A}$ is in operation and generating cash flows. Since this return is risk-free, the portfolio must earn the risk-free rate of return. Therefore,

$$
d R=r\left(F-\frac{\sigma_{A} A F_{A}}{\sigma_{a}}-\frac{\sigma_{A} B F_{B}}{\sigma_{b}}-\frac{\phi F_{X}}{\sigma_{x}}\right) d t .
$$

Equating this to the above expression for $d R$ means that $F$ satisfies the differential equation

$$
\begin{gathered}
\frac{1}{2} \sigma_{A}^{2} A^{2} F_{A A}+\frac{1}{2} \sigma_{B}^{2} B^{2} F_{B B} \frac{1}{2}+\frac{1}{2} \phi^{2} F_{X X}+\rho_{A B} \sigma_{A} \sigma_{B} F_{A B} \\
+\rho_{X B} \sigma_{B} \phi F_{X B}+\rho_{X A} \sigma_{A} \phi F_{X A}+\left(\mu_{A}-\frac{\mu_{a} \sigma_{A}}{\sigma_{a}}+\frac{r \sigma_{A}}{\sigma_{a}}\right) A F_{A} \\
+\left(\mu_{B}-\frac{\mu_{b} \sigma_{B}}{\sigma_{b}}+\frac{r \sigma_{B}}{\sigma_{b}}\right) B F_{B}+\left(r X+\nu+A-\frac{\mu_{x} \phi}{\sigma_{x}}+\frac{r \phi}{\sigma_{x}}\right) F_{X}-r F=0
\end{gathered}
$$

Further simplification can most readily be obtained by defining

$$
\begin{aligned}
& \lambda_{A}=\frac{\mu_{a} \sigma_{A}}{\sigma_{a}}-\frac{r \sigma_{A}}{\sigma_{a}}=\frac{\sigma_{A}}{\sigma_{a}}\left(\mu_{a}-r\right), \\
& \lambda_{B}=\frac{\mu_{b} \sigma_{B}}{\sigma_{b}}-\frac{r \sigma_{B}}{\sigma_{b}}=\frac{\sigma_{B}}{\sigma_{b}}\left(\mu_{b}-r\right)
\end{aligned}
$$


where $\lambda_{A}$ and $\lambda_{B}$ are the risk premiums of project $\mathrm{A}$ and project $\mathrm{B}$ respectively, $\mu_{a}-r$ and $\mu_{b}-r$ the risk premiums of the spanning assets $a$ and $b$ respectively and $\sigma_{A} / \sigma_{a}$ and $\sigma_{B} / \sigma_{b}$ adjust for the difference in volatilities between projects and spanning assets. If $\delta_{A}=r+\lambda_{A}-\mu_{A}$ and $\delta_{B}=r+\lambda_{B}-\mu_{B}$ are the dividend yields of project $\mathrm{A}$ and B respectively, the (A.7) coefficient on $A F_{A}, \mu_{A}-\left(\mu_{a} \sigma_{A} / \sigma_{a}\right)+\left(r \sigma_{A} / \sigma_{a}\right)$, becomes $r-\delta_{A}$ and the (A.7) coefficient on $B F_{B}, \mu_{B}-\left(\mu_{b} \sigma_{B} / \sigma_{b}\right)+\left(r \sigma_{B} / \sigma_{b}\right)$, becomes $r-\delta_{B}$.

Now let $G$ denote the market value of a claim to the future cash flow generated by the firm's existing physical assets excluding project A. Clearly $G$ is independent of $X, A$ and $B$, so $d G=0$ over any time interval $d t$. Thus, the return on a long position in $G$ consists only of the current cash flow $(\nu d t+\phi d \zeta)$. Hence, using (A.3), a long position in $G$ combined with a short position in $\phi /\left(\sigma_{x} x\right)$ units of asset $x$ yields a total return of

$$
\nu d t+\phi d \zeta-\left(\frac{\phi}{\sigma_{x} x}\right) d x=\left(\nu-\frac{\phi \mu_{x}}{\sigma_{x}}\right) d t .
$$

Since this return is risk-free, it must be that

$$
\nu-\frac{\phi \mu_{x}}{\sigma_{x}}=r\left(G-\frac{\phi}{\sigma_{x}}\right)
$$

which implies that the (A.7) coefficient on $F_{X}, r X+\nu-\left(\mu_{x} \phi / \sigma_{x}\right)+\left(r \phi / \sigma_{x}\right)$, is equal to $r(X+G)+A$. Making this substitution back into (A.7) yields Equation (2.28). The same derivation above applies for Equation (2.39) with $A$ omitted from the coefficient on $F_{X}$. 


\section{A.2 Solution Procedures}

\section{A.2.1 Numerical Solution Procedure for Equation (2.11)}

The partial differential equation is solved on a grid with nodes

$$
\left\{\left(X_{l}, A_{m}\right): l=1, \ldots, L, m=1, \ldots, M\right\}
$$

where $X_{l}-X_{l-1}=d X$ and $A_{m}-A_{m-1}=d A$. The investment and liquidation constraints are

$$
\begin{gathered}
I_{A} \leq X+G+\gamma_{A} \theta_{A} V_{A_{m}} \\
X+G+F^{U A}\left(\gamma_{A} A_{m}\right) \leq 0
\end{gathered}
$$

respectively where $V_{A_{m}}=A_{m} / \delta_{A}$. The respective investment and liquidation payoffs are $V_{A_{m}}-I_{A}$ and $F^{U A}\left(\gamma_{A} A_{m}\right)$. At node $\left(X_{l}, A_{m}\right)$ the resulting difference equation can be written in the form

$$
\begin{aligned}
0= & a_{m} F_{l, m+1}+b_{m} F_{l, m}+c_{m} F_{l, m-1}+d_{l} F_{l+1, m}+e_{l} F_{l-1, m} \\
& +f_{m}\left(F_{l+1, m+1}-F_{l+1, m-1}-F_{l-1, m+1}+F_{l-1, m-1}\right)
\end{aligned}
$$

where

$$
\begin{aligned}
a_{m} & =\frac{\sigma_{A} A_{m}^{2}}{2 d A^{2}}+\frac{\left(r-\delta_{A}\right) A_{m}}{2 d A} \\
b_{m} & =-\frac{\sigma_{A} A_{m}^{2}}{d A^{2}}-\frac{\phi^{2}}{d X^{2}}-r \\
c_{m} & =\frac{\sigma_{A} A_{m}^{2}}{2 d A^{2}}-\frac{\left(r-\delta_{A}\right) A_{m}}{2 d A} \\
d_{l} & =\frac{r\left(X_{l}+G\right)}{2 d X}+\frac{\phi^{2}}{2 d X} \\
e_{l} & =-\frac{r\left(X_{l}+G\right)}{2 d X}+\frac{\phi^{2}}{2 d X^{2}} \\
f_{m} & =\frac{\rho_{X A} \sigma_{A} \phi A_{m}}{4 d X d A}
\end{aligned}
$$


and $F_{l, m}=F\left(X_{l}, A_{m}\right)$. This equation is defined whenever $2 \leq l \leq L-1$ and $2 \leq m \leq M-1$. It is extended to the edges of the grid using four boundary conditions: (i) When $l=1$, if the investment constraint is satisfied then $V_{A_{m}}-I_{A}$ is used, if the liquidation constraint is satisfied then $F^{U A}\left(\gamma_{A} A_{m}\right)$ is used and for all other nodes

$$
F^{U A}\left(\gamma_{A} A_{m}\right)+\frac{X_{1}\left(V_{A_{m}}-I_{A}-F^{U A}\left(\gamma_{A} A_{m}\right)\right)}{I_{A}-G-\gamma_{A} \theta_{A} V_{A_{m}}},
$$

a linear interpolation between the investment and liquidity regions is used. (ii) When $l=L, F^{U A}\left(A_{m}\right)$, the unconstrained value is used. (iii) When $m=1, F_{l, 1}=0$ is used since $F(X, 0)=0$. (iv) When $m=M$, if the investment constraint is satisfied then $V_{A_{M}}-I_{A}$ is used, if the liquidation constraint is satisfied then $F^{U A}\left(\gamma_{A} A_{M}\right)$ is used and for all other nodes

$$
F^{U A}\left(\gamma_{A} A_{M}\right)+\frac{X_{l}\left(V_{A_{M}}-I_{A}-F^{U A}\left(\gamma_{A} A_{M}\right)\right)}{I_{A}-G-\gamma_{A} \theta_{A} V_{A_{M}}}
$$

a linear interpolation between the investment and liquidity regions is used.

The solution is begun by setting $F_{l, m}=V_{A_{m}}-I_{A}$ if the investment constraint is satisfied as well as $V_{A_{m}}-I_{A}>0$. At all other nodes $F_{l, m}=F^{U A}\left(\gamma_{A} A_{m}\right)$ is used. After implementing the initial solution the system is solved using the method of Successive Over Relaxation. During each iteration of this method, the difference equation is solved at each node $\left(X_{l}, A_{m}\right)$ in turn. The calculated value of $F_{l, m}$ is replaced with $F^{U A}\left(\gamma_{A} A_{m}\right)$ if the liquidation constraint is binding, and with $V_{A_{m}}-I_{A}$ if doing so would result in a higher node value as well as the investment constraint being satisfied. Iteration is stopped when the largest change in any $F_{l, m}$ measured relative to its value at the end of the preceeding iteration is less than 0.01 .

\section{A.2.2 Numerical Solution Procedure for Equation (2.28)}

The partial differential equation is solved on a grid with nodes

$$
\left\{\left(X_{l}, A_{m}, B_{n}\right): l=1, \ldots, L, m=1, \ldots, M, n=1, \ldots, N\right\}
$$


where $X_{l}-X_{l-1}=d X, A_{m}-A_{m-1}=d A$ and $B_{n}-B_{n-1}=d B$. The firm can invest without divesting assets if

$$
I_{B} \leq X+G+\gamma_{A} \theta_{A} V_{A_{m}}+\gamma_{B} \theta_{B} V_{B_{n}}
$$

invest by divesting assets if

$$
I_{B} \leq X+G+\gamma_{A} V_{A_{m}}+\gamma_{B} \theta_{B} V_{B_{n}}
$$

and is forced into liquidation when

$$
X+G+\gamma_{A} V_{A_{m}}+F^{U B}\left(\gamma_{B} B_{n}\right) \leq 0
$$

The payoff to investing without divesting is

$$
V_{B_{n}}-I_{B}
$$

to investing by divesting the optimal amount

$$
V_{B_{n}}-I_{B}-\left(\frac{J_{B}}{\gamma_{A}}-\theta_{A} V_{A_{m}}\right)\left(\frac{1-\gamma_{A}}{1-\theta_{A}}\right)
$$

where $J_{B}=I_{B}-X-G-\gamma_{B} \theta_{B} V_{B_{n}}$, and liquidation is

$$
F^{U B}\left(\gamma_{B} B_{n}\right)
$$

At node $\left(X_{l}, A_{m}, B_{n}\right)$ the resulting difference equation can be written in the form

$$
\begin{gathered}
0=a_{m} F_{l, m+1, n}+b_{m, n} F_{l, m, n}+c_{m} F_{l, m-1, n}+d_{n} F_{l, m, n+1}+e_{n} F_{l, m, n-1}+f_{l, m} F_{l+1, m, n} \\
+g_{l, m} F_{l-1, m, n}+h_{m, n}\left(F_{l, m+1, n+1}-F_{l, m+1, n-1}-F_{l, m-1, n}+F_{l, m-1, n-1}\right) \\
+i_{m}\left(F_{l+1, m+1, n}-F_{l+1, m-1, n}-F_{l-1, m+1, n}+F_{l-1, m-1, n}\right) \\
+j_{n}\left(F_{l+1, m, n+1}-F_{l+1, m, n-1}-F_{l-1, m, n+1}+F_{l-1, m, n-1}\right)
\end{gathered}
$$


where

$$
\begin{aligned}
a_{m} & =\frac{\sigma_{A}^{2} A_{m}^{2}}{2 d A^{2}}+\frac{\left(r-\delta_{A}\right) A_{m}}{2 d A}, \\
b_{m, n} & =-\frac{\sigma_{A}^{2} A_{m}^{2}}{d A^{2}}-\frac{\sigma_{B}^{2} B_{n}^{2}}{d B^{2}}-\frac{\phi^{2}}{d X^{2}}-r \\
c_{m} & =\frac{\sigma_{A}^{2} A_{m}^{2}}{2 d A^{2}}-\frac{\left(r-\delta_{A}\right) A_{m}}{2 d A}, \\
d_{n} & =\frac{\sigma_{B}^{2} B_{n}^{2}}{2 d B^{2}}+\frac{\left(r-\delta_{B}\right) B_{n}}{2 d B} \\
e_{n} & =\frac{\sigma_{B}^{2} B_{n}^{2}}{2 d B^{2}}-\frac{\left(r-\delta_{B}\right) B_{n}}{2 d B}, \\
f_{l, m} & =\frac{r\left(X_{l}+G\right)+A_{m}}{2 d X}+\frac{\phi^{2}}{2 d X^{2}} \\
g_{l, m} & =-\frac{r\left(X_{l}+G\right)+A_{m}}{2 d X}+\frac{\phi^{2}}{2 d X^{2}} \\
h_{m, n} & =\frac{\rho_{A B} \sigma_{A} \sigma_{B} A_{m} B_{n}}{4 d A d B}, \\
i_{m} & =\frac{\rho_{X A} \sigma_{A} \phi A_{m}}{4 d X d A}, \\
j_{n} & =\frac{\rho_{X B} \sigma_{B} \phi B_{n}}{4 d X d B},
\end{aligned}
$$

and $F_{l, m, n}=F^{B A}\left(X_{l}, A_{m}, B_{n}\right)$. This equation is defined whenever $2 \leq l \leq L-1$, $2 \leq m \leq M-1$ and $2 \leq n \leq N-1$. It is extended to the edges of the grid using six boundary conditions: (i) When $l=1$, the logic demonstrated in Table (A.1) is applied. Panel One lists the investment and liquidation constraints and Panel Two the investment and liquidation payoffs. For each row, given that the constraint in Panel One is satisfied the maximum of the selected payoffs in Panel Two is applied. All remaining nodes are set to

$$
F^{U B}\left(\gamma_{B} B_{n}\right)+X_{1}\left(\frac{V_{B_{n}}-I_{B}-V_{A_{m}}\left(1-\gamma_{A}\right)-F^{U B}\left(\gamma_{B} B_{n}\right)}{I_{B}-G-\gamma_{A} V_{A_{m}}-\gamma_{B} \theta_{B} V_{B_{n}}}\right),
$$

a linear interpolation between the liquidation and investment via divestment regions. (ii) When $l=L, F_{L, m, n}^{B A}=F^{U B}\left(B_{n}\right)$, the unconstrained value. (iii) When $m=1$, $F_{l, 1, n}^{B A}=F\left(X_{l}, B_{n}\right)$ is used since $F^{B A}(X, 0, B)=F(X, B)$. (iv) When $m=M$, $F_{l, M, n}^{B A}=F^{U B}\left(B_{n}\right)$, the unconstrained value is used. This is because the asset in place is generating sufficient cash to make the firm unconstrained. (v) When $n=1, F_{l, m, 1}^{B A}=$ 


\begin{tabular}{|c|c|c||c|c|c|}
\hline \multicolumn{3}{|c||}{ One } & \multicolumn{3}{c|}{ Two } \\
\hline A.19 & A.20 & A.21 & A.22 & A.23 & A.24 \\
\hline$\checkmark$ & & & $\checkmark$ & & $\checkmark$ \\
\hline & $\checkmark$ & & & $\checkmark$ & $\checkmark$ \\
\hline & & $\checkmark$ & & & $\checkmark$ \\
\hline
\end{tabular}

Table A.1: This table demonstrates the logic applied at the boundaries when $l=1$ and $n=N$ as well as the logic used for the initial solution. Panel One lists the investment constraints as well as the liquidation constraint, Panel Two lists the investment payoffs as well as the liquidation payoff. Working from left to right if the equations in Panel One are satisfied, as illustrated by a tick, the maximum is taken of the selected payoffs in Panel Two. For the boundary conditions all other nodes are set to a linear interpolation between the liquidation and investment regions as described by Equations (A.26) and (A.27). While in the initial solution, all remaining nodes are set to the liquidation payoff. The table is also applied when successive over relaxation is implemented replacing the PDE solution with the Panel Two results if they are larger conditional on the Panel One equations holding.

0 is used because $F^{B A}(X, 0, A)=0$. (vi) When $n=N$, the logic demonstrated in Table (A.1) is applied as before. All remaining nodes are set to

$$
F^{U B}\left(\gamma_{B} B_{N}\right)+X_{l}\left(\frac{V_{B_{N}}-I_{B}-V_{A_{m}}\left(1-\gamma_{A}\right)-F^{U B}\left(\gamma_{B} B_{N}\right)}{I_{B}-G-\gamma_{A} V_{A_{m}}-\gamma_{B} \theta_{B} V_{B_{N}}}\right),
$$

a linear interpolation between the liquidation and investment via divestment regions.

The solution is begun by setting $F_{l, m, n}$ equal to (A.22) if Equation (A.19) is satisfied and (A.24) at all other nodes. After implementing the initial solution the system is solved using the method of Successive Over Relaxation. During each iteration of this method, the difference equation is solved at each node $\left(X_{l}, A_{m}, B_{n}\right)$ in turn. The calculated value of $F_{l, m, n}$ is replaced with an investment/liquidation value according to the logic of Table (A.1) if doing so would result in a higher node value. Iteration is stopped when the largest change in any $F_{l, m, n}$ measured relative to its value at the end of the preceding iteration is less than 0.01. The same method and procedure is used to solve for $F^{A B}$, the option to invest in project $\mathrm{A}$ given that project $\mathrm{B}$ is in place and generating cash. 


\section{A.2.3 Numerical Solution Procedure for Equation (2.39)}

The partial differential equation is solved on a grid with nodes

$$
\left\{\left(X_{l}, A_{m}, B_{n}\right): l=1, \ldots, L, m=1, \ldots, M, n=1, \ldots, N\right\}
$$

where $X_{l}-X_{l-1}=d X, A_{m}-A_{m-1}=d A$ and $B_{n}-B_{n-1}=d B$. The following constraints are used within the solution procedure:

$$
\begin{gathered}
I_{A}+I_{B} \leq X_{l}+G+\gamma_{A} \theta_{A} V_{A_{l}}+\gamma_{B} \theta_{B} V_{B_{n}}, \\
I_{A} \leq X_{l}+G+\gamma_{A} \theta_{A} V_{A_{l}}, \\
I_{B} \leq X_{l}+G+\gamma_{B} \theta_{B} V_{B_{n}}, \\
X_{l}+G+F^{U A}\left(\gamma_{A} A_{m}\right)+F^{U B}\left(\gamma_{B} B_{n}\right) \leq 0 .
\end{gathered}
$$

The first three represent investment constraints while the last one is the liquidation constraint. At node $\left(X_{l}, A_{m}, B_{n}\right)$ the payoff to investing in both $\mathrm{A}$ and $\mathrm{B}$ is

$$
V_{A_{m}}-I_{A}+V_{B_{n}}-I_{B}
$$

where $V_{A_{m}}=A_{m} / \delta_{A}$ and $V_{B_{n}}=B_{n} / \delta_{B}$, the payoff to investing in A and postponing investment in $\mathrm{B}$ is

$$
V_{A_{m}}-I_{A}+F^{B A}\left(X_{l}-I_{A}, A_{m}, B_{n}\right)
$$

where $F^{B A}\left(X_{l}-I_{A}, A_{m}, B_{n}\right)$ is an interpolated ${ }^{1}$ value of the numerical solution to $F^{B A}$, the payoff to investing in $\mathrm{B}$ and postponing investment in $\mathrm{A}$ is

$$
V_{B_{n}}-I_{B}+F^{A B}\left(X_{l}-I_{B}, A_{m}, B_{n}\right)
$$

\footnotetext{
${ }^{1}$ Extrapolation is used when $X_{l}-I_{A}$ lies outside the grid.
} 
where and $F^{A B}\left(X_{l}-I_{B}, A_{m}, B_{n}\right)$ is an interpolated ${ }^{2}$ value of the numerical solution to $F^{A B}$ and the payoff to liquidation is

$$
F^{U A}\left(\gamma_{A} A_{m}\right)+F^{U B}\left(\gamma_{B} B_{n}\right)
$$

At node $\left(X_{l}, A_{m}, B_{n}\right)$ the resulting difference equation can be written in the form

$$
\begin{gathered}
0=a_{m} F_{l, m+1, n}+b_{m, n} F_{l, m, n}+c_{m} F_{l, m-1, n}+d_{n} F_{l, m, n+1}+e_{n} F_{l, m, n-1}+f_{l} F_{l+1, m, n} \\
+g_{l} F_{l-1, m, n}+h_{m, n}\left(F_{l, m+1, n+1}-F_{l, m+1, n-1}-F_{l, m-1, n}+F_{l, m-1, n-1}\right) \\
+i_{m}\left(F_{l+1, m+1, n}-F_{l+1, m-1, n}-F_{l-1, m+1, n}+F_{l-1, m-1, n}\right) \\
+j_{n}\left(F_{l+1, m, n+1}-F_{l+1, m, n-1}-F_{l-1, m, n+1}+F_{l-1, m, n-1}\right)
\end{gathered}
$$

where

$$
\begin{aligned}
a_{m} & =\frac{\sigma_{A}^{2} A_{m}^{2}}{2 d A^{2}}+\frac{\left(r-\delta_{A}\right) A_{m}}{2 d A}, \\
b_{m, n} & =-\frac{\sigma_{A}^{2} A_{m}^{2}}{d A^{2}}-\frac{\sigma_{B}^{2} B_{n}^{2}}{d B^{2}}-\frac{\phi^{2}}{d X^{2}}-r, \\
c_{m} & =\frac{\sigma_{A}^{2} A_{m}^{2}}{2 d A^{2}}-\frac{\left(r-\delta_{A}\right) A_{m}}{2 d A}, \\
d_{n} & =\frac{\sigma_{B}^{2} B_{n}^{2}}{2 d B^{2}}+\frac{\left(r-\delta_{B}\right) B_{n}}{2 d B}, \\
e_{n} & =\frac{\sigma_{B}^{2} B_{n}^{2}}{2 d B^{2}}-\frac{\left(r-\delta_{B}\right) B_{n}}{2 d B}, \\
f_{l} & =\frac{r\left(X_{l}+G\right)}{2 d X}+\frac{\phi^{2}}{2 d X^{2}}, \\
g_{l} & =-\frac{r\left(X_{l}+G\right)}{2 d X}+\frac{\phi^{2}}{2 d X^{2}}, \\
h_{m, n} & =\frac{\rho_{A B} \sigma_{A} \sigma_{B} A_{m} B_{n}}{4 d A d B}, \\
i_{m} & =\frac{\rho_{X A} \sigma_{A} \phi A_{m}}{4 d X d A}, \\
j_{n} & =\frac{\rho_{X B} \sigma_{B} \phi B_{n}}{4 d X d B},
\end{aligned}
$$

and $F_{l, m, n}=F\left(X_{l}, A_{m}, B_{n}\right)$. This equation is defined whenever $2 \leq l \leq L-1$, $2 \leq m \leq M-1$ and $2 \leq n \leq N-1$. It is extended to the edges of the grid

\footnotetext{
${ }^{2}$ Extrapolation is used when $X_{l}-I_{B}$ lies outside the grid.
} 
using six boundary conditions: (i) When $l=1$, it is supposed that the liquidation constraint is binding, so that $F_{1, m, n}=F^{U A}\left(\gamma_{A} A_{m}\right)+F^{U B}\left(\gamma_{B} B_{n}\right)$. (ii) When $l=L$, $F_{L, m, n}=F^{U A}\left(A_{m}\right)+F^{U B}\left(B_{n}\right)$, the sum of the unconstrained values. (iii) When $m=1, F_{l, 1, n}=F\left(X_{l}, B_{n}\right)$ is used since $F(X, 0, B)=F(X, B)$. (iv) When $n=1$, $F_{l, m, 1}=F\left(X_{l}, A_{m}\right)$ is used since $F(X, A, 0)=F(X, A)$. (v) Table (A.2) demonstrates the logic used at the boundary when $m=M$. Panel One lists the three investment constraints and Panel Two the investment payoffs. For each row, given that the constraints in Panel One are satisfied the maximum is taken of the selected payoffs in Panel Two and applied. All remaining nodes are set to

$$
\begin{gathered}
F^{U A}\left(\gamma_{A} A_{M}\right)+F^{U B}\left(\gamma_{B} B_{n}\right) \\
+\frac{\left(X_{l}+G\right)\left(V_{A_{M}}-I_{A}+F^{B A}\left(X_{l}-I_{A}, A_{M}, B_{n}\right)-F^{U A}\left(\gamma_{A} A_{M}\right)-F^{U B}\left(\gamma_{B} B_{n}\right)\right)}{I_{A}-\gamma_{A} \theta_{A} V_{A_{M}}}
\end{gathered}
$$

a linear interpolation between the liquidation and investment region. (vi) The same logic of Table (A.2) is used at the boundary when $n=N$. All remaining nodes are set to

$$
\begin{gathered}
F^{U A}\left(\gamma_{A} A_{m}\right)+F^{U B}\left(\gamma_{B} B_{N}\right) \\
+\frac{\left(X_{l}+G\right)\left(V_{B_{N}}-I_{B}+F^{A B}\left(X_{l}-I_{B}, A_{m}, B_{N}\right)-F^{U A}\left(\gamma_{A} A_{m}\right)-F^{U B}\left(\gamma_{B} B_{N}\right)\right)}{I_{B}-\gamma_{B} \theta_{B} V_{B_{N}}}
\end{gathered}
$$

a linear interpolation between the liquidation and investment region. The solution is begun by applying the logic displayed within Table (A.2) to all applicable nodes in a similar fashion to boundary conditions (v) and (vi). After this process all remaining nodes are set to equal the liquidation payoff. After implementing the initial solution the system is solved using the method of Successive Over Relaxation. During each iteration of this method, the difference equation is solved at each node $\left(X_{l}, A_{m}, B_{n}\right)$ in turn. The calculated value of $F_{l, m, n}$ is replaced with an investment/liquidation value according to the logic of Table (A.2) if doing so would result in a higher node 


\begin{tabular}{|c|c|c|c||c|c|c|c|}
\hline \multicolumn{5}{|c||}{ One } & \multicolumn{5}{c|}{ Two } \\
\hline A.28 & A.29 & A.30 & A.31 & A.32 & A.33 & A.34 & A.35 \\
\hline$\checkmark$ & $\checkmark$ & $\checkmark$ & & $\checkmark$ & $\checkmark$ & $\checkmark$ & $\checkmark$ \\
\hline$\checkmark$ & $\checkmark$ & & & $\checkmark$ & $\checkmark$ & & $\checkmark$ \\
\hline$\checkmark$ & & $\checkmark$ & & $\checkmark$ & & $\checkmark$ & $\checkmark$ \\
\hline & $\checkmark$ & $\checkmark$ & & & $\checkmark$ & $\checkmark$ & $\checkmark$ \\
\hline & $\checkmark$ & & & & $\checkmark$ & & $\checkmark$ \\
\hline & & $\checkmark$ & & & & $\checkmark$ & $\checkmark$ \\
\hline & & & $\checkmark$ & & & & $\checkmark$ \\
\hline
\end{tabular}

Table A.2: This table demonstrates the logic applied at the boundaries when $m=M$ and $n=N$ as well as the logic used for the initial solution. Panel One lists the investment constraints as well as the liquidation constraint, Panel Two lists the investment payoffs as well as the liquidation payoff. Working from left to right if the equations in Panel One are satisfied, as illustrated by a tick, the maximum is taken of the selected payoffs in Panel Two. For the boundary conditions all other nodes are set to a linear interpolation between the liquidation and investment regions as described by Equations (A.36) and (A.37). While in the initial solution, all remaining nodes are set to the liquidation payoff. The table is also applied when successive over relaxation is implemented, replacing the PDE solution with the Panel Two results if they are larger conditional on the Panel One equations holding.

value. Iteration is stopped when the largest change in any $F_{l, m, n}$ measured relative to its value at the end of the preceding iteration is less than 0.01 . 


\section{Bibliography}

Almeida, H. and Campello, M. (2007). Financial constraints, asset tangibility, and corporate investment. Review of Financial Studies, 20(5):1429-1460.

Almeida, H., Campello, M., and Weisbach, M. S. (2011). Corporate financial and investment policies when future financing is not frictionless. Journal of Corporate Finance, 17(3):675-693.

Berger, P. G. and Ofek, E. (1995). Diversification's effect on firm value. Journal of Financial Economics, 37(1):39-65.

Billett, M. T. and Mauer, D. C. (2003). Cross-subsidies, external financing constraints, and the contribution of the internal capital market to firm value. Review of Financial Studies, 16(4):1167-1201.

Boardman, C. M., Reinhart, W. J., and Celec, S. E. (1982). The role of the payback period in the theory and application of duration to capital budgeting. Journal of Business Finance 83 Accounting, 9(4):511-522.

Bolton, P., Wang, N., and Yang, J. (2014). Investment under uncertainty and the value of real and financial flexibility. Technical report, National Bureau of Economic Research.

Boyle, G. and Guthrie, G. (2006). Payback without apology. Accounting $\mathscr{E}$ Finance, 46(1):1-10.

Boyle, G. W. and Guthrie, G. A. (2003). Investment, uncertainty, and liquidity. Journal of Finance, 58(5):2143-2166. 
Cleary, S., Povel, P., and Raith, M. (2007). The u-shaped investment curve: Theory and evidence. Journal of Financial and Quantitative Analysis, 42(01):1-39.

Clementi, G. L. and Hopenhayn, H. A. (2006). A theory of financing constraints and firm dynamics. The Quarterly Journal of Economics, 121(1):229-265.

Çolak, G. and Whited, T. M. (2007). Spin-offs, divestitures, and conglomerate investment. Review of Financial Studies, 20(3):557-595.

Custodio, C. (2014). Mergers and acquisitions accounting and the diversification discount. Journal of Finance, 69(1):219-240.

Décamps, J.-P., Mariotti, T., and Villeneuve, S. (2006). Irreversible investment in alternative projects. Economic Theory, 28(2):425-448.

Denis, D. J. and Sibilkov, V. (2009). Financial constraints, investment, and the value of cash holdings. Review of Financial Studies, 23(1):247-269.

Dittmar, A. and Mahrt-Smith, J. (2007). Corporate governance and the value of cash holdings. Journal of Financial Economics, 83(3):599-634.

Dixit, A. (1993a). Choosing among alternative discrete investment projects under uncertainty. Economics Letters, 41(3):265-268.

Dixit, A. K. (1993b). The art of smooth pasting. Taylor \& Francis.

Dixit, A. K. and Pindyck, R. S. (1994). Investment under uncertainty. Princeton University Press.

Drobetz, W., Grüninger, M. C., and Hirschvogl, S. (2010). Information asymmetry and the value of cash. Journal of Banking \& Finance, 34(9):2168-2184.

Erickson, T. and Whited, T. M. (2002). Two-step gmm estimation of the errors-invariables model using high-order moments. Econometric Theory, 18(03):776-799.

Faulkender, M. and Wang, R. (2006). Corporate financial policy and the value of cash. Journal of Finance, 61(4):1957-1990. 
Flor, C. R. and Hirth, S. (2013). Asset liquidity, corporate investment, and endogenous financing costs. Journal of Banking \& Finance, 37(2):474-489.

Gan, J. (2007). Collateral, debt capacity, and corporate investment: Evidence from a natural experiment. Journal of Financial Economics, 85(3):709-734.

Graham, J. R., Lemmon, M. L., and Wolf, J. G. (2002). Does corporate diversification destroy value? Journal of Finance, 57(2):695-720.

Hennessy, C. A. and Whited, T. M. (2005). Debt dynamics. Journal of Finance, 60(3):1129-1165.

Hirth, S. and Uhrig-Homburg, M. (2010a). Investment timing, liquidity, and agency costs of debt. Journal of Corporate Finance, 16(2):243-258.

Hirth, S. and Uhrig-Homburg, M. (2010b). Investment timing when external financing is costly. Journal of Business Finance \& Accounting, 37(7-8):929-949.

Hirth, S. and Viswanatha, M. (2011). Financing constraints, cash-flow risk, and corporate investment. Journal of Corporate Finance, 17(5):1496-1509.

Hund, J., Monk, D., and Tice, S. (2010). Uncertainty about average profitability and the diversification discount. Journal of Financial Economics, 96(3):463-484.

Inderst, R. and Müller, H. M. (2003). Internal versus external financing: An optimal contracting approach. Journal of Finance, 58(3):1033-1062.

Jensen, M. C. (1986). Agency cost of free cash flow, corporate finance, and takeovers. Corporate Finance, and Takeovers. American Economic Review, 76(2).

Johnson, N. B., Pfeiffer, T., and Schneider, G. T. (2015). Two-stage capital budgeting under resource constraints. Available at SSRN 2613163.

Keefe, M. and Tate, J. (2013). Is the relationship between investment and conditional cash flow volatility ambiguous, asymmetric or both? Accounting $\&$ Finance, $53(4): 913-947$. 
Laeven, L. and Levine, R. (2007). Is there a diversification discount in financial conglomerates? Journal of Financial Economics, 85(2):331-367.

Lang, L., Poulsen, A., and Stulz, R. (1995). Asset sales, firm performance, and the agency costs of managerial discretion. Journal of Financial Economics, 37(1):3-37.

Lang, L. H. and Stulz, R. M. (1993). Tobin's q, corporate diversification and firm performance. Technical report, National Bureau of Economic Research.

Leland, H. E. (2007). Financial synergies and the optimal scope of the firm: Implications for mergers, spinoffs, and structured finance. Journal of Finance, 62(2):765807.

Lewellen, W. G. (1971). A pure financial rationale for the conglomerate merger. Journal of Finance, 26(2):521-537.

Lins, K. and Servaes, H. (1999). International evidence on the value of corporate diversification. Journal of Finance, 54(6):2215-2239.

Lyandres, E. (2007). Costly external financing, investment timing, and investmentcash flow sensitivity. Journal of Corporate Finance, 13(5):959-980.

Mazur, M. and Zhang, S. (2015). Diversification discount over the long run: New perspectives. Finance Research Letters, 15:93-98.

McDonald, R. and Siegel, D. (1986). The value of waiting to invest. The Quarterly Journal of Economics, 101(4):707-727.

Myers, S. C. and Majluf, N. S. (1984). Corporate financing and investment decisions when firms have information that investors do not have. Journal of Financial Economics, 13(2):187-221.

Nishihara, M. and Shibata, T. (2013). The effects of external financing costs on investment timing and sizing decisions. Journal of Banking \& Finance, 37(4):11601175. 
Pástor, L. and Pietro, V. (2003). Stock valuation and learning about profitability. Journal of Finance, 58(5):1749-1790.

Pinkowitz, L., Stulz, R., and Williamson, R. (2006). Does the contribution of corporate cash holdings and dividends to firm value depend on governance? A crosscountry analysis. Journal of Finance, 61(6):2725-2751.

Pinkowitz, L. and Williamson, R. (2002). What is a dollar worth? The market value of cash holdings. Working paper.

Shibata, T. and Nishihara, M. (2012). Investment timing under debt issuance constraint. Journal of Banking \& Finance, 36(4):981-991.

Stein, J. C. (1995). Internal capital markets and the competition for corporate resources. Technical report, National Bureau of Economic Research.

Thakor, A. V. (1990). Investment "myopia" and the internal organization of capital allocation decisions. Journal of Law, Economics, \& Organization, 6(1):129-154.

Villalonga, B. (2004). Diversification discount or premium? New evidence from the business information tracking series. Journal of Finance, 59(2):479-506.

Whited, T. M. (2001). Is it inefficient investment that causes the diversification discount? Journal of Finance, 56(5):1667-1691. 